Márcio José da Cunha

\title{
Descoberta do Conhecimento em Base de Dados como Ferramenta Aplicada em Processos Sucroalcooleiros
}

\author{
Tese apresentada à Escola \\ de Engenharia de São Carlos da Uni- \\ versidade de São Paulo, como parte dos \\ requisitos para obtenção do título de \\ Doutor em Engenharia Mecânica Área \\ de concentração Dinâmica, Máquinas e \\ Sistemas
}

Orientador: Prof. Dr. Glauco Augusto de Paula Caurin

\section{São Carlos}

2011

Esse exemplar é a versão final corrigida. O exemplar de defesa encontra-se na Secretaria de Pós-Graduação da Engenharia Mecânica. 
AUTORIZO A REPRODUÇÃO E DIVULGAÇÃO TOTAL OU PARCIAL DESTE TRABALHO, POR QUALQUER MEIO CONVENCIONAL OU ELETRÓNICO, PARA FINS DE ESTUDO E PESQUISA, DESDE QUE CITADA A FONTE.

Ficha catalográfica preparada pela Seção de Tratamento da Informação do Serviço de Biblioteca - EESC/USP

Cunha, Márcio José da

Descoberta do conhecimento em base de dados como ferramenta aplicada em processos sucroalcooleiros / Márcio José da Cunha ; orientador Glauco Augusto de Paula Caurin. -- São Carlos, 2011.

Tese (Doutorado - Programa de Pós-Graduação em Engenharia Mecânica e Área de Concentração Dinâmica das Máquinas e Sistemas) -- Escola de Engenharia de São Carlos da Universidade de São Paulo, 2011.

1. Mineração de dados. 2. KDD. 3. Produção de açúcar e álcool. 4. Otimização de processos. I. Título. 


\section{FOLHA DE JULGAMENTO}

Candidato(a): Analista de Sistemas MARCIO JOSÉ DA CUNHA.

Tese defendida e julgada em 11/02/2011 perante a Comissão Julgadora:

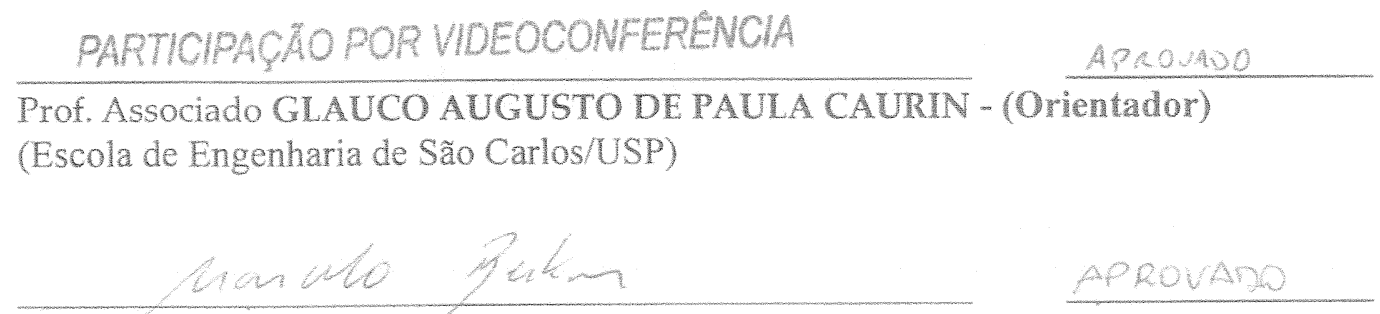

Prof. D. MARCELO BECKER

(Escola de Engenharia de São Carlos/USP)

Prof ${ }^{\text {. Dr. }}$. KALINKA REGINA LUCAS JAQUIE CASTELO BRANCO

(Instituto de Ciências Matemáticas e de Computação/USP)

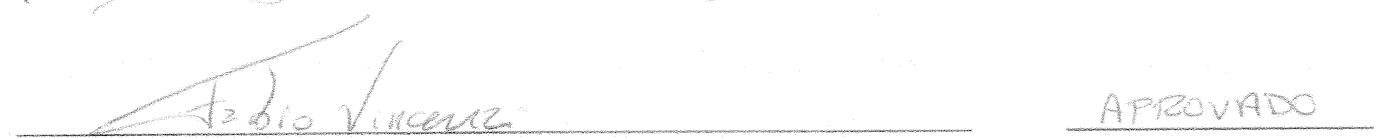

Prof. Dr. FÁBIO VINCENZI ROMUALDO DA SILVA

(Universidade Federal de Uberlândia/UFU)

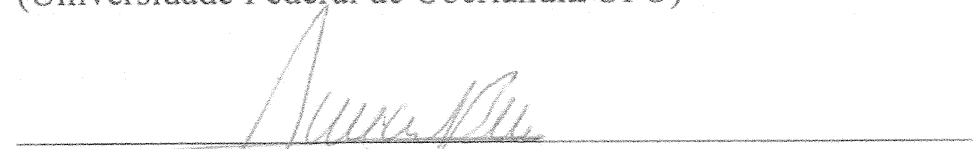

Dr. ARMANDO JOSÉ DAL BEM

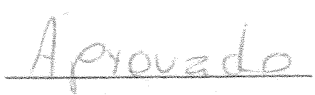

(Virgolino de Oliveira S/A - Açúcar e Álcool)

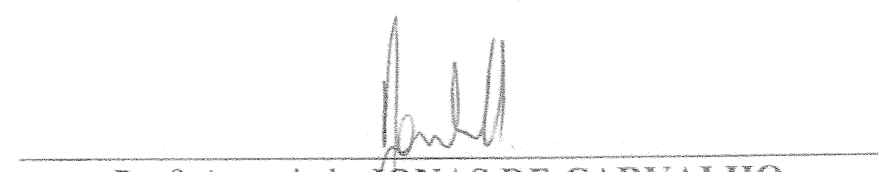

Prof. Associado JONAS DE CARVALHO

Coordenador do Programa de Pós-Graduação em

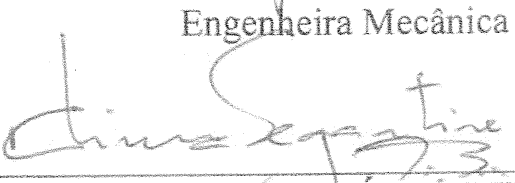

Prof. Associado PAULO CESAR LIMA SEGANTINE

Presidente da Cómissão da Pós-Graduação da EESC 


\section{Agradecimentos}

Primeiramente, agradeço a Deus pela oportunidade e pela vitória nos desafios, que não foram poucos.

Em especial, ao amigo e Prof. Dr. Glauco A. P. Caurin pela orientação, confiança, amizade e pelos conselhos dados para que esse trabalho fosse concluído.

Também gostaria de agradecer a Professora Kalinka Regina L. J. Castelo Branco pela ajuda e pela amizade.

Gostaria de agradecer a minha esposa Ledmila, pelo amor, carinho e afeto nas horas difíceis. Gostaria de agradecer também aos meus pais, Carlos e Antônia pela ajuda e por ter me dado condições de concluir esse trabalho. Dedico também esse trabalho ao meu irmão Marcelo, aos meus cunhados, cunhadas e sobrinhos.

Ao pessoal do Laboratório de Mecatrônica pela ajuda, amizade e conselhos.

Ao pessoal do Grupo Virgulino Oliveira por acreditarem nesse trabalho e por disponibilizar as informações necessárias para a conclusão do mesmo.

Um agradecimento ao departamento de desenvolvimento eletrônico da Smar Equipamentos Industriais, em especial aos amigos Cléber Fonceca, Ciro Carpintieri, Renato Veiga e o Renato Carrijo. 


\section{Resumo}

CUNHA, M. J. (2011) Descoberta do Conhecimento em Base de Dados como Ferramenta Aplicada em Processos Sucroalcooleiros. São Carlos. 126p. Tese (Doutorado) - Escola de Engenharia de São Carlos, Universidade de São Paulo, 2011.

Nos dias atuais, a quantidade de dados armazenados na indústria é considerada extensa e contínua. Nas indústrias de produção de açúcar e álcool, nem sempre todas as variáveis do processo são analisadas devido a imensa quantidade de dados, a diversidade dos setores no processo e pela grande dificuldade em saber como se deve analisar tais dados. Este trabalho propõe a utilização do processo da Descoberta do Conhecimento em Base de Dados, o processo KDD, como uma ferramenta para ser aplicada em processos industriais, especificamente no processo de produção de açúcar e álcool. Os experimentos foram realizados com dados obtidos do processo de fermentação, durante a safra sucroalcooleira. Os resultados mostram que é possível aplicar o processo de KDD para este tipo de indústria, podendo ser aplicado como uma ferramenta de previsão de produção de açúcar e álcool.

Palavras chave: KDD, produção de açúcar e álcool, otimização de processos. 



\section{Abstract}

CUNHA, M. J. (2011) A Proposal to use KDD as a tool to Discovery Alcohol and Sugar Production Plant Behavior. São Carlos. 126p. phD Thesis - Escola de Engenharia de São Carlos, Universidade de São Paulo, 2011.

Nowadays, the amount of data stored in the industry is considered large and continuous. In the sugar and alcohol industrial production, not always all the process variables are analyzed due to the immense amount of data, the diversity of sectors in the process and the great difficulty in knowing how to analyze such data. This work proposes the use of proposes the use of the process of Knowledge Discovery in Databases, KDD process, as a tool to be applied in industrial processes, in specifically in sugar cane and alcohol process. The experiments are done with Fermentation data process obtained during the sugar and alcohol harvest. The results show that it is possible to apply the KDD process for this type of industry, where it can be used as a forecasting tool for the production of sugar and alcohol.

Keywords: KDD, sugar and alcohol production, process optimization. 



\section{Lista de Figuras}

1.1 Visão Geral do Processamento de Dados em um Data Warehouse. . . . . . . . . . 2

2.1 Arquitetura dos Níveis de Informação na Indústria. . . . . . . . . . . . . . . 6

2.2 Arquitetura da Indústria com Sistemas MES . . . . . . . . . . . . . . . . . . 8

3.1 Visão Geral do Processo de Recepção da Cana-de-açúcar . . . . . . . . . . . . . . . 11

3.2 Visão Geral do Processo de Fabricação de Açúcar e Álcool . . . . . . . . . . . . . . 12

3.3 Visão Geral do Processo de Fabricação de Açúcar e Álcool (SMAR, 2005). . . . . 14

3.4 Equipamento Difusor utilizado no Processo de Extração do Caldo por Difusão. 15

3.5 Esquema de Terno de Extração do Caldo por Moagem (SMAR, 2005) . . . . . . . 16

3.6 Processo de Geração de Energia (SMAR, 2005) . . . . . . . . . . . . . . . 17

3.7 Processo de Tratamento de Caldo $(\mathrm{SMAR}, 2005) \ldots \ldots \ldots \ldots \ldots$

3.8 Processo de Decantação do Caldo (SMAR, 2009) . . . . . . . . . . . . . 20

3.9 Setor de Fermentação em Usina de cana-de-açúcar (SMAR, 2005). . . . . . . . . 21

3.10 Setor de Armazenamento em Usina de cana-de-açúcar (SMAR, 2005). . . . . . . 22

4.1 Evolução de Sistemas Computacionais. . . . . . . . . . . . . . . . . . . . . . . . 24

4.2 Evolução de Sistemas Computacionais. . . . . . . . . . . . . . . . . . . 26

4.3 Série Temporal com 1000 pontos (Original) . . . . . . . . . . . . . . . 30

4.4 Série Temporal com 600 pontos (Redimensionada) . . . . . . . . . . . . . . 30

5.1 Fluxograma de Instrumentação do Processo de Fermentação. . . . . . . . . . . 38

5.2 Equipamentos Utilizados no Processo de Fermentação. . . . . . . . . . . . . . . . 39 
5.3 Tela de Sinóptico de um Sistema Supervisório para o Processo de Fermentação. . 40

5.4 Estrutura dos Módulos Desenvolvidos no Porjeto. . . . . . . . . . . . . . . . 41

5.5 Esquema de Aquisição de Dados do Processo de Fermentação. . . . . . . . . . . . . 43

5.6 Exemplo de Tabela com Dados do Processo de Fermentação. . . . . . . . . . . . 44

5.7 ART Mosto Original. . . . . . . . . . . . . . . . . . . . 45

5.8 ART Mosto Dimensão Modificada. . . . . . . . . . . . . . . . . . . . . . 46

5.9 Interface de Treinamento de Redes Neurais NARX do Matlab. . . . . . . . . . 47

5.10 Módulo de Identificação de Sistemas do Matlab. . . . . . . . . . . . . . . . . . . 48

5.11 Erro Percentual Relativo do Mês de Agosto. . . . . . . . . . . . . . . . . . . . 49

6.1 Pontos do Processo Fermentativo Interpolados. . . . . . . . . . . . . . . . . 52

6.2 Variáveis de Entrada do Processo Fermentativo Interpolados Julho de 2008. . . . 54

6.3 Variáveis de Entrada do Processo Fermentativo Interpolados Julho de 2008. . . . 54

6.4 Variáveis de Entrada e Saída Processo Fermentativo Normalizadas. . . . . . . . . 55

6.5 Comparativo Saída Real x Saída Simulada. . . . . . . . . . . . . . . . . 55

6.6 Validação de rede $\operatorname{NARX}(\mathrm{Ago} / 2008) \ldots \ldots \ldots \ldots \ldots \ldots$

6.7 Erro Percentual Relativo do Mês de Agosto. . . . . . . . . . . . . . . . . . . 57

6.8 Validação da rede NARX $($ Set/2008) . . . . . . . . . . . . . . . . 58

6.9 Erro Percentual Relativo do Mês de Setembro. . . . . . . . . . . . . . . . . . 59

6.10 Validação da rede NARX $(\mathrm{Out} / 2008) \ldots \ldots \ldots$. . . . . . . . . . 60

6.11 Erro Percentual Relativo do Mês de Outubro. . . . . . . . . . . . . . . . . . 61

6.12 Validação da rede NARX $(\mathrm{Nov} / 2008) \ldots \ldots \ldots \ldots$. . . . . . . . . 62

6.13 Erro Percentual Relativo do Mês de Novembro. . . . . . . . . . . . . . . . . . 63

6.14 Validação da rede NARX $(\mathrm{Dez} / 2008) . \ldots \ldots$. . . . . . . . . . . . . 64

6.15 Erro Percentual Relativo do Mês de Dezembro. . . . . . . . . . . . . . . . . 65

6.16 Variáveis do Processo de Fermentação no Mês de Agosto. . . . . . . . . . . . 67

6.17 Comparativo Sistema Identificado e o Sistema Real para o Mês de Agosto. . . . . 69

6.18 Erro Percentual Relativo do Mês de Agosto. . . . . . . . . . . . . . . . . . . 70 
6.19 Comparativo Sistema Identificado e o Sistema Real para o Mês de Setembro. . . 71

6.20 Erro Percentual Relativo do Mês de Setembro. . . . . . . . . . . . . . . . . . . . 72

6.21 Comparativo Sistema Identificado e o Sistema Real para o Mês de Outubro. . . . 73

6.22 Erro Percentual Relativo do Mês de Outubro. . . . . . . . . . . . . . . . . . 74

6.23 Comparativo Sistema Identificado e o Sistema Real para o Mês de Novembro. . . 75

6.24 Erro Percentual Relativo do Mês de Novembro. . . . . . . . . . . . . . . . . . 76

6.25 Comparativo Sistema Identificado e o Sistema Real para o Mês de Dezembro. . . 77

6.26 Erro Percentual Relativo do Mês de Dezembro. . . . . . . . . . . . . . . . . . . 78

A.1 Representação do Processo de Identificação de Sistemas. . . . . . . . . . . . . . . . 85

A.2 Fluxograma do Algoritmo de Identificação de Sistemas. . . . . . . . . . . . . . 87

B.1 Série Temporal Ações Microsoft. . . . . . . . . . . . . . . . . . . . . . . 96

B.2 Previsão do Comportamento Solar Utilizando Séries Temporais. . . . . . . . . . . 97

B.3 Árvores Auto-Regressivas. . . . . . . . . . . . . . . . . . . . . . . 100

C.1 Rede Neural NARX. . . . . . . . . . . . . . . . . . . . . . . . . . 103 



\section{Lista de Tabelas}

4.1 Distribuição das Atividades do KDD em Fases. . . . . . . . . . . . . . . . . . 26

4.2 Técnicas para Tratamento de Dados. . . . . . . . . . . . . . . . . . 28

5.1 Distribuição das Atividades do KDD em Fases. . . . . . . . . . . . . . . . . . . . 42

6.1 Erros de Previsão do Grau do Vinho com Levedura. . . . . . . . . . . . . . . 66

6.2 Erros de Previsão do Grau do Vinho com Levedura. . . . . . . . . . . . . . . . 79

6.3 Comparação dos Erros de Previsão do Grau do Vinho com Levedura. . . . . . . . 80 



\section{Lista de Siglas}

AR Auto-Regressive Model - Modelo Auto-regressivo

ART Auto-Regressive Tree - Árvores Auto-regressiva

ART Quantidade de massa de glucose, frutose e sacarose contida na cana

ARMAX Auto-Regressive Moving eXogenous Model-Modelo linear, auto-regressivo, de média móvel e com entrada externa

ARX Auto-Regressive eXogenous Model - Modelo linear, auto-regressivo e entrada externa

BI Business Inteligence - Inteligência de Negócios

BRIX Quantidade de Sólidos Solúveis Contidos no Caldo

DDE Dynamic Data Exchange - Troca Dinâmica de Dados

EMA Exponential Moving Average - Média Móvel Exponencial

ERP Enterprise Resource Planning - Planejamento de recursos da corporação

HMI Human and Machine Interface - Interface Homem Máquina

KDD Knowledge Discovery in Data Base - Descoberta do Conhecimento em Base de Dados

MES Manufacturing Execution System - Sistema de Execução de Produção

MESA Manufacturing Enterprise Solutions Association

MI Manufacturing Intelligence - Inteligência de Manufatura

MIMO Multiple Input Multiple Output - Sistemas com múltiplas entradas e múltiplas saídas

MISO Multiple Input Single Output - Sistemas com múltiplas entradas e uma saída 
MMA Moving Average Modelo - Modelo de Média Movel

MSE Mean Square Error - Erros Médios Quadráticos

NARMAX Non Linear Auto Regressive Moving eXogenous Model - Modelo não linear, auto regressivo, de média móvel e entrada externa

NARX Non Linear Auto Regressive eXogenous Model - Modelo não linear, auto regressivo e entrada externa

OLE Object Linking Embedding - Ligação e incorporação de objetos

OPC OLE for Process Control - Padrão OLE aplicados em Controle de Processos

PCTS Pagamento de Cana pelo Teor de Sacarose

POL Quantidade de Sacarose presente na cana-de-açúcar ou no caldo

PMRE Percentual Mean Relative Error - Erros Percentuais Relativos Médios

PRE Percentual Relative Error - Erros Percentuais Relativos

RLS Recursive Least Square - Método dos mínimos quadrados recursivo

SCADA Supervisory Control \& Data Acquisition Systems - Sistemas supervisórios de controle e aquisição de dados

SGBD Sistema Gerenciador de Banco de Dados

SISO Single Input Single Output - Sistemas com uma entrada e uma saída

SMA Simple Moving Average - Média Móvel Simples

WMA Weighted Moving Average - Média Móvel Ponderada 


\section{Sumário}

Resumo iii

$\begin{array}{lll}\text { Abstract } & \text { v }\end{array}$

Lista de Figuras $\quad$ vii

Lista de Tabelas $\quad$ xi

Lista de Siglas $\quad$ xiii

1 Introdução 1

1.1 Objetivos do Trabalho . . . . . . . . . . . . . . . . . . 4

1.2 Organização do Trabalho . . . . . . . . . . . . . . . . . . 4

2 Os Níveis de Informação na Indústria 5

3 Fábrica de Açúcar e Álcool $\quad 11$

3.1 Recepção e Alimentação . . . . . . . . . . . . . . . . . . . . . . 12

3.2 Extração do Caldo da Cana-de-açúcar . . . . . . . . . . . . . . . . 13

3.2.1 Processo de Extração do Caldo por Difusão . . . . . . . . . . . . . . . . . 14

3.2.2 Processo de Extração do Caldo por Moagem . . . . . . . . . . . . . . 15

3.2 .3 Embebição . . . . . . . . . . . . . . . . . . . . . . . 16

3.3 Geração de Energia . . . . . . . . . . . . . . . . . . . . . . . . . . . . 17

3.4 Produção de Álcool . . . . . . . . . . . . . . . . . . . . . . . . . . . . . . . . 17

3.4.1 Tratamento Primário do Caldo . . . . . . . . . . . . . . . . . . 18

3.4 .2 Fermentação . . . . . . . . . . . . . . . . . . . . . . 20

3.4.3 A atual prática da Fermentação Alcoólica no Brasil . . . . . . . . . . . . . 21

3.4.4 Centrifugação do Vinho . . . . . . . . . . . . . . . . . . . . . 22

3.4 .5 Destilação . . . . . . . . . . . . . . . . . . 22

3.4 .6 Armazenamento . . . . . . . . . . . . . . . . 22 
4.1 Etapas do Processo do KDD . . . . . . . . . . . . . . . . . . . 26

4.2 Pré-processamento de Dados . . . . . . . . . . . . . . . . . . . 27

4.3 Transformação de Dados . . . . . . . . . . . . . . . . . . . . . . . 28

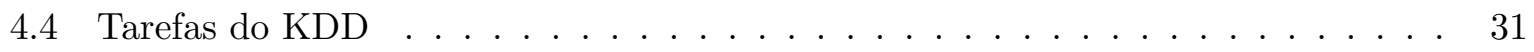

4.4 .1 Descoberta de Associações . . . . . . . . . . . . . . . . . . . . . . . . 31

4.4 .2 Descoberta de Associações Generalizadas . . . . . . . . . . . . . . . . . 31

4.4 .3 Descoberta de Sequências . . . . . . . . . . . . . . . . . . 32

4.4 .4 Descoberta de Sequências Generalizadas . . . . . . . . . . . . . . . 32

4.4 .5 Classificação . . . . . . . . . . . . . . . . . . . 32

4.4 .6 Regressão . . . . . . . . . . . . . . . . . . . . . . . 33

4.4 .7 Sumarização . . . . . . . . . . . . . . . . . . . . . 33

4.4 .8 Clusterização . . . . . . . . . . . . . . . . . . . . . 34

4.5 Áreas de Aplicação do KDD . . . . . . . . . . . . . . . . . . . . . . . . 34

$\begin{array}{lll}5 & \text { Metodologia } & 37\end{array}$

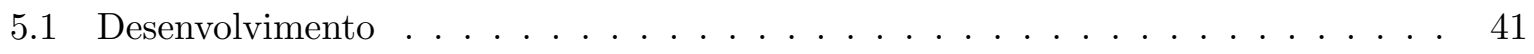

5.1 .1 Definição e Aquisição de Dados . . . . . . . . . . . . . . . . . . . . . 41

5.1 .2 Tratamento de Dados . . . . . . . . . . . . . . . . . . . . . 44

5.1 .3 Mineração de Dados . . . . . . . . . . . . . . . . . . . . . . . . 46

5.1 .4 Validação . . . . . . . . . . . . . . . . . . . . . . . . 48

6 Testes e Resultados $\quad 51$

6.1 Aplicação de Redes Neurais NARX na Mineração de Dados do Processo KDD . . 52

6.2 Aplicação de Identificação de Sistemas na Mineração de Dados do Processo KDD 67

$\begin{array}{llr}7 & \text { Conclusões } & 81\end{array}$

A Identificação de Sistemas $\quad 85$

A.1 Etapas do Processo de Identificação de Sistemas . . . . . . . . . . . . . . 86

B Séries Temporais $\quad 95$

B.1 Métodos de Previsão de Séries Temporais . . . . . . . . . . . . . . . . . . 98

B.1.1 Modelos Auto-Regressivos . . . . . . . . . . . . . . . . . . . . 98

B.2 Modelo de Médias Móveis . . . . . . . . . . . . . . . . . . . . . . . . . 99

B.3 Árvores Auto-Regressivas . . . . . . . . . . . . . . . . . . . 100

$\begin{array}{ll}\text { C Redes Neurais Artificiais NARX } & 101\end{array}$ 
Referências Bibliográficas 



\section{Capítulo 1}

\section{Introdução}

É notável que, nos últimos anos a evolução tecnológica dos sistemas industriais passou por um crescimento considerável. Com a Era Digital, diversas mudanças ocorreram, dentre elas a introdução de microprocessadores em equipamentos de campo, adição de softwares em ambientes industriais dentre outras. A partir dessas mudanças, a indústria começou obter maior confiabilidade nas informações geradas no processo, onde os dados do processo eram apenas monitorados de maneira empírica. Como por exemplo, a verificação visual de uma temperatura para a abertura manual de uma válvula, passam a ser monitorada e controlada por computadores, em que os resultados e ocorrências, inerentes nesse tipo de operação, são armazenados em sistemas de banco de dados (BRANDÃO, 2005).

Um grande exemplo dessa evolução pode ser observada no setor sucroalcooleiro. O setor sucroalcooleiro passou por evoluções e revoluções em termos de tecnologia. Um exemplo disso é o processo de moagem da cana. No início da produção de açúcar e álcool, a moagem da cana era feita de maneira manual, onde as moendas eram movimentadas por seres humanos ou animais. Nos dias atuais, o processo de moagem da cana, tem a sua maior parte automatizada e monitorada por sistemas de computação, onde a maioria de suas variáveis são controladas ou monitoradas.

Um fato importante a ser considerado: em cenários onde o processo é automatizado e toda a informação pode ser acessada de alguma maneira, ocorre a geração de grandes quantidades de dados provenientes das mais diferentes partes do processo industrial. Esses dados, geralmente, são obtidos através de aquisições feitas nos instrumentos de campo espalhados no processo. Depois da aquisição, os dados são tratados para que sejam entendidos pelos operadores e chefes 
de automação. A partir desse momento, os dados são armazenados em base de dados, onde são utilizados para análises históricas. Geralmente, esses dados são armazenados em bases de dados dedicadas (FOURTULAN, 2006), conhecidas como Data Warehouse.

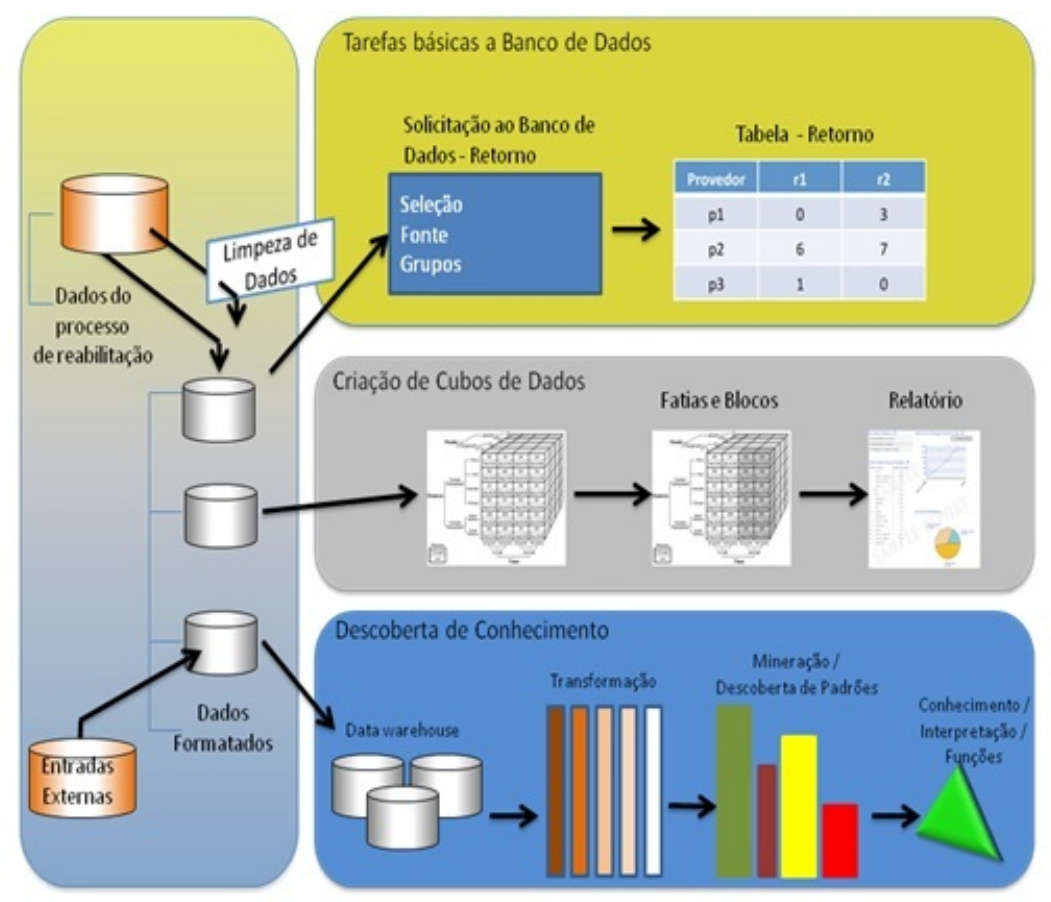

Figura 1.1 - Visão Geral do Processamento de Dados em um Data Warehouse.

Atualmente, estima-se que alguns bancos de dados já tenham atingido um número elevado de registros armazenados, ultrapassando medidas de 10 Terabytes. Esse aspecto, em termos de volume de dados, se deve a grande oferta de recursos com capacidade de armazenamento cada vez maior e o desenvolvimento de softwares aplicados às atividades organizacionais em empresas (SHIBA, 2008)

Como consequência dessa alta disponibilidade de recursos para armazenamento de dados, as organizações, em especial as indústrias sucroalcooleiras, foram de alguma forma obrigadas a investir em setores que lidam com esse tipo de atividade, desde ambientes responsáveis pela etapa de capturas de informações até a etapa de transformação dos dados em informações úteis para análise futuras (BERRY, 2004).

Um grande problema encontrado nessa etapa de armazenamento, é que nem sempre os dados armazenados são considerados dados úteis para serem utilizados em análises, por exemplo. Geralmente, somente são armazenados dados considerados importantes ou úteis em determinadas tarefas executadas no processo, como por exemplo, dados provenientes de um controle 
inerente no processo (controle de temperatura). Os outros dados, considerados como não muito importantes, não são armazenados ou são simplesmente descartados.

Pelo fato de se ter toda essa informação armazenada, as organizações questionavam se era possível realizar alguma outra atividade com os dados armazenados que pudesse auxiliar no processo de tomada de decisão (SASSI, 2006). Através de uma análise inteligente desses dados, eles se tornaria um recurso valioso a ser usado na descoberta de novos padrões (FRAWLEY W., 1992). Nas usinas de açúcar e álcool, muitos dados são ignorados pela falta desse tipo de cultura de análise, pois somente os dados que são monitorados e controlados possuem históricos.

A partir desse fato, são levantados os seguintes itens:

- O que se fazer com a grande quantidade de informações que são coletadas no processo?

- Tais informações podem ser armazenadas ou podem ser descartadas?

- Existe a possibilidade de se obter algum tipo de conhecimento nesses dados que são armazenados?

- Com relação aos dados descartados, eles realmente não são úteis ou eles podem ser utilizados para extrair o um novo conhecimento em conjunto com dados considerados úteis?

- Com os dados armazenados, existe a possibilidade de se obter informações (padrões) tais como, informações de produção, informações que auxiliam na manutenção de equipamentos?

- Existe a necessidade ou a possibilidade de se desenvolver novos equipamentos (sensores, atuadores, controladores) aplicados em partes do processo que ainda não são monitoradas? Tais informações, podem ser consideradas como úteis, isto é, elas podem ser utilizadas em outros tipos de análises, como por exemplo, em análises para verificar se existe a necessidade de se fazer melhorias em determinados processos industriais?

A utilização de tecnologias para a aquisição e armazenamento e tecnologias de análise de dados, nas mais diferentes áreas do conhecimento, ultrapassa em quantidade de armazenamento e processamento da mente humana. Assim, diversas ferramentas e métodos têm sido propostos, com o objetivo de se extrair algum tipo de informação sobre essa quantidade dados (LEE, 2005).

Nesse contexto, surgiu a Descoberta de Conhecimento em Base de Dados (Knowledge Discovery in Databases- KDD), que inicialmente fora definida como a extração de informação implícita, 
desconhecida e potencialmente útil a partir de um grande volume de dados. Em outra definição para KDD, (SASSI, 2006) tem-se que a descoberta do conhecimento em base de dados, se dá pelo processo de identificação de padrões válidos, novos, potencialmente úteis e compreensíveis em repositórios de dados, visando a melhoria do entendimento de um determinado problema. O termo KDD foi definido pelo Gartner Group como sendo todo o processo de extração do conhecimento em grandes volumes de dados, devido ao aumento do fluxo de dados armazenados em bancos de dados nas empresas.

\subsection{Objetivos do Trabalho}

O presente trabalho tem como objetivo desenvolver, aplicar e avaliar a utilização do processo KDD em ambientes industriais, em especial no setor sucroalcooleiro. A análise é feita sobre a viabilidade de se aplicar o uso desse tipo de ferramentas em tarefas diárias de um determinado setor da usina. Tais tarefas aqui apresentadas lidam com o estudo e a previsão de comportamentos futuros de um determinado processo, bem como sua modelagem sistêmica. O setor de fermentação, escolhido nesse trabalho, é considerado na indústria sucroalcooleira como um setor complexo, devido ao seu comportamento, sensibilidade (fatores físicos e bioquímicos), e principalmente pela falta de ferramentas que auxiliem no processo de tomada de decisão. Os resultados apresentados nesse trabalho são obtidos por meio de informações do processo de fermentação. Essas informações foram coletadas de uma dorna de fermentação no período de safra, ocorrida entre os meses de Julho a Dezembro do ano de 2008.

\subsection{Organização do Trabalho}

Este trabalho está organizado da seguinte forma: no Capítulo 2 é feita a descrição de como estão definidos os diversos níveis da informação dentro das industrias. Já no Capítulo 3 são descritos os setores inerentes em uma usina de açúcar e álcool. No Capítulo 4 é feita a descrição do processo de Descoberta do Conhecimento em Base de Dados utilizado nesse trabalho, bem como a revisão bibliográfica de sua aplicação na indústria. Nos Capítulos 5, ?? e ?? são descritas as ferramentas utilizadas na etapa de mineração de dados do processo de Descoberta do Conhecimento em Base de Dados. No Capítulo 6 são apresentados os experimentos e resultados obtidos com esse trabalho. Por fim, no Capítulo 7 são relatadas as conclusões obtidas com esse trabalho, bem como as propostas de trabalhos futuros. 


\section{Capítulo 2}

\section{Os Níveis de Informação na Industria}

O nível de informação na indústria vem sofrendo mudanças exigindo que equipamentos de campo e softwares dedicados evoluam rapidamente nos ultimo anos. A principal mudança está ligada a necessidade de integração entre os equipamentos dispostos no processo e os softwares utilizados na configuração e supervisão. Tal integração garante à indústria uma maior confiabilidade em seus processos.

O advento da computação e a inserção de microcontroladores na indústria, dentro dos dispositivos que compõe o processo, possibilitaram mudanças na comunicação, tornando as informações imunes a ruídos e, também, a maior confiabilidade no processamento e nas medidas feitas no processo. Dentre os exemplos de redes de comunicação industrial destacam-se o Foundation Fieldbus, Profibus, HART, AS-I, Device-Net, dentre outros (BRANDÃO, 2005)

Para que as informações atinjam níveis mais altos dentro da industria, é necessário que haja um protocolo que converta essas informações oriundas de equipamentos do processo para softwares dispostos em um nível maior de informação. Atualmente, diversos softwares de configuração e de supervisão adotaram protocolos de comunicação com interface Windows, tais como o OPC - OLE for Process Control, protocolo DDE - Dynamic Data Exchange.

No entanto, o protocolo OPC tornou-se padrão na indústria por ser considerado mais robusto e eficiente, por ter uma fundação OPC Foundation, responsável pelas regras e diretrizes do protocolo, pela economia de tempo e gastos no desenvolvimento de novos aplicativos e na manutenção de aplicativos existentes, pela facilidade de integração, dentre outros (JANKE, 2000). 
Desse modo, a arquitetura da informação dentro da indústria pode ser definida conforme a Figura 2.1:

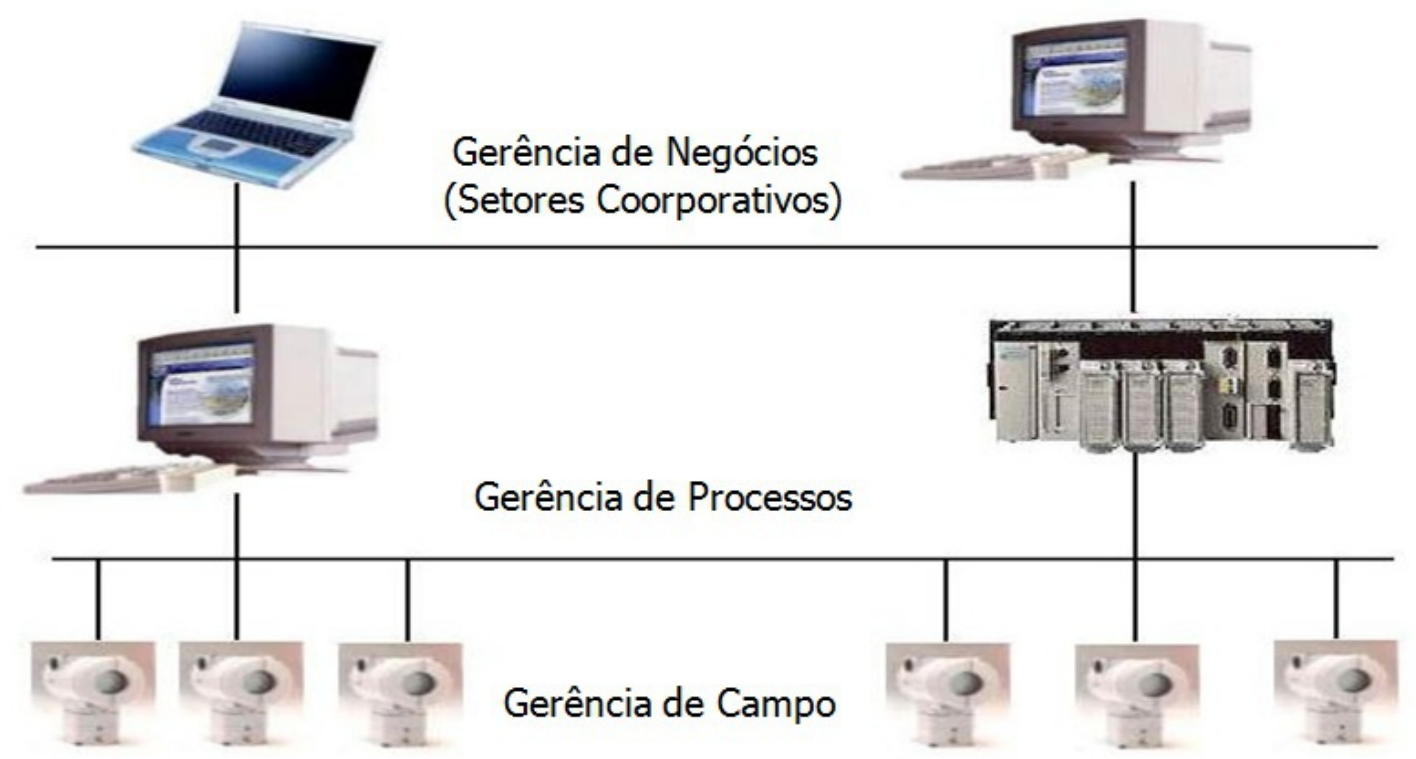

Figura 2.1 - Arquitetura dos Níveis de Informação na Indústria.

Assim, os níveis de informação na indústria são definidos como sendo:

- Gerência de Campo - Nesse nível, são obtidas informações referentes aos equipamentos dispostos no processo, tais como informações de controle, de instrumentação, de comportamento de instrumentos (válvulas e atuadores) e manutenção. As entradas ou as saídas dos equipamentos, são alimentadas de acordo com a sua finalidade, ou seja, um dispositivo de temperatura é ligado a um termopar e um dispositivo do tipo posicionador é conectado à uma válvula, por exemplo;

- Gerência de Processos - Conhecido também como o nível da Supervisão, o nível de Gerência de Processos é onde se encontram os aplicativos responsáveis pela configuração, manutenção e supervisão do processo. Nesse nível é feita a caracterização do comportamento do processo, as configurações dos equipamentos (faixa de operação, tipo de equipamento), configurações das malhas de controle do processo, criação de sinópticos de supervisão e gerenciamento de equipamentos. Esse nível é considerado como a parte que comanda todo o processo; 
- Gerência de Negócios - Esse nível está relacionado com a área corporativa, onde as informações sobre o processo são enviadas para os níveis superiores ou de gerência da indústria. Nesse nível, encontram-se os Sistemas de Informação, os Sistemas Gerenciadores de Banco de Dados, ferramentas de Apoio à Decisão, ferramentas de exportação de dados, dentre outros.

Os sistemas supervisórios são considerados como um conjunto de ferramentas e softwares, capazes de interligar todos os níveis de informação da indústria, disponibilizando informações desde o nível de campo até o nível de gerência. Por meio de informações obtidas pelos protocolos de comunicação (redes de campo, padrões de comunicação), os sistemas supervisórios disponibilizam o monitoramento e o rastreamento das informações do processo, onde se é possível que tais informações possam ser apresentadas para um determinado usuário, ou até mesmo que sejam armazenadas em base de dados.

Atualmente, os sistemas de automação industrial utilizam tecnologias de computação e comunicação para automatizar a monitoração e controle dos processos, efetuando a coleta de dados em ambientes complexos, eventualmente dispersos geograficamente, e a respectiva apresentação de modo amigável para o operador, com recursos gráficos elaborados (interfaces homem-máquina) e conteúdo multimídia. Geralmente, os sistemas supervisórios se localizam nos níveis de Gerência de Campo e nos níveis de Gerência de Processo.

Nos Níveis de Gerência de Negócios, são encontrados outros tipos de sistemas presentes na indústria; os sistemas ERP (Enterprise Resource Planning), o sistemas MES(Manufacturing Execution System) e os sistemas MI (Manufacturing Intelligence) (ICONICS, 2010).

Sistemas ERP é responsável por agrupar todas as informações de uma determinada organização em apenas um sistema de informação, ou seja, os sistemas ERP são compostos por apenas uma base de dados que integra todas as áreas da empresa. Cada módulo da empresa possui uma base de dados que por sua vez se integra com a base de dados principal da empresa. Os módulos de um sistema ERP são dedicados aos diversos setores da empresa tais como movimentação financeira, cadastro de funcionários, gestão financeira, contabilidade, custos, dentre outros (LAUDON, 1988).

Com avanço da tecnologia, existiu uma grande necessidade de se integrar as informações oriundas do processo, como informações de sensores por exemplo ou de sistemas supervisórios, com os sistemas ERP. Tal necessidade foi considerada pela indústria como uma grande lacuna 
entre os sistemas ERP e o processo, uma vez que o sistema ERP conseguia controlar todos os setores da empresa, mas não tinha controle sobre o que estaria acontecendo no processo (MESA, 2010).

Para suprir essa necessidade, surgiram os sistemas MES. Sistemas MES são sistemas que integram a automação do processo no chão de fábrica a um sistema de gerenciamento de informação, onde tais informações são utilizadas para a otimização da produção, desde o pedido de um produto até a sua concepção. Sistemas MES são considerados como sistemas de informações operacionais, de comunicação bidirecional entre o sistema de produção (chão-de-fábrica) com o sistema corporativo, onde são aprimoradas as estratégias dedicadas à manufatura. Os sistemas MES garantem gerenciar com muito mais eficiência a tomada de decisão com base em informações úteis, atuais, confiáveis, onde tais informações estão aproximadas da realidade dos mais diversos setores da empresa.

Um sistema MES é usado para definir, monitorar, controlar e sincronizar os cinco elementos de produção. São eles materiais, equipamentos, pessoas (funcionários), instruções do processo e documentação. Com isso, consegue-se o preenchimento da lacuna entre o mundo corporativo e o processo. Os sistemas MES provem informações em tempo real sobre todas as atividades correntes da produção, integrando assim as informações entre os vários departamentos e funções da empresa. A Figura 2.2 mostra a nova arquitetura da indústria com a inclusão de sistemas MES:

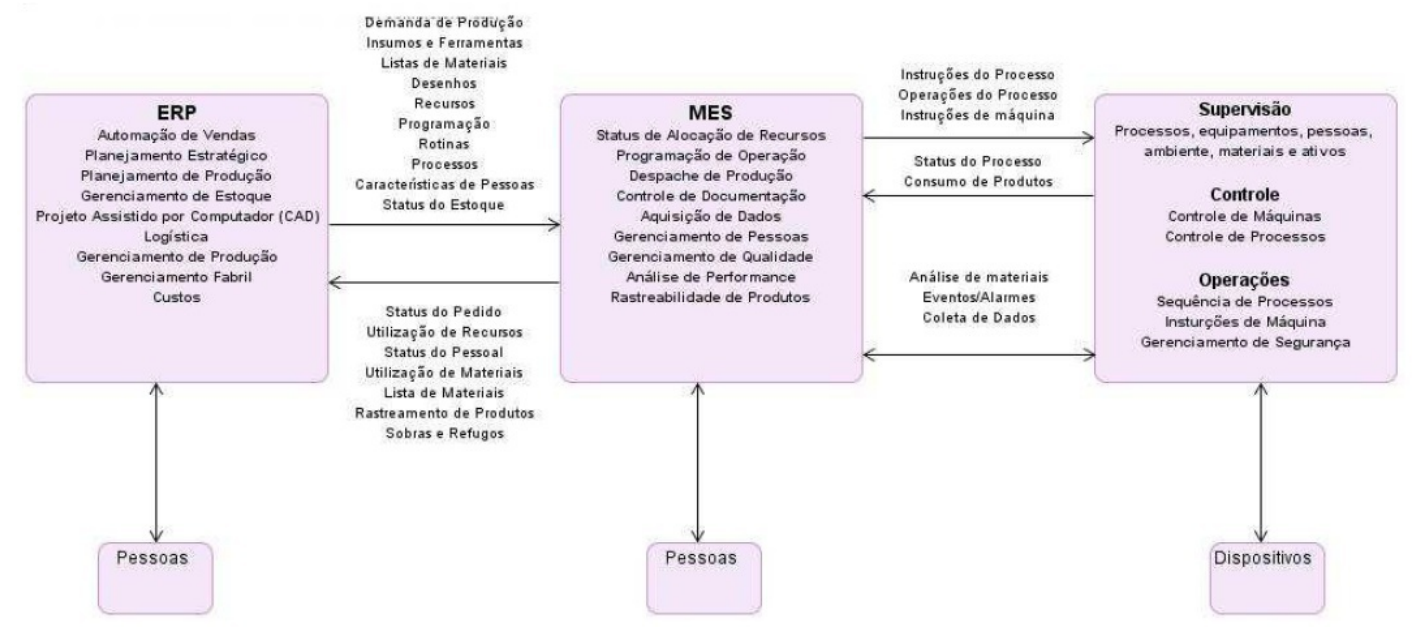

Figura 2.2 - Arquitetura da Indústria com Sistemas MES.

Um sistema MES coleta e acumula informações do realizado no chão de fábrica e as realimenta para o sistema de planejamento. Para tal, pode-se dividir as tarefas do sistema em duas partes. A primeira é de controlar a produção, relacionando o que está sendo produzido com 
que foi produzido, de modo a desprezar ações corretivas quando houver desvios. Na segunda, o sistema MES libera as ordens de produção, detalhadas pelos sistemas de gestão da empresa (ERP), para que as mesmas sejam atingidas e garantidas. Existe um órgão responsável por propor metodologias e abordagens para o melhor uso de informações industriais, agrupando excelência em execução com os requisitos corporativos, a MESA International. Assim, a MESA International definiu onze funções principais do MES para atender a demanda de necessidades em ambientes industriais, tais como (JOAQUIM, 2006):

- Operações Detalhadas - permitir a otimização de performance de atividades controladas pelo tempo, baseadas em recursos;

- Status e Alocação de Recursos - servir como guia para os recursos da empresa (máquinas, pessoas, ferramentas) sobre as atividades que foram executadas, que estão sendo executadas e as que serão executadas;

- Liberação da Produção - executar comandos para mandar materiais ou ordens para elementos distintos da planta para inicializar um determinado processo;

- Controle de Documentos - gerenciar e distribuir informações sobre os recursos, desde informações sobre produtos até as ordens;

- Rastreabilidade de Produtos - histórico de produtos, desde a criação até a expedição;

- Análises de Performance - comparador entre dados obtidos na planta com as métricas estabelecidas pela a empresa;

- Gerenciamento de Pessoas - direcionamento de operações pessoais durante a troca baseada em qualificações, padrões de trabalho e as necessidades do negócio;

- Gerenciamento de Manutenção - planejar e monitorar atividades referentes a manutenção de equipamentos e outros recursos da planta para obter a meta de performance da planta;

- Gerenciamento de Processos - direcionamento do fluxo de trabalho da planta, baseado em planejamentos e nas atuais atividades do processo;

- Gerenciamento de Qualidade - analisar, rastrear características de produtos e processos da planta;

- Aquisição e Manipulação de Dados - aquisição de dados sobre os processos, materiais e operacionais que envolvem pessoas, máquinas e o processo. 
Com a grande quantidade de dados armazenados, surgiu a necessidade da criação de ferramentas que auxiliasse em análises e no conhecimento inerentes. De início, foram propostas ferramentas baseadas no BI(Business Inteligence - Inteligência do Negócio) utilizadas em outros tipos de empresas. Devido à necessidade de adaptação de tais ferramentas, um novo conceito de ferramentas surgiu adaptados para a indústria ou manufatura. Surgiram as soluções do tipo MI (Manufacturing Intelligence - Inteligência da Manufatura), em que tais soluções são utilizadas como ferramentas de apoio à decisões tomadas em processos industriais, no sentido de verificar qual a visibilidade das tarefas que estão em execução, monitoramento de recursos (equipamentos e pessoas) dentre outros.

As soluções do tipo MI é a sinergia entre os mais diversos tipos de sistema tais como HMI/SCADA (interface Homem-Máquina), ERP ou MES. O sistema MI adiciona o nível de inteligência em ambientes de manufatura. As soluções MI, de uma maneira genérica, promovem a viabilidade entre os sistemas ERP e as operações que ocorrem no nível de chão-de-fábrica. De uma maneira geral, os sistemas MI são considerados como uma adaptação de ferramentas de apoio à decisão para o nível da indústria (ICONICS, 2010).

A proposta desse trabalho pode ser estendida também como um sistema do MI, fornecendo o conhecimento de uma forma aproximada do processo para o engenheiro ou responsável, para que esse conhecimento do processo possa auxiliar em tomadas de decisões futuras.

No próximo capítulo, é mostrado como é o funcionamento de uma usina de açúcar e álcool, onde são descritos os tipos de processo, desde a recepção da cana-de-açúcar até o armazenamento de álcool. 


\section{Capítulo 3}

\section{Fábrica de Açúcar e Álcool}

A aplicabilidade deste trabalho é voltada para processos sucroalcooleiros, em particular o setor de fermentação. Nesse capítulo, são descritos os processos inerentes que constituem uma usina de açúcar e álcool, desde a recepção da cana-de-açúcar até o produto final.

Os fluxogramas ilustrados nas Figuras 3.1 e 3.2 (DAL BEM, 2003), mostram em blocos, o funcionamento dos processos da recepção e dos processos de fabricação de açúcar e álcool:

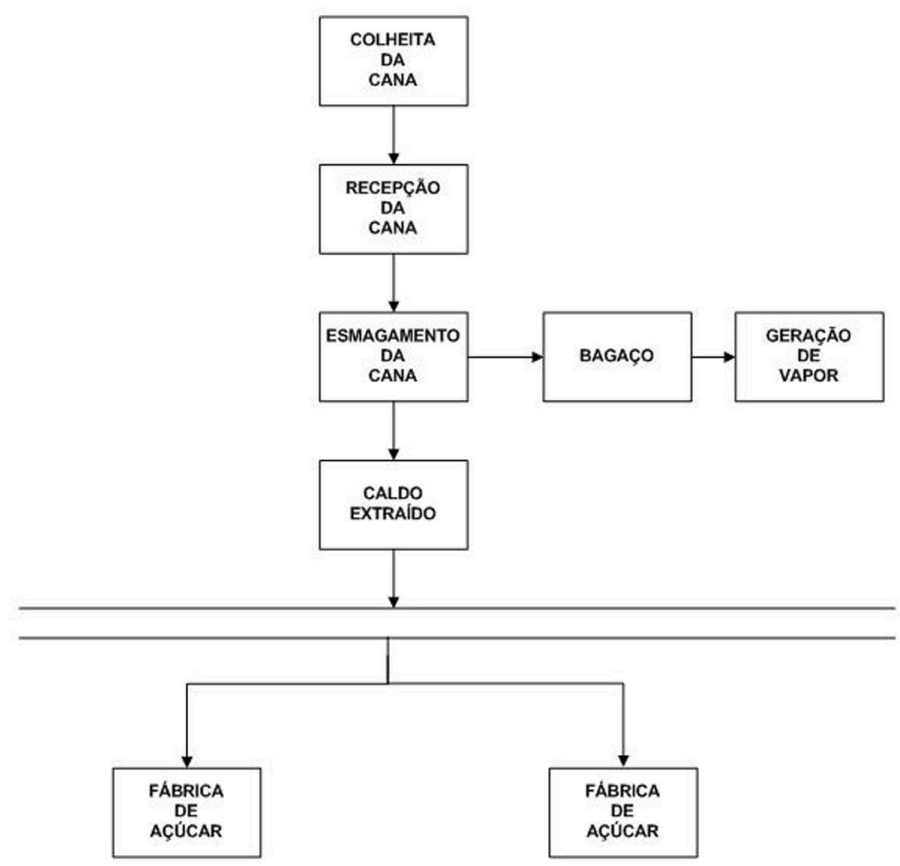

Figura 3.1 - Visão Geral do Processo de Recepção da Cana-de-açúcar 


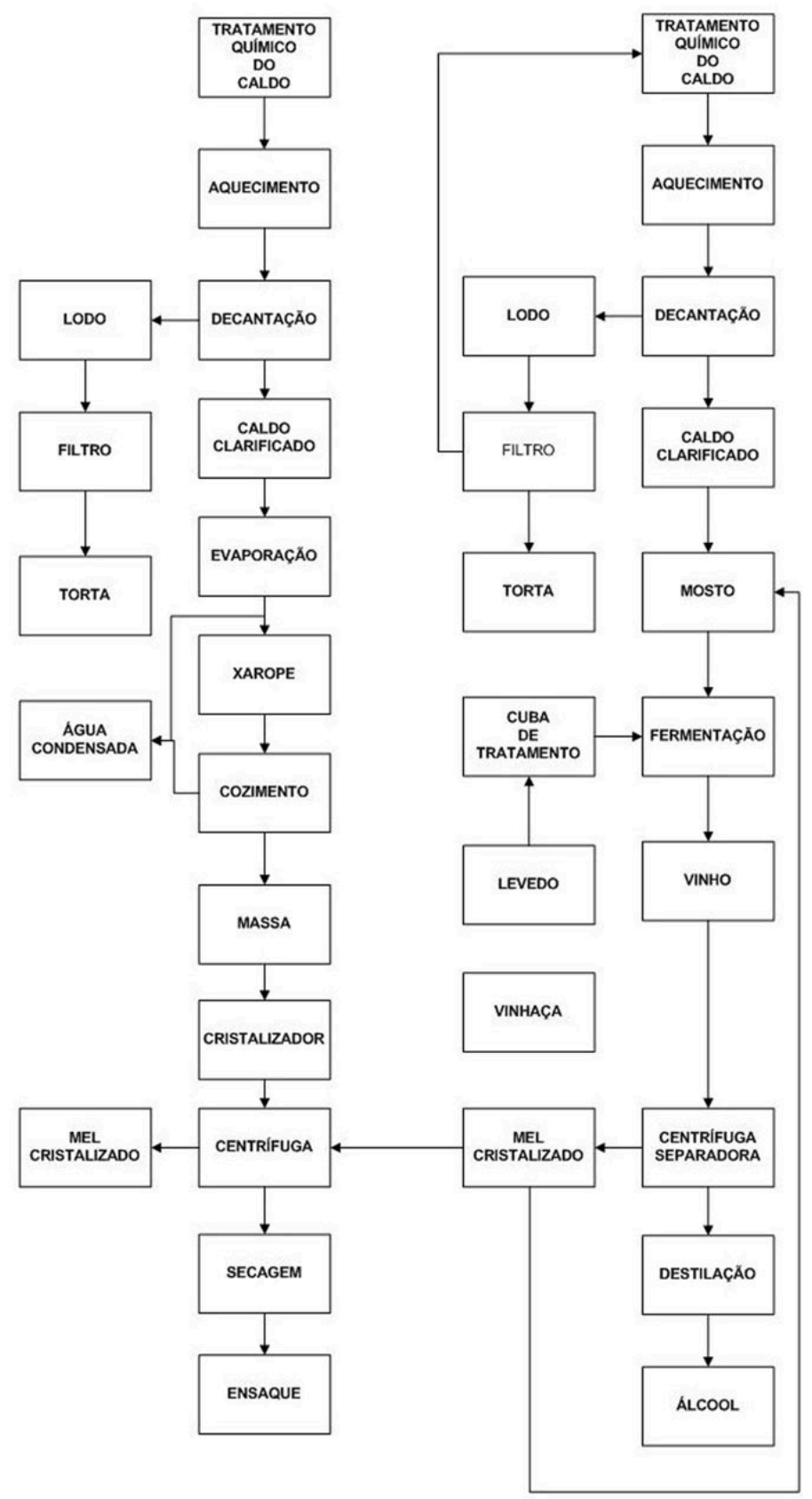

Figura 3.2 - Visão Geral do Processo de Fabricação de Açúcar e Álcool

Nas próximas seções, são descritos os módulos que fazem parte da usina de cana-de-açúcar.

\subsection{Recepção e Alimentação}

O sistema de recepção e alimentação é o responsável pela coleta da cana-de-açúcar, que é a matéria-prima utilizada no processo de fabricação. Quando a cana chega a usina ela deve ser pesada de acordo com as normas e regras de controle agrícola e industrial, referentes a recepção. 
Logo após, a cana é analisada em um laboratório conhecido como Pagamento de Cana pelo Teor de Sacarose (PCTS), onde são retiradas amostras da cana que foi entregue para a análise de suas principais características e principais componentes.

Essas análises são compostas dos seguintes elementos:

- Determinação da quantidade de sacarose presente na cana ou no caldo da cana (POL), em que tal medida é definida em porcentagem;

- Determinação do açúcar redutor (AR), responsável pela definição da quantidade, em porcentagem, da massa de glucose e frutose contida na cana;

- Determinação das impurezas minerais, carregadas com a cana desde o corte até o carregamento. Essa quantidade é definida em função da qualidade da cana, tipo de corte, tipo de carregamento, umidade do solo, variedade da cana, infestação por ervas daninhas, etc. Tal medida é obtida apenas em análise laboratorial;

- Determinação da fibra da cana, considerada a parte sólida da cana. Esse valor está na ordem de $10 \%$ a $15 \%$ da massa da cana. Logo após o processo de moagem, a fibra recebe o nome de bagaço passa a ter sua aplicação pelo processo de geração de energia, por meio da sua queima nas caldeiras;

- Determinação da quantidade de sólidos solúveis contidos no caldo de cana. Tal quantidade é conhecida como BRIX, e a sua medida é definida em porcentagem;

- Determinação dos sólidos solúveis, que são encontrados e dissolvidos no caldo de cana. Sua medida é dada em porcentagem.

Depois de coletadas as amostras, para análise laboratorial, ocorre a fase de descarga da cana. Esta pode ser previamente armazenada em pátios ou barracões (prática cada vez mais em desuso, devido a deterioração da matéria), ou descarregada diretamente na mesa de alimentação e desta para a moenda ou para o difusor.

\subsection{Extração do Caldo da Cana-de-açúcar}

A extração do caldo da cana consiste na separação do caldo da fibra da cana. Nas usinas de cana-de-açúcar, a extração do caldo é feita por dois processos: difusão (Difusor) ou moagem 


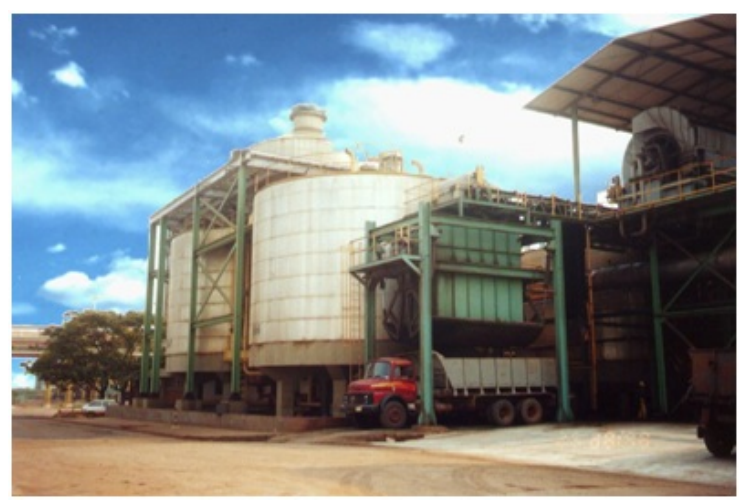

Figura 3.3 - Visão Geral do Processo de Fabricação de Açúcar e Álcool (SMAR, 2005).

(Moenda). Para ambos os processos, a cana passa antes pelo processo de preparo, que consiste, basicamente, em um processo de desfibração (estilhamento) seguido para a extração do caldo, propriamente dita.

\subsubsection{Processo de Extração do Caldo por Difusão}

A difusão é definida como o fenômeno pelo qual duas soluções de diferentes concentrações, separadas por uma membrana permeável, misturam-se depois de algum tempo e adquirem a mesma concentração. As células da cana postas em contato com a água funcionam como paredes semi permeáveis e a sacarose contida nessas células é extraída no escoamento de um fluído, resultado da mistura de água e do caldo diluído. Tal extração é feita através de um leito poroso da cana desfibrada. A extração depende muito da proporção de células rompidas durante o preparo da cana, e também da disponibilidade de acesso do líquido de extração a estas células (HIGA, 2003).

Geralmente esse número de células que não foram rompidas na cana é de aproximadamente $3 \%$. Dentre os fatores que podem afetar o crescimento desse número de células não rompidas estão vinculados à temperatura de extração, em que essa deve ser alta o bastante para produzir a viscosidade e aumentar a extração. Outro fator importante a se destacar é o tempo de retenção da fibra no difusor, tendo em vista que esse tempo deve ser alto, para que se consiga uma boa extração.

Uma grande desvantagem encontrada nesse tipo de extração é a falta de otimização e experiência com o processo, tendo em vista que muitos destes sistemas foram projetados baseados em experiências com difusores para extração de açúcar de beterrabas. Outra limitação está relacionada com a falta de experiência na operação desses equipamentos do processo de moagem 
por difusão e a incerteza de durabilidade desses equipamentos.

Porém, é de se esperar que com o aumento do número de unidades instaladas o rendimento desta abordagem melhore continuamente (BRUMAZI, 2009). Na Figura 3.4, é ilustrado o difusor, equipamento utilizado no processo de difusão:

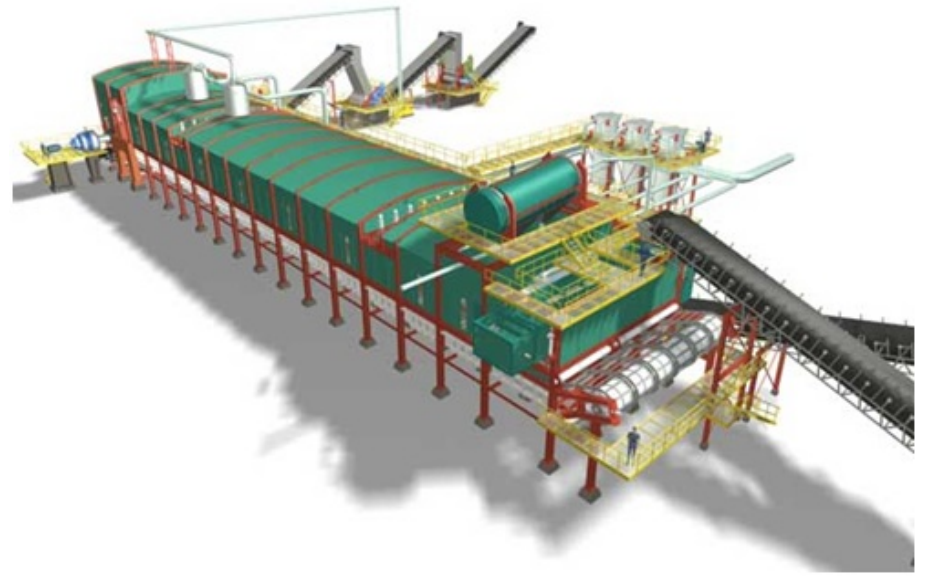

Figura 3.4 - Equipamento Difusor utilizado no Processo de Extração do Caldo por Difusão.

\subsubsection{Processo de Extração do Caldo por Moagem}

Amplamente utilizado para a extração do caldo da cana, o processo de moagem geralmente é realizado por ternos de moenda. Quanto maior o número de ternos, maior a eficiência da extração da moenda (DAL BEM, 2003) (BAYMA, 1974). Estes consistem em eixos de rolos montados na forma de um triângulo (rolo de entrada, rolo de saída e o rolo superior), de tal forma que a cana desfibrada seja esmagada duas vezes, uma no rolo superior e no rolo de entrada e a outra no rolo superior e no rolo de saída. Assim, a cana desfibrada passa pelo rolo superior e rolo de entrada e em seguida ela é conduzida por uma bagaceira até o rolo de saída (SMAR, 2005). O esquema pode ser visualizado pela Figura 3.5.

Um fato importante está relacionado com o tamanho dos rolos utilizados nesse tipo de extração, pois é ele que determina a capacidade de moagem do terno em toneladas de cana por hora.

O acionamento dos rolos é feito por meio de um pinhão localizado no eixo do rolo superior, este ligado indiretamente a uma turbina a vapor por sistema de engrenagens redutoras. Os rolos de entrada e saída são fixos, enquanto que o rolo superior é comandado por um sistema de 
pressão hidráulica que aciona os comandos de subida e descida.

A cana é conduzida de um terno para outro por meio de esteiras intermediárias, geralmente do tipo taliscas de arraste, passando sucessivamente por vários ternos na moenda. Assim, a quantidade de caldo, que era de 7 partes para cada 1 desfibra, cai para uma relação de 2 a 2,5.

Para aumentar a eficiência de extração é utilizado método de embebição, que consiste em adicionar água ao bagaço. Esse processo é explicado no tópico seguinte.

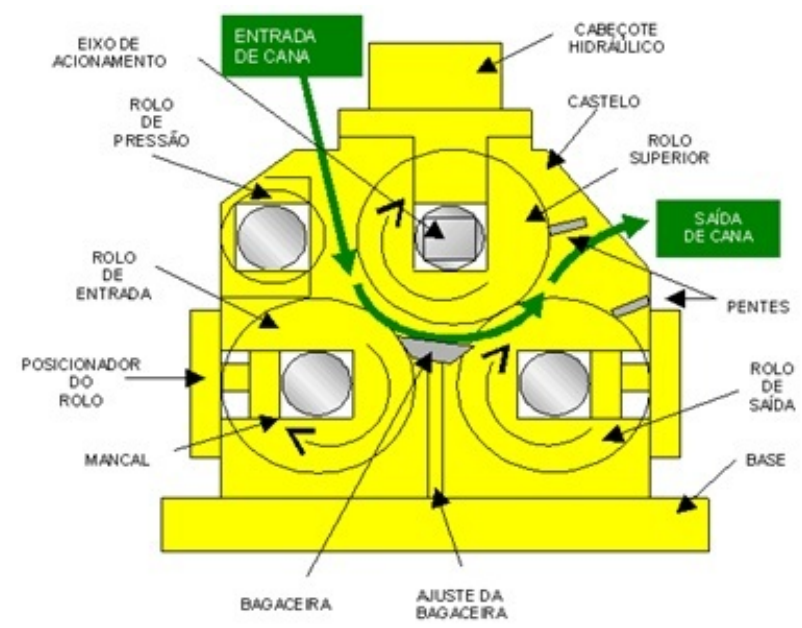

Figura 3.5 - Esquema de Terno de Extração do Caldo por Moagem (SMAR, 2005).

\subsubsection{Embebição}

O processo de embebição é realizado depois que a cana passa exaustivamente sobre os vários ternos da moenda. Nesse processo é adicionada água ao bagaço para extrair o caldo remanescente, aumentando a extração de açúcar. Fazendo-se uma analogia, é como a ação de encharcar um pano sujo com água para depois torcê-lo. Com isso, a taxa de extração da sacarose aumenta, variando de $92 \%$ a $96 \%$ (HIGA, 2003).

Dentre os tipos de embebição, tem-se:

- Simples: nesse tipo de embebição a água é adicionada em apenas um ponto da esteira da moenda. Sucessivamente, quando se aplica em dois pontos tem-se a embebição dupla, em três pontos embebição tripla e assim por diante.

- Composta: nesse tipo de embebição é adicionada água nos ternos dispostos nas últimas posições, e esses repassam o caldo extraído para os seus anteriores. 
Nas usinas de cana-de-açúcar, o método de embebição mais utilizado é o de embebição composta, por ser considerado mais eficiente na extração do caldo.

\subsection{Geração de Energia}

O bagaço resultante da extração é utilizado como combustível das caldeiras, responsáveis por gerar energia térmica na usina. Essa energia liberada é utilizada para converter água em vapor, utilizado no acionamento de turbinas, responsáveis em converter energia térmica em energia mecânica.

A energia mecânica gerada, é utilizada no acionamento de equipamentos dispostos na usina como picadores, moendas, geradores para a produção de energia elétrica, dentre outros.

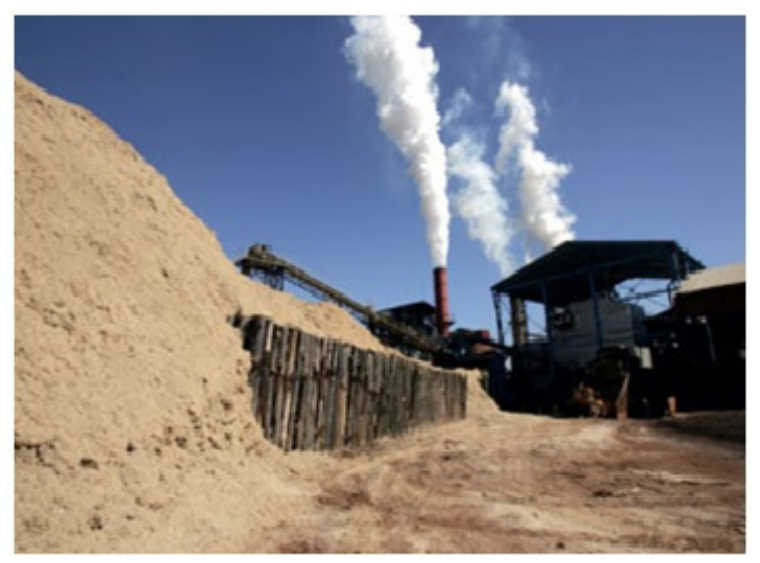

Figura 3.6 - Processo de Geração de Energia (SMAR, 2005).

\subsection{Produção de Álcool}

A produção de álcool se inicia pela fermentação do caldo da cana ou a partir da fermentação de uma mistura desse caldo com mel residual do processo de fabricação do açúcar, por meio de um processo bioquímico. Antes do caldo ser enviado para o processo de fermentação, ele deve passar por tratamentos para que ele seja de purificado, eliminando assim todas as impurezas e substâncias que atrapalham no processo fermentativo.

Após a fermentação, o produto resultante passa por um processo de separação do fermento e segue para a destilação. O fermento separado retorna ao processo. Essas fases do processo são descritas a seguir. 


\subsubsection{Tratamento Primário do Caldo}

O tratamento do caldo é o processo responsável por retirar todas as impurezas do caldo. Tais impurezas devem ser eliminadas, pois comprometem a qualidade do produto final, além de danificarem os equipamentos inerentes no processo (BASSETO, 2006). O caldo extraído na moagem ou na difusão possui uma mistura complexa, isto é, o caldo possui na sua composição, matérias estranhas que foram incorporadas de forma acidental nos processos anteriores, como a colheita, o transporte e as operações de moagem. Essas matérias estranhas contidas no caldo são classificadas como impurezas solúveis (cinzas) e insolúveis (bagaço e impurezas minerais).

A primeira etapa do tratamento do caldo ocorre nos processos de extração do caldo, onde se retira parcialmente o bagaço, através de equipamentos como a bagaceira, e em seguida o caldo é submetido ao processo de separação de impurezas minerais, por meio dos equipamentos de separação de areia.

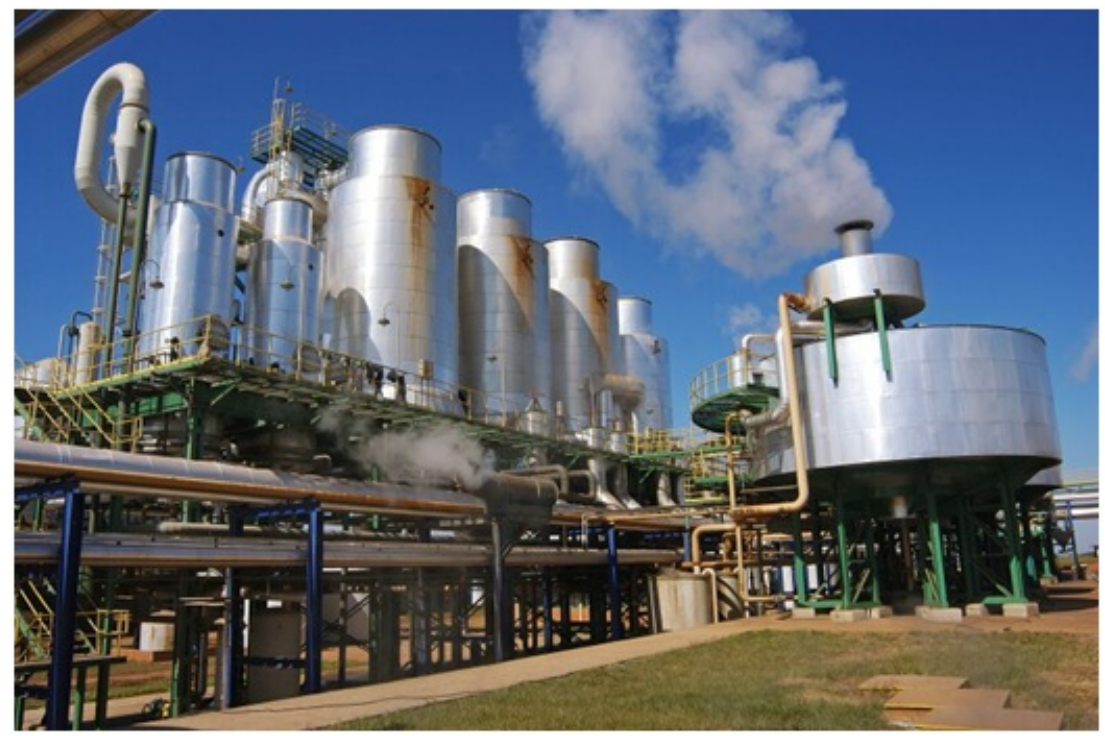

Figura 3.7 - Processo de Tratamento de Caldo (SMAR, 2005).

Com o caldo praticamente limpo, isto é, livre de impurezas e devidamente esterilizado, o caldo está pronto para ser encaminhado para a fermentação. Logo após, o caldo é enviado para outros módulos para que se continue o seu tratamento.

A princípio, o caldo passa por um Tratamento Químico para que ele tenha melhorias nas etapas de fermentação, evaporação e cozimento. Para a produção de açúcar bruto são utilizadas técnicas de defecação ou caleagem e a sulfodefecação ou sulfocalagem para o Açúcar Branco. Na defecação ou calagem, são adicionados leite de cal ao caldo até que ele atinja um pH perfeito 
para a produção de açúcar. $\mathrm{O}$ pH deve variar entre 7,2 e 8,2, aquecidos a uma temperatura que varia entre 100 e $105^{\circ} \mathrm{C}$. Esse fenômeno é necessário para que ocorra a aglutinação das partículas e por consequência a precipitação dos decantadores.

A sulfodefecação ou sulfocalagem consiste em executar a sulfitação do caldo com gás sulfuroso $\left(\mathrm{SO}_{2}\right)$. Assim a sulfitação provoca a melhora da decantação, pois reduz a viscosidade do caldo, melhorando também as qualidades do caldo para a evaporação e cozimento.

Logo após essas etapas, o caldo é aquecido em temperaturas que variam entre $90^{\circ} \mathrm{C}$ a $150^{\circ} \mathrm{C}$, com o objetivo de se esterilizar o caldo, eliminando assim bactérias existentes.

Na Decantação o caldo é enviado para aparelhos, conhecidos como decantadores, para que haja a separação de impurezas (lodo) do caldo. Estima-se que o tempo de retenção do caldo nos decantadores varia entre 2 à 4 horas em média. Com o avanço tecnológico, os decantadores conseguem reduzir esse tempo em 40 minutos, pois esses decantadores trabalham com um tempo menor na retenção do caldo.

Logo após, o caldo passa por um processo de decantação, para que seja feita a separação dos componentes do caldo. Dessa forma, diversos componentes são encontrados, bem como o lodo, que é considerado como um material rico em açúcar. Por ter essa característica, o lodo passa por um processo de filtragem, para que todo o açúcar nele contido seja extraído. Nesse processo de filtragem, são adicionados ao lodo fragmentos de bagaço, conhecidos como bagacilhos, que funcionam como uma malha de retenção de partículas sólidas. O resultado final é o caldo filtrado, que retorna para o tratamento químico e a torta resultante será utilizada na lavoura de cana-de-açúcar, onde é utilizada como adubo (DAL BEM, 2003) (SMAR, 2005). 


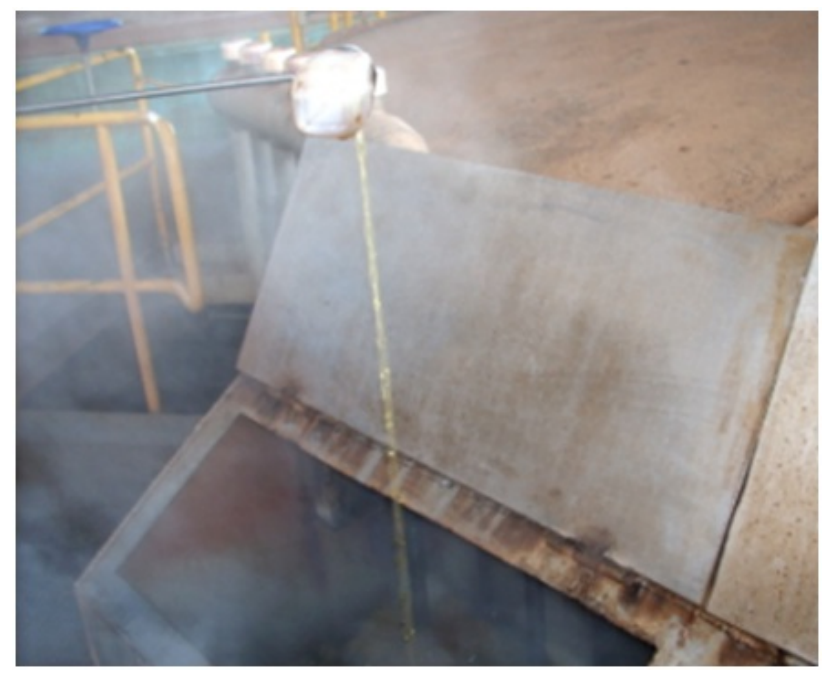

Figura 3.8 - Processo de Decantação do Caldo (SMAR, 2009).

\subsubsection{Fermentação}

A fermentação é considerada como uma das principais etapas da produção de álcool em usinas de açúcar e álcool. De uma maneira geral, na fermentação ocorre a transformação dos açúcares contidos no caldo em álcool, por meio de uma de procedimentos que adicionam ao caldo o mosto, que é a combinação soluções de açúcares e méis que auxiliam na fermentação. Essas reações ocorrem em tanques de fermentação conhecidos como dornas.

Os açúcares, ou sacarose, são transformados em álcool de acordo com a reação de Gay Lussac (AMORIN, 2005):

$$
\begin{gathered}
\mathrm{C}_{12} \mathrm{H}_{22} \mathrm{O}_{11}+\mathrm{H}_{2} \mathrm{O}=>\mathrm{C}_{6} \mathrm{H}_{12} \mathrm{O}_{6}+\mathrm{C}_{6} \mathrm{H}_{12} \mathrm{O}_{6} \\
\mathrm{C}_{6} \mathrm{H}_{12} \mathrm{O}_{6}=>2 \mathrm{CH}_{3} \mathrm{CH}_{2} \mathrm{OH}+2 \mathrm{CO}_{2}+23,5 \mathrm{kcal}
\end{gathered}
$$

A fermentação pode ser dividida em três fases, a fermentação preliminar, a fermentação principal e a fermentação complementar. Na fermentação preliminar é adicionado o fermento e se inicia o desprendimento de gás carbônico. Nessa etapa ainda não se tem produção de álcool.

Logo após a fermentação preliminar, ocorre a fermentação principal. Nessa etapa a produção de $\mathrm{CO}_{2}$ aumenta significativamente onde se tem a impressão que o mosto está em estado de ebulição. Nessa etapa ocorre também o aumento do volume e da temperatura do mosto. As 
variáveis de processo monitoradas nessa etapa são a densidade de açúcares e a temperatura do mosto. Para o controle da densidade de açúcares, é adicionado água e para controle da temperatura utiliza-se de um sistema de resfriamento.

A fermentação complementar ocorre quando se tem a liberação de $\mathrm{CO}_{2}$ e a temperatura do mosto diminui. Um fato importante, é que nessa fase podem aparecer infecções e possíveis formações de alcoóis superiores, fato esse ocorrido pelo excesso de óleo contido na cana oriundo de processos anteriores.

Por fim, o mosto torna-se vinho devido à inexistência de sacarose em sua composição. Na Figura 3.9, ilustra as dornas do setor de fermentação:

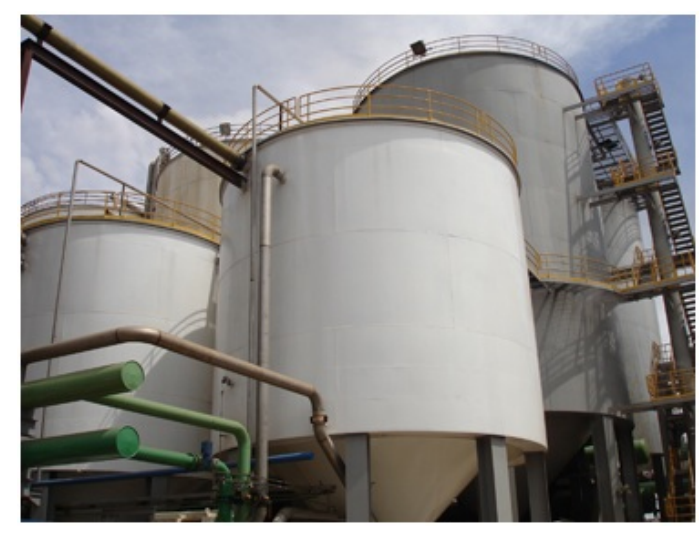

Figura 3.9 - Setor de Fermentação em Usina de cana-de-açúcar (SMAR, 2005).

\subsubsection{A atual prática da Fermentação Alcoólica no Brasil}

A prática da fermentação no Brasil segue os passos citados anteriormente: o preparo do caldo, fermentação e a destilação. Na maioria das usinas e destilarias brasileiras, observa-se que nos dias atuais a alimentação das dornas com o mosto é realizada de forma simultânea no que diz respeito a colocação do fermento.

Na maioria das destilarias de álcool ou até mesmo nas indústrias de bebidas destiladas no Brasil, a fermentação se processa de forma intermitente, isto é, onde todas as etapas de preparo, tratamento e fermentação ocorrem várias vezes. Esse processo é conhecido como processo de fabricação em batelada (AMORIN, 2005). 


\subsubsection{Centrifugação do Vinho}

Após a fermentação, vinho é levado para as centrífugas, onde ocorre a recuperação do fermento, e se obtém um concentrado do fermento recuperado conhecido como leite de levedura, que é utilizado nas cubas onde são feitos os tratamento do caldo. A outra parte do vinho, ou seja, o vinho sem fermento é encaminhado para as colunas de destilação para a obtenção do álcool.

\subsubsection{Destilação}

Quando o vinho chega da fermentação, ele possui em sua composição 7 a 10 GL de álcool e outros componentes de natureza liquida como água, com teores de $89 \%$ a $93 \%$, glicerol, dentre outros, os de natureza sólida como bagacilhos, leveduras, bactérias e os de natureza gasosa como o $\mathrm{CO}_{2}$ e o $\mathrm{SO}_{2}$.

Para a recuperação do álcool contido no vinho é utilizado o processo de destilação, onde ocorre a separação das substâncias presentes no vinho. Geralmente, essa operação ocorre em sete colunas distribuídas em quatro troncos.

\subsubsection{Armazenamento}

Os alcoóis produzidos, o hidratado e o anidro, são quantificados por meio de medidores de vazão ou outros equipamentos e são enviados para a armazenagem em tanques de grande volume, dispostos em parques de tanques onde ficaram armazenados até sua comercialização.

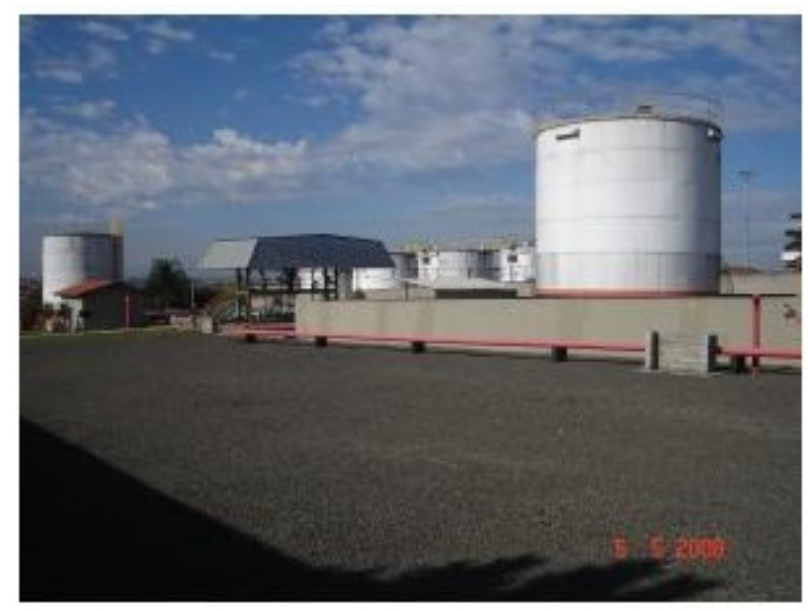

Figura 3.10 - Setor de Armazenamento em Usina de cana-de-açúcar (SMAR, 2005). 


\section{Capítulo 4}

\section{Descoberta de Conhecimento em Base de Dados}

Diversos autores, definem a Descoberta do Conhecimento em Base de Dados como um processo que objetiva a identificação de novos padrões encontrados em um conjunto de dados. Esses padrões possuem características essenciais para serem considerados como informações úteis, válidas e inéditas (BARIONI, 2002).

Em outras definições, o KDD é um conjunto de etapas responsáveis pela extração de conhecimentos potencialmente válidos, novos e úteis, objetivando uma melhor compreensão de um problema (SASSI, 2006). Enfim, pode-se definir o KDD como um processo, onde o uso do conhecimento extraído de base de dados é intensivo e estruturado em etapas, em que tais etapas são compostas por interações entre uma pessoa e um Banco de Dados, acessados e controlados por um Sistema Gerenciador de Banco de Dados. Tal Sistema Gerenciador de Banco de Dados é responsável em fornecer o suporte, por meio de ferramentas heterôgenas, para tais análises.

Um ponto importante, é a definição de como pode ser tratado o conhecimento. O conhecimento é ato de se descobrir, ou de alguma forma, extrair informações válidas por meio de um conjunto de dados, sem a necessidade de se ter uma formulação prévia de hipóteses, informações relevantes e desconhecidas, que possivelmente podem ser utilizadas no processo de tomada de decisão ((CABENA, 1997) apud et al. (SASSI, 2006)).

A evolução do KDD está relacionada com a evolução natural dos sistemas computacionais desde a década de 60, onde as informações eram armazenadas e processadas em arquivos texto, gerando uma grande quantidade de informações de forma desorganizada. Hoje toda a política 
de armazenamento, organização de dados e tratamento de transações de dados está alocada no SGBD (DATE, 2000).

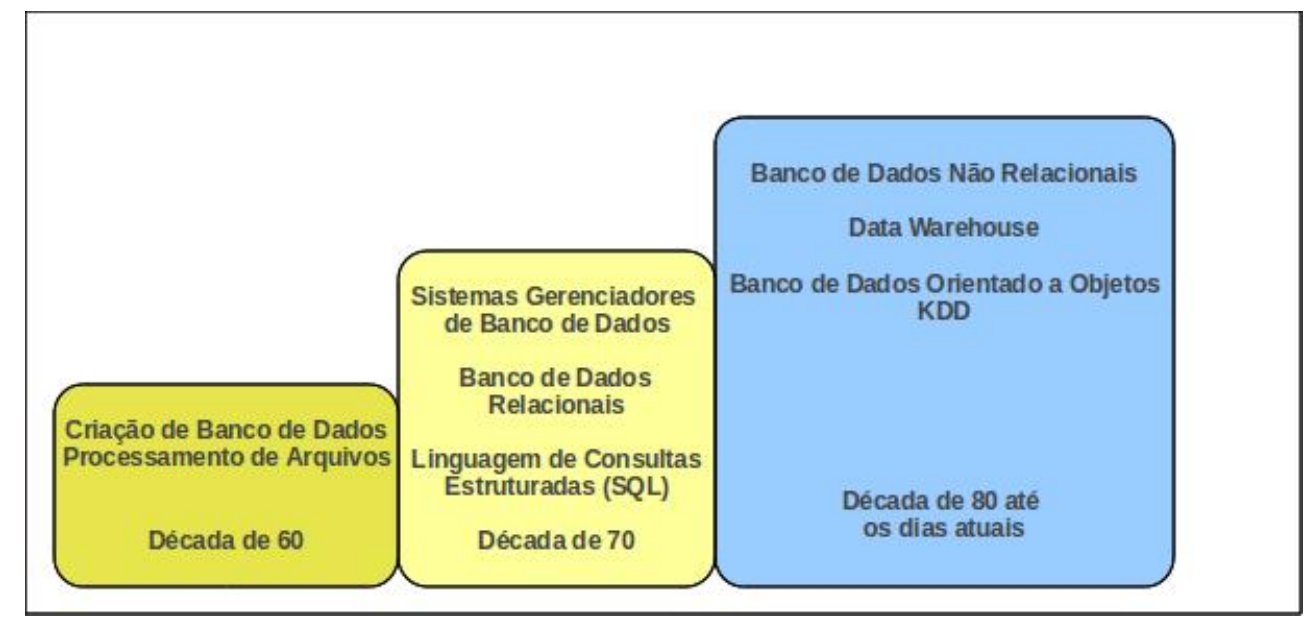

Figura 4.1 - Evolução de Sistemas Computacionais.

O KDD define os seguintes itens, ao longo de seu processamento (SILVA, 2002):

- Dados como um conjunto de fatos ou informações;

- Padrões, definidos como padrões ou linguagens, utilizados para descrever um determinado subconjunto de dados, podendo ser considerados também como modelos aplicáveis a um determinado subconjunto de dados;

- Processo, onde são definidas as sequências dos passos que devem ser seguidos para o que funcionamento do KDD seja satisfatório;

- Validações de padrões descobertos a partir de novos dados, descobertos com algum grau de certeza;

- Novidade é o resultado de um determinado padrão encontrado e que satisfaz o objetivo inerente no processo do KDD;

- Compreendimento de padrões descobertos, de maneira imediata (MEIRA, 2008).

A forma de funcionamento do KDD, pode ser compreendida como uma série de etapas, baseadas em técnicas, tais como: aprendizado de máquina, reconhecimento de padrões e técnicas estatísticas para descobrimento de padrões. Outras técnicas que podem ser citadas são técnicas de visualização de dados, que estimulam a percepção e a inteligência humana, fornecendo um entendimento mais apropriado sobre o entendimento e a associação de novos padrões (REZENDE et al., 
2002). Por esse motivo, o KDD obteve um crescimento significativo por prover a integração com outros tipos de tecnologias, tais como Inteligência Artificial, Visualização de Dados, Algoritmos Genéticos (LUO, 2008).

Atualmente, as pesquisas que envolvem o uso do KDD como ferramentas para o descobrimento de novos padrões de dados, ou até mesmo para o auxílio na tomada de decisão em ambientes organizacionais, obtiveram um crescimento significativo, pois é possível aplicar ferramentas de análises potencialmente complexas em um conjunto de dados, de maneira útil e inédita (SHIBA, 2008).

Em alguns casos, o termo KDD é confundido como Mineração de Dados (Data Mining). No KDD, a Mineração de Dados foi incorporada como um item do processo KDD, sendo considerada como uma das mais importantes, pois é responsável pelo processamento para que seja encontrados os novos padrões em um conjunto de dados. A Mineração de Dados está relacionada com a forma de como os algoritmos de extração do conhecimento serão aplicados (FAYYAD, 1996) e (MEIRA, 2008).

No início do KDD, três autores são envolvidos para que se tenha qualidade no processo. São eles: ((REZENDE et al., 2002);(BARIONI, 2002))

- Analista de Dados: é o profissional responsável pelo conhecimento. É ele o responsável em determinar quais serão as técnicas envolvidas para o funcionamento do processo do KDD;

- Analista de Domínio: é o profissional que possui o conhecimento do domínio onde o processo do KDD será aplicado. Ele também é o responsável em verificar se os padrões ou os conhecimentos encontrados pelo processo KDD são válidos ou não, para ser aplicado à possíveis processos de tomadas de decisão;

- Usuário: é o profissional responsável por executar todas as tarefas do processo do KDD. Também pode ser utilizado para a coleta das informações.

Fazendo uma analogia para a indústria, o Analista de Dados é o profissional da Informação responsável em desenvolver aplicações para o processo do KDD. Para isso, ele utiliza-se de ferramentas fornecidas externamente ou desenvolvidas pela sua equipe, em que tais ferramentas são aplicadas na coleta de informações, processamento de informações e análise de novos padrões descobertos.

O Analista de Domínio por sua vez, é o engenheiro responsável por um determinado setor 
na indústria. É esse profissional o responsável em dizer quais são as variáveis do processo que devem ser analisadas ou armazenadas, quais as respostas esperadas e quais os padrões que devem ser descobertos. Por fim, o usuário pode ser um determinado operador responsável em auxiliar os analistas em suas atividades.

\subsection{Etapas do Processo do KDD}

As etapas do KDD são representadas como um conjunto de fases orientadas por atividade, que são direcionadas à extração, manipulação e mineração de dados. As fases do KDD são representadas na Figura 4.2:

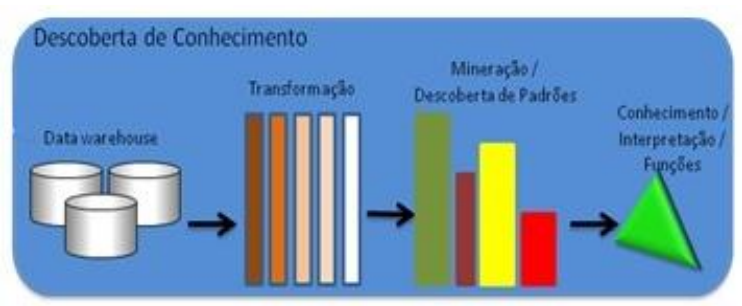

Figura 4.2 - Evolução de Sistemas Computacionais.

Em (SHIBA, 2008), é definida uma tabela que descreve as etapas do processo do KDD, de acordo com os objetivos, pré-processamento, mineração de dados e pós-processamento, conforme a Tabela 4.1

Tabela 4.1 - Distribuição das Atividades do KDD em Fases.

\begin{tabular}{|c|c|}
\hline Fases & Etapas \\
\hline Pré-processamento & $\begin{array}{c}\text { Compreendimento do Domínio } \\
\text { Compreendimento do Modelo de Dados } \\
\text { Escolha e Seleção de Dados }\end{array}$ \\
\hline Mineração de Dados & $\begin{array}{c}\text { Seleção de Métodos para a Mineração de Dados } \\
\text { Planejamento da Geração dos Modelos } \\
\text { Testes } \\
\text { Aplicação da Mineração de Dados }\end{array}$ \\
\hline Pós-processamento & $\begin{array}{c}\text { Visualização } \\
\text { Interpretação dos Padrões Minerados } \\
\text { Avaliação dos Resultados }\end{array}$ \\
\hline
\end{tabular}

Em outra referência (FAYYAD, 1996), as etapas do KDD são descritas em 9 passos:

- Conhecimento do Domínio: tal conhecimento está vinculado ao entendimento da área de 
domínio da aplicação do KDD, objetivando os requisitos do usuário;

- Seleção de Dados: nessa etapa são feitas as seleções dos dados utilizados no processo de extração, por meio dos procedimentos de acesso definidos;

- Pré-processamento: o pré-processamento é responsável pela limpeza e pré-processamento dos dados. Os dados considerados inválidos ou inúteis são desprezados;

- Redimensionamento de Dados: são realizadas técnicas para que se encontre a interdependência entre os dados;

- Escolha do Algoritmo de Mineração de Dados: nessa etapa são definidas as técnicas de mineração de dados que serão utilizadas;

- Escolha das Ferramentas de Mineração de Dados: definidas as técnicas de mineração de dados, agora é necessário que se escolha qual a ferramenta utilizada na fase de mineração. Importante, é que essa ferramenta deve atingir todos os objetivos definidos na escolha da técnica de mineração de dados;

- Mineração de Dados: considerada como sendo a inteligência do KDD, nessa etapa são processados os dados para o descobrimento de novos padrões;

- Interpretação dos Resultados: a partir dos padrões identificados por meio da mineração de dados, o analista verifica se os padrões podem ser considerados como válidos;

- Resultados: a partir da validação feita na Interpretação dos dados, os resultados são utilizados para auxiliar em processos de tomada de decisão ou até mesmo em situações em que se é necessário executar o processo do KDD novamente.

Mas para que esses passos sejam executados de maneira eficiente, alguns passos iniciais devem ser tomados. Tais passos são descritos nos próximos tópicos.

\subsection{Pré-processamento de Dados}

Geralmente, os dados quando são analisados possuem algum tipo de anomalia que indicam que os dados não foram de alguma maneira gerados ou armazenados de forma correta. Dentre essas anomalias, destacam-se os valores ruidosos, as inconsistências de dados e valores ausentes. 
Nesse ponto, diversas técnicas são aplicadas de acordo com as situações encontradas nos dados, conforme a Tabela 4.2 :

Tabela 4.2 - Técnicas para Tratamento de Dados.

\begin{tabular}{||c|c||}
\hline \hline Tipos de Dados & Ferramentas \\
\hline \hline Ruidores & Interpolação de Dados \\
& $\begin{array}{c}\text { Agrupamento de Dados } \\
\text { Técnicas de Inspeção (Humana ou Computacional) } \\
\text { Técnicas de Regressão de Dados }\end{array}$ \\
\hline Valores & Desconsideração de Valores Nulos \\
Ausentes & Suprimento de Valores Nulos \\
\hline Valores & Manual \\
Inconsistêntes & Ferramentas de Engenharia e Conhecimento \\
& \\
\hline
\end{tabular}

Vale ressaltar que, as técnicas citadas para o construção de ferramentas para o tratamento de Valores Ausentes, podem gerar um vício nos dados, pois pode-se ter uma grande quantidade de repetições nos dados (SILVA, 2002).

\subsection{Transformação de Dados}

Quando se trabalha com o processo do KDD, geralmente se deseja que seja feita a integração de todos os dados que serão analisados, isto é, os dados que são utilizados no processo geralmente podem vir de Base de Dados, planilhas, arquivos texto dentre outros tipos de armazenamento de arquivos. Para que essa transformação seja bem sucedida, é necessário que se observe os seguintes tópicos (HAN, 2006):

- Integração de Esquemas:

- Redundância de Atributos:

- Identificação de Valores Conflitantes: 
Seguindo tais etapas, é possível que se consiga a redução de redundância de dados e a eliminação da inconsistências nos dados, aumentando a precisão dos dados, bem como a velocidade de processamento das etapas do KDD.

A partir do método de mineração de dados, são definidas as técnicas de Transformação de Dados que serão utilizadas. Dentre os tipos de Transformação de Dados, pode-se destacar o processo de Agregação de Dados, Generalização, Normalização e Redução de Dados.

Na Agregação, é feita uma totalização de determinados valores, em que são considerados as características do atributo ou as instâncias que ele pertence. Um exemplo disso é a totalização de vendas de um determinado vendedor. A Generalização leva em conta a substituição de dados tidos em sua forma primária ou crus, em informações mais significativas ou de alto nível. Por exemplo um campo que caracteriza uma idade em uma determinada tabela de alunos, pode gerar informações de quais são as faixas etárias de alunos de uma determinada universidade.

Normalizar dados significa que os dados deverão obedecer uma determinada faixa de operação, geralmente variando de -1 a 1, ou de -2 a 2, e assim sucessivamente. Por fim, a Redução de Dados é muito utilizada quando se deseja trabalhar com algoritmos de inteligência artificial no processo de mineração de dados. A Redução de Dados consiste em reduzir de alguma forma a grande quantidade de informações, o que facilita muito a parte de análise. Portanto, o principal objetivo da redução de dados é reduzir a quantidade, sem perder suas características (HAN, 2006).

Para exemplificar o processo de Redução de Dados, considere a seguinte série temporal definida pela seguinte equação:

$$
y(k)=\operatorname{sen}(2 * \pi * 5 * t)
$$

A resposta da série é representada pela Figura 4.3, processada em um intervalo de 1 a 1000: 


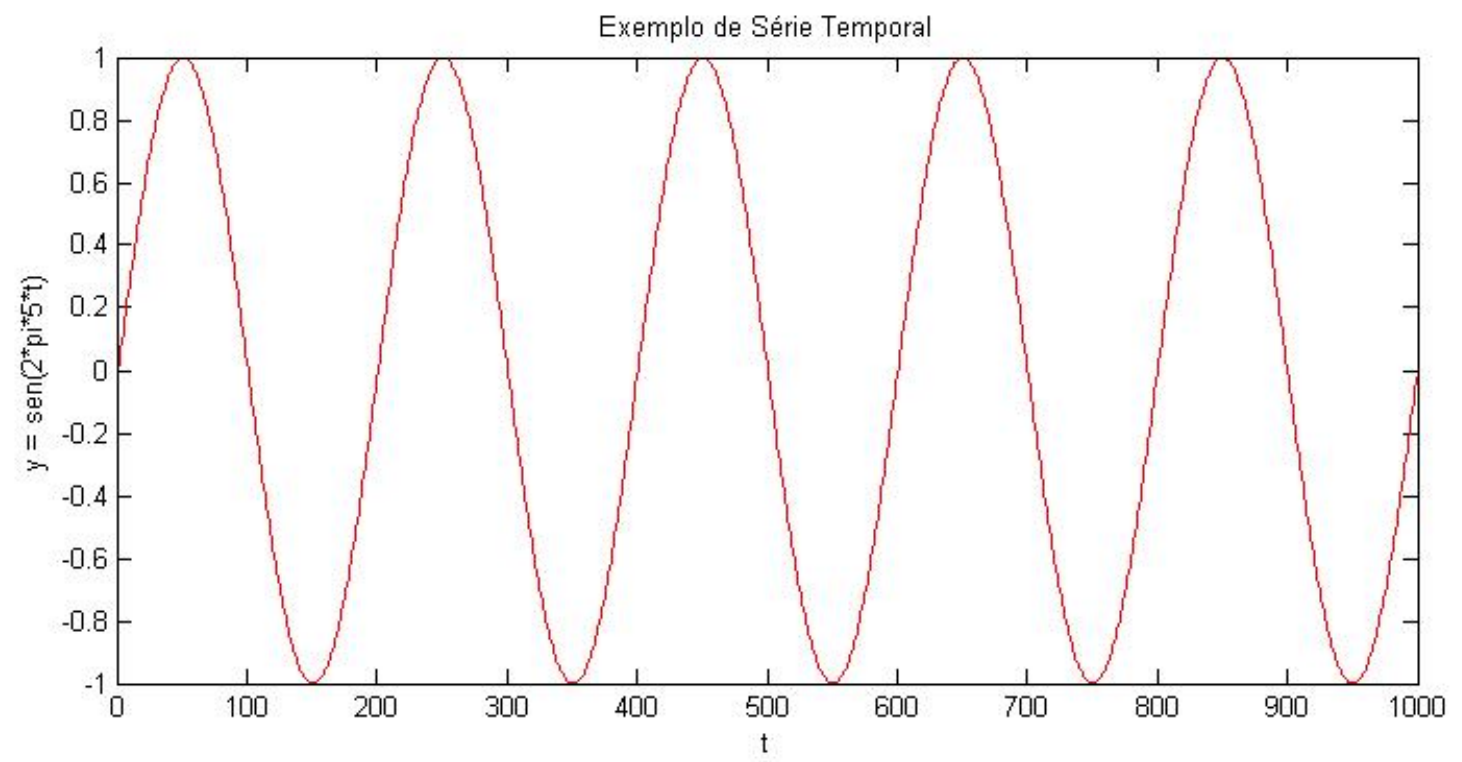

Figura 4.3 - Série Temporal com 1000 pontos (Original).

Nesse exemplo, é necessário que se reduza a quantidade de pontos dessa série para 600 pontos, sem que ela perca suas características iniciais. Por meio de técnicas de Interpolação de Dados, a resposta da série temporal para 600 pontos é definida, como na Figura 4.4:

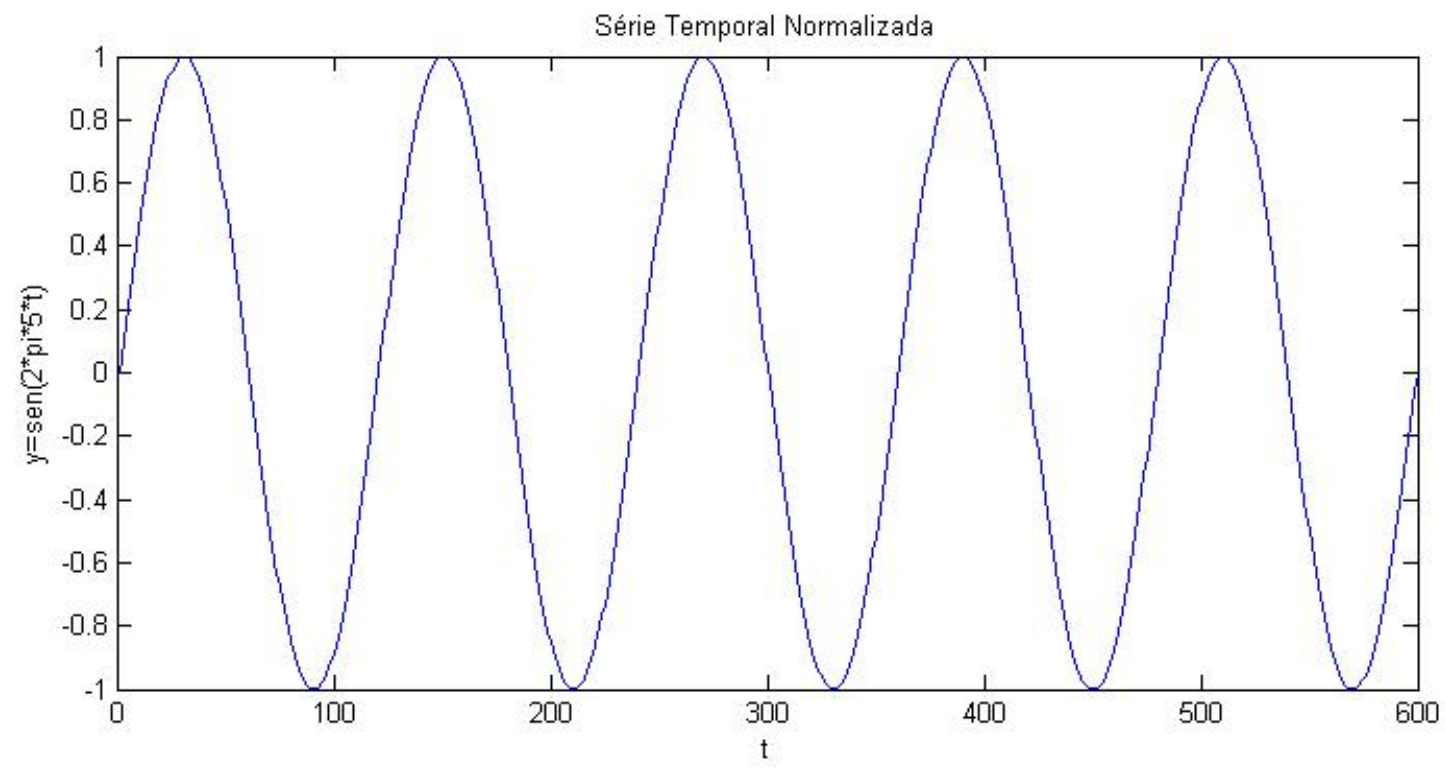

Figura 4.4 - Série Temporal com 600 pontos (Redimensionada). 


\subsection{Tarefas do KDD}

As tarefas do KDD podem ser classificadas de duas formas, primárias e compostas. As tarefas primárias são consideradas como tarefas homogêneas e não são unidas ou compostas por outras tarefas. Já nas tarefas compostas, podem ser desmembradas em outras tarefas.

O funcionamento das tarefas do KDD está ligado a forma de que como os dados serão processados, ou seja, se os dados serão processados seguindo um padrão existente, ou se os dados serão processados sem a necessidade de se guiar por padrões existentes. Esses tipos de processamentos são chamados de Aprendizagem.

Existem dois tipos de aprendizagem, a supervisionada e a não supervisionada. Na aprendizagem supervisionada são fornecidos padrões ou classes que descreve onde os dados utilizados no processamento pertencem. Os algoritmos da aprendizagem supervisionada são considerados como preditivos, provendo uma previsão ou até mesmo tendências, pois eles conseguem encontrar informações nos dados analisados inexistentes na base.

Já na aprendizagem não supervisionada, as classes não são conhecidas. A característica dos algoritmos desse tipo de Aprendizagem é que eles são descritivos, descrevendo de maneira concisa os dados analisados, além de fornecer características e definir suas propriedades (SILVA, 2002).

Alguns autores tratam as tarefas do KDD, como sendo as tarefas configuradas na mineração de dados. Outros autores, definem essas mesmas tarefas como as tarefas do KDD. A seguir, são descritas as principais tarefas do KDD (GOLDSCHMIDT, 2005).

\subsubsection{Descoberta de Associações}

Essa tarefa consiste em encontrar um conjunto de dados de forma simultânea e frequente em uma base de dados. Formalmente, a descoberta de associações é definida como uma busca por regras e associações frequentes e válidas em um banco de dados, a partir de especificações de parâmetros descritos pelo especialista no processo do KDD, em conjunto com o especialista de domínio.

\subsubsection{Descoberta de Associações Generalizadas}

A Descoberta de Associações Generalizadas são consideradas como extensões da Descoberta de Associações, pelo fato que compreensão dessa tarefa depende da percepção de que é comum 
a existência da hierarquia e abstração de conceitos. Um exemplo que pode ser considerado é o da roupa, por ser um vestuário bem generalizado. Porém quando se fala em calça, e camisa, a ideia é bem mais direcionada. Assim, o conceito de roupa pertence a um nível de abstração que está acima do nível de abstração da calça e da camisa.

\subsubsection{Descoberta de Sequências}

Esse tipo de descoberta, é definida como uma expansão da Descoberta de associações generalizadas, considera o aspecto temporal entre as transações registradas em um determinado banco de dados. A diferença entre elas é que a Descoberta de Associações, o padrão descoberto pertencem a uma determinada transação, os padrões intra-transação. Já na Descoberta de Sequências, os padrões pertencem a várias transações, obedecendo a uma determinada ordem cronológica. Tais padrões são conhecidos como padrões segmentados.

\subsubsection{Descoberta de Sequências Generalizadas}

De forma análoga a descoberta de sequências, a descoberta de sequências generalizadas utiliza a hierarquia e abstração entre os conceitos eventualmente existentes a uma determinada aplicação. Exemplo, registros de compra envolvendo roupas e calçados em momentos distintos e gerando generalizações distintas.

\subsubsection{Classificação}

O principal objetivo da classificação é examinar características de uma determinada informação e associar essa informação a uma determinada classe, por meio de uma classificação. Assim sendo, o principal objetivo da Classificação é a construção de modelos capazes de gerar classificações para novas informações, permitindo que essas informações sejam agrupadas em classes pré-definidas.

Geralmente, essa tarefa de Classificação é realizada em duas partes. A primeira etapa, considerada como a tarefa de atividade de aprendizado, em que são definidas quais as classes que serão utilizadas pela Classificação. A segunda etapa, conhecida como aprendizado supervisionado, são verificadas tuplas aleatórias e feita a associação para as classes. Caso a associação obteve sucesso, ou o padrão encontrado pela associação é considerado como válidos então, o modelo obtido pela classificação é válido. 
Por exemplo, considere um conjunto de idades para que se classifique o grau de maturidade de um determinado indivíduo. Assim, um indivíduo que possuir idade inferior a um ano, é considerado como um bebê. Em uma outra de faixa de idade, entre um e dez anos, o indivíduo é considerado como uma criança. De dez a vinte anos, o indivíduo pode ser considerado como um adolescente, dos vinte aos cinquenta o indivíduo é considerado como um adulto e por fim, se o indivíduo possuir mais de cinquenta anos, ele é considerado como uma pessoa idosa.

$\mathrm{Na}$ indústria, um exemplo a ser considerado é o controle de temperatura de uma caldeira. Se a temperatura estiver abaixo de cem graus, a temperatura é considerada como normal. Caso a temperatura esteja entre cento e um graus e quatrocentos graus, a temperatura é considerada como alta e possivelmente alguma ação do operador ou do sistema deverá ser tomada.

\subsubsection{Regressão}

A regressão tem por objetivo a busca de funções matemáticas lineares ou não, em um determinado conjunto de dados obtidos. Uma outra definição de Regressão, é que a mesma pode ser considerada como uma estimativa, a partir de uma definição de um determinado valor numérico para alguma variável desconhecida, a partir de variáveis conhecidas, através de dados históricos armazenados.

Por exemplo, considerando uma base de dados de uma empresa do ramo imobiliário, onde a partir de dados referentes ao aluguel dos imóveis de uma determinada região, é calculado um novo valor de aluguel de um novo imóvel construído na mesma região. Na indústria, é possível conhecer qual será o comportamento de uma determinado processo por meio de valores históricos do processo.

\subsubsection{Sumarização}

O método de Sumarização consiste em identificar métodos responsáveis por descrever, de uma maneira compacta, um determinado conjunto de dados, apresentando as suas principais características de informações contidas dentro de um determinado conjunto de dados.

Um exemplo prático de Sumarização a ser considerado é a descrição dos assinantes de uma determinada revista que residem na região central do Brasil. A Sumarização descreve as características desses assinantes, tais como o tipo de renda, escolaridade, residência própria dentre outros (BARIONI, 2002). Na indústria, a Sumarização pode ser utilizada na descrição de var- 
iáveis de um determinado processo, tais como, se uma determinada variável é de entrada ou saída, se é uma variável controlada, dentre outras características.

\subsubsection{Clusterização}

A tarefa da Clusterização é de descrever os dados em categorias ou em agrupamentos. O seu principal objetivo é de particionar os registros de um determinado banco de dados em vários subconjuntos de dados, produzindo um segmento de conjunto de registros de acordo com um critério pré definido. Geralmente, esses critérios são definidos por meio de uma ferramenta de Clusterização, gerando as descrições sobre os dados. A Clusterização é considerada como um tipo de aprendizado não supervisionada, pois tem o objetivo de agrupar dados semelhantes ou conseguir identificar algum tipo de exceção inerentes nos dados (FAYYAD, 1996).

\section{5 Áreas de Aplicação do KDD}

As áreas de aplicação do KDD são as mais diversificadas possíveis, isto porque o KDD pode ser aplicado em diversas áreas do conhecimento ou em áreas específicas como aplicações comerciais, governamentais, medicina, financeira, dentre outras (HARDING, 2006).

Dentre alguns exemplos ((SILVA, 2002); (GOLDSCHMIDT, 2005); (FAYYAD, 1996)), podese destacar também:

- Empréstimos Bancários: Através de um conjunto de informações referentes a um determinado indivíduo que queira fazer um empréstimo, a agência de empréstimo toma a decisão se esse empréstimo pode ser liberado ou não. O papel do KDD nesse tipo de tarefa é justamente ajudar no sentido de se gerar novas regras ou padrões de empréstimos, com base em dados históricos armazenados;

- Diagnósticos: Esses diagnósticos são identificados para ser utilizados em manutenções preventivas de dispositivos eletromecânicos, evitando o máximo que falhas ocorram. O KDD é utilizado para que sejam descobertos novos padrões, que auxiliam na prevenção e no controle de novas falhas;

- Tecnologia Espacial: um exemplo clássico da aplicação do KDD a pesquisas espaciais é a detecção de manchas de óleo a partir de imagens de satélite, visando a observação e a precaução para que providências sejam tomadas para evitar desastres. O KDD permite 
que tais sistemas sejam treinados para que sejam encontradas novos padrões de manchas de óleo e até mesmo a ausência delas. Vale ressaltar que o KDD auxilia em processos de tomada de decisão que lidam com o controle de tais manchas;

Ainda segundo o autor, as aplicações do KDD se estende em aplicações acadêmicas que envolvem pesquisas nos mais diversos tipos de bancos de dados, desde banco de dados espaciais, onde são desenvolvidas aplicações de rastreamento espacial, sensoriamento remoto, até banco de dados multimídia, onde aplicações são desenvolvidas a fim de se alcançar novos padrões de multimídia (música, imagens).

Em Aplicações Comerciais, o KDD é tido como um forte aliado no que diz respeito às análises de mercado, como por exemplo, compreender e saber quais são as necessidades dos clientes ou até mesmo para indicar qual a preferência do consumidor (SASSI, 2006). (KITAYAMA et al., 2002) utilizou o KDD para analise do perfil de consumidores de energia elétrica no Japão. A partir dessa análise, foram elaboradas estratégias de marketing e estratégias de negócio para o tratamento desses clientes. (SU et al., 2006) desenvolveram uma técnica que permite gerenciar os hábitos de consumo no varejo.

Em ambientes industriais, observa-se o crescimento de aplicações e pesquisas que envolvem o KDD. (CHEN et al., 2006) aplicou o KDD para solucionar problemas relacionados à situações de baixa produção de semicondutores. (SADOYAN et al., 2006) desenvolveram algoritmos baseados em KDD aplicados no controle de processos de manufatura. O algoritmo extrai padrões de grandes quantidades de dados relacionados ao processo e o processamento é feito por meio de algoritmos de árvores de decisão.

Em (McDONALD, 2006) o KDD é aplicado em geração de energia. O autor cita que o KDD pode ser aplicado em dois domínios de aplicação, em análises de pooling em redes elétricas e no monitoramento das condições de geração de energia. Já em (BROWNE et al., 2005) o KDD foi utilizado para auxiliar na produção de aço, onde as análises feitas com o KDD alimentavam um sistema de tomada de decisão baseado em Lógica Fuzzy.

Em (HARDING, 2006), é feito um estado da arte de como o processo do KDD pode ser aplicado nos mais diversos setores da industria. Os setores detalhados e como pode-se aplicar o processo KDD são:

- Qualidade e Controle de Produção - o KDD é aplicado como ferramenta de auxílio para a pradronização na qualidade e na produção de produtos em ambientes industriais; 
- Desenvolvimento de Novos Produtos - por meio de pesquisas de mercado, o KDD fornece alternativas de criação de novos produtos ou a manutenção de produtos existentes;

- Engenharia de Aplicação - o processo KDD tem por objetivo auxiliar engenheiros e técnicos na concepção de novos projetos e na manutenção de projetos existentes;

- Manutenção de Equipamentos - através do processo KDD, é possível identificar a necessidade de manutenção ou troca de equipamentos dispostos em processo produtivo.

Nos próximos capítulos, são mostradas as ferramentas utilizadas na etapa de mineração de dados do processo KDD, o processo de Identificação de Sistemas e as redes neurais NARX. 


\section{Capítulo 5}

\section{Metodologia}

Inicialmente, para comprovar a aplicabilidade do processo KDD em ambientes Sucroalcooleiros, foram utilizados dados experimentais de apenas uma dorna de fermentação alcoólica de uma usina de cana-de-açúcar, tendo em vista que esse processo é considerado como um dos mais complexos nas indústrias Sucroalcooleiras, devido a diversos fatores de não-linearidade, influência de variáveis externas, dentre outros. Outra observação a ser feita é com relação à dinâmica do processo, pois se algumas das variáveis do processo sofrerem mudança, o produto final pode ser totalmente comprometido, conforme visto no Capítulo 3.

Os dados experimentais utilizados nesse trabalho, foram obtidos através de sensores e atuadores distribuídos no processo de fermentação. Cada sensor ou atuador é posicionado no processo de acordo com o seu objetivo e funcionalidade. Na Figura 5.1, tem-se o fluxograma parcial da disposição dos equipamentos no processo de fermentação (SMAR, 2005): 


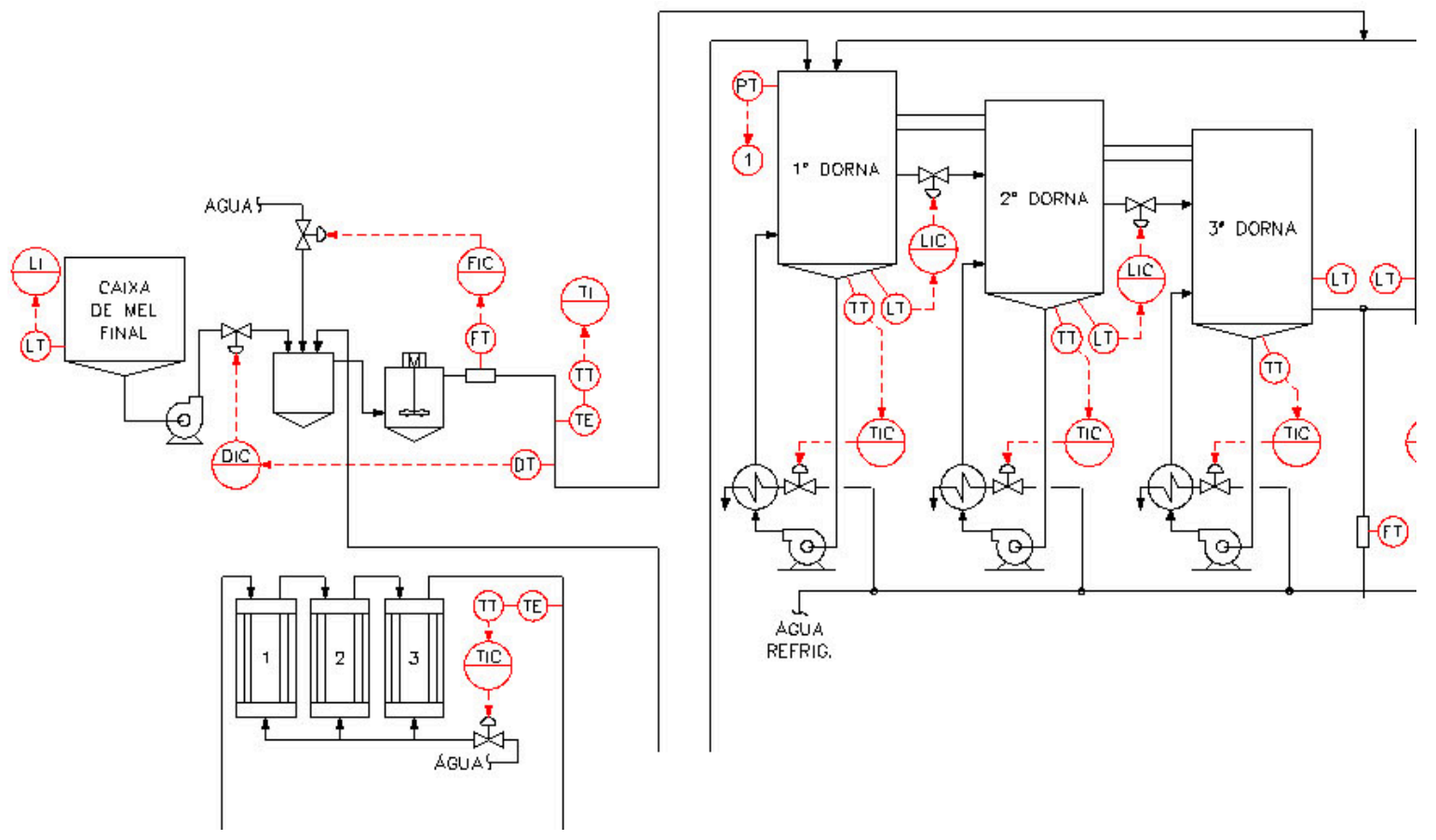

Figura 5.1 - Fluxograma de Instrumentação do Processo de Fermentação.

Como pode ser observado na Figura 5.1, os equipamentos estão localizados em áreas estratégicas do processo onde se é necessário haver o monitoramento (supervisão) e o controle, como por exemplo, acionamento de motores, acionamento de válvulas, monitoramento das variáveis do processo (temperatura e pressão, por exemplo), dentre outros.

No fluxograma, existem siglas que determinam a funcionalidade do equipamento em uma determinada área do processo, ou até mesmo se existem nessas áreas malhas de controle. Os exemplos dessas siglas no fluxograma são TT, que significa monitoramento de temperatura, e TIC controle de temperatura. A descrição dessa simbologia pode ser encontrada em (SMAR, 2005).

A Figura 5.2 mostra a aplicação do diagrama do processo de fermentação. Nesse exemplo, os equipamentos foram instalados em uma tubulação para o monitoramento da temperatura do caldo utilizado no processo de fermentação a partir da documentação descrita no diagrama (SMAR, 2005). 


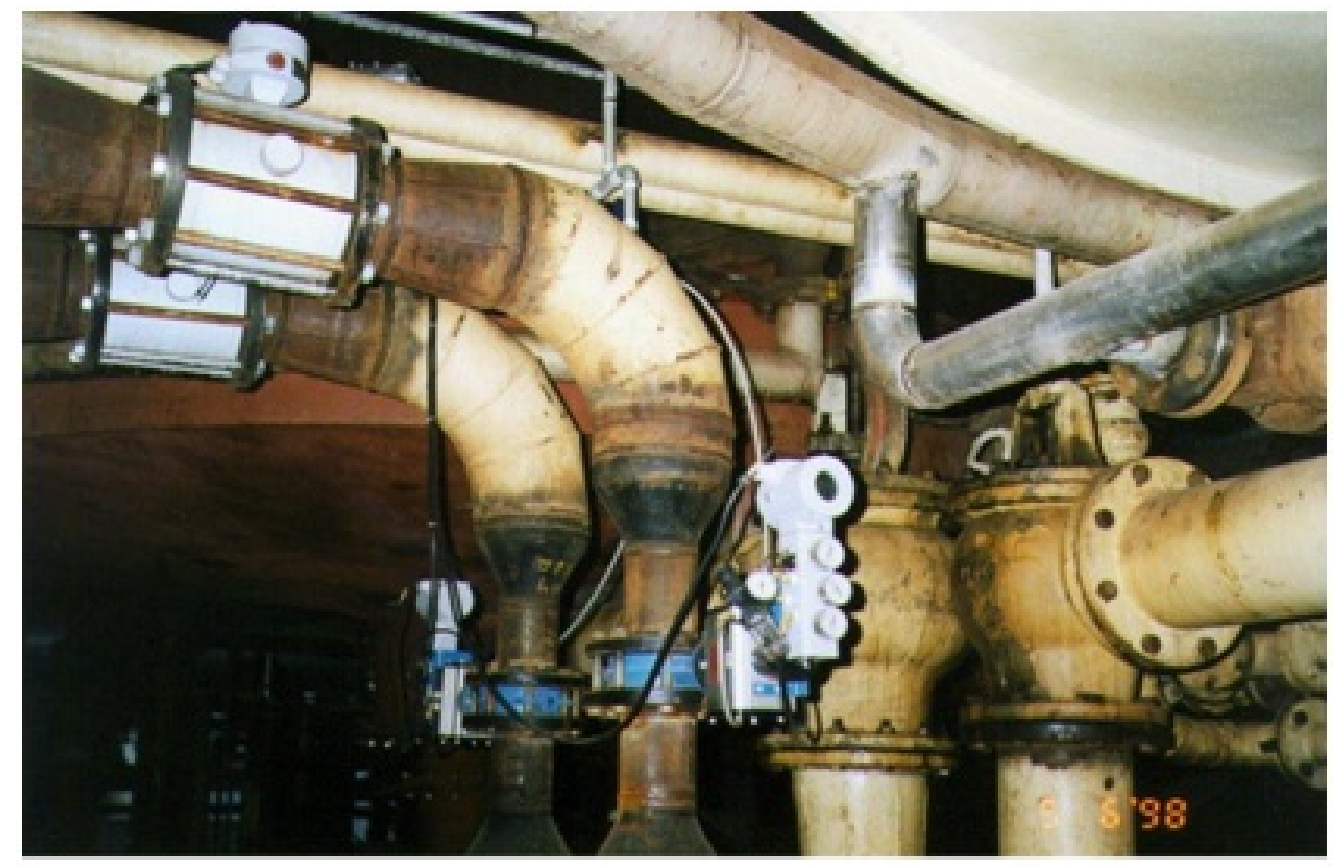

Figura 5.2 - Equipamentos Utilizados no Processo de Fermentação.

Conforme visto no Capítulo 2, os sistemas supervisórios são responsáveis pelo monitoramento e rastreamento das informações de um determinado processo produtivo. A Figura 5.3 mostra um exemplo de uma tela de um sistema supervisório do processo de fermentação (SMAR, 2005): 


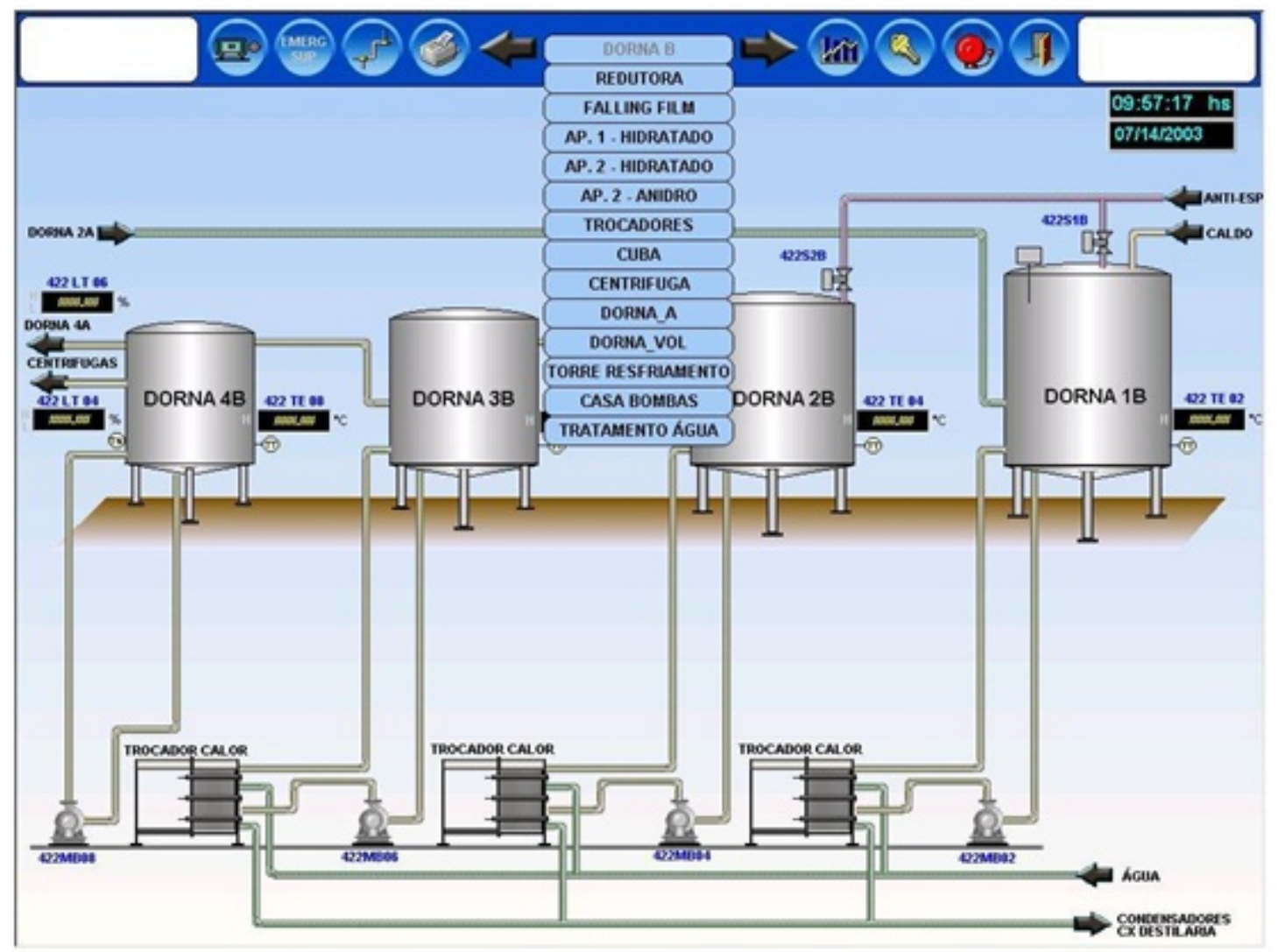

Figura 5.3 - Tela de Sinóptico de um Sistema Supervisório para o Processo de Fermentação.

As telas do sistema supervisório, conhecidas também como sinópticos, têm por objetivo representar, o mais próximo possível, a realidade encontrada no processo, isto é, demonstrar qual é o seu comportamento (funcionamento). Na Figura 5.3 encontram-se elementos que fazem parte do processo de fermentação, tais como as dornas de fermentação, as tubulações de caldo, as tubulações de água, tubulações de anti-espumante, os motores, as bombas e os trocadores de calor.

Assim, por meio dos sinópticos, é possível realizar operações que no passado eram feitas apenas manualmente no processo, tais como abrir e fechar válvulas, ligar e desligar motores, monitorar variáveis do processo, acionar alarmes, etc. 


\subsection{Desenvolvimento}

Depois de definida a estrutura de aquisição de dados do processo de fermentação, foram desenvolvidos módulos para a continuidade do processo KDD, descritos pelo fluxograma da Figura 5.4:

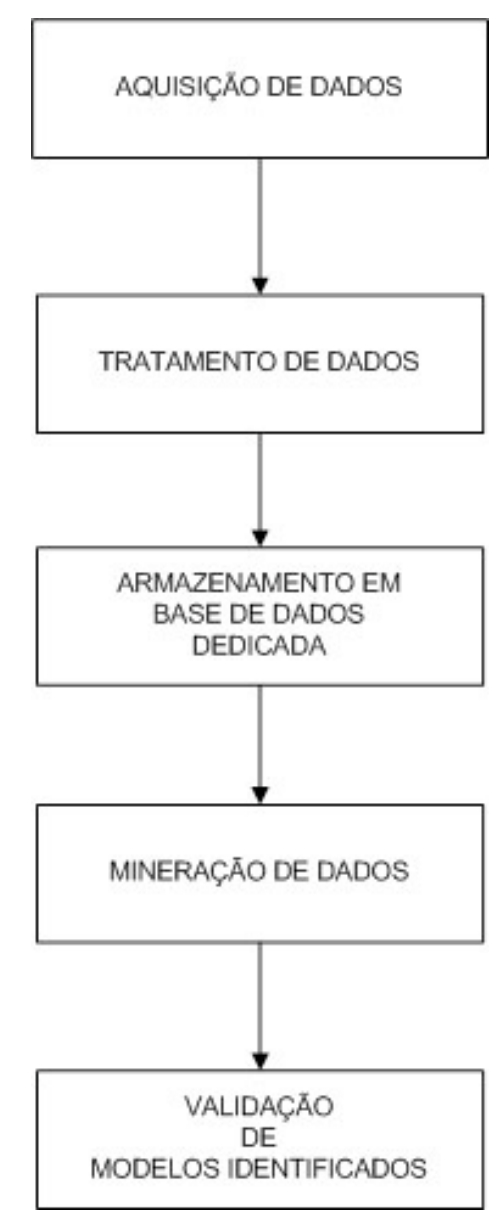

Figura 5.4 - Estrutura dos Módulos Desenvolvidos no Porjeto.

As funcionalidades de cada módulo são aplicadas de acordo com o tipo de tarefa que elas representam no processo KDD, e são descritas nos próximos itens desse capítulo.

\subsubsection{Definição e Aquisição de Dados}

Antes da etapa de aquisição das informações e criação do banco de dados do processo fermentação, foram mapeadas as variáveis utilizadas no processo KDD, descritas na Tabela 5.1. Foram coletadas informações informações de apenas uma dorna de fermentação. 
Tabela 5.1 - Distribuição das Atividades do KDD em Fases.

\begin{tabular}{||c|c|c||}
\hline \hline Variável & Tipo & Unidade \\
\hline \hline ART do Mosto & Entrada & ART \\
\hline Brix do Mosto & Entrada & Brix \\
\hline Temperatura do Mosto & Entrada & $\circ \mathrm{C}$ \\
\hline Grau do Vinho Bruto & Entrada & $\circ$ (Graus) \\
\hline Fermento Tratado & Entrada & Tonelada por Hora \\
\hline Grau do Vinho de Levedura & Saída & $\circ($ Graus $)$ \\
\hline
\end{tabular}

As informações estão dispostas nos sistemas supervisórios por meio do padrão de comunicação OPC, conforme visto no capítulo 2. Para o armazenamento dessas informações em banco de dados, os sistemas supervisórios dispõem de conexões do tipo OBDC (Open Data Base Connectivity).

A arquitetura da aquisição das informações referentes ao processo de fermentação da usina, é mostrado na Figura 5.5: 


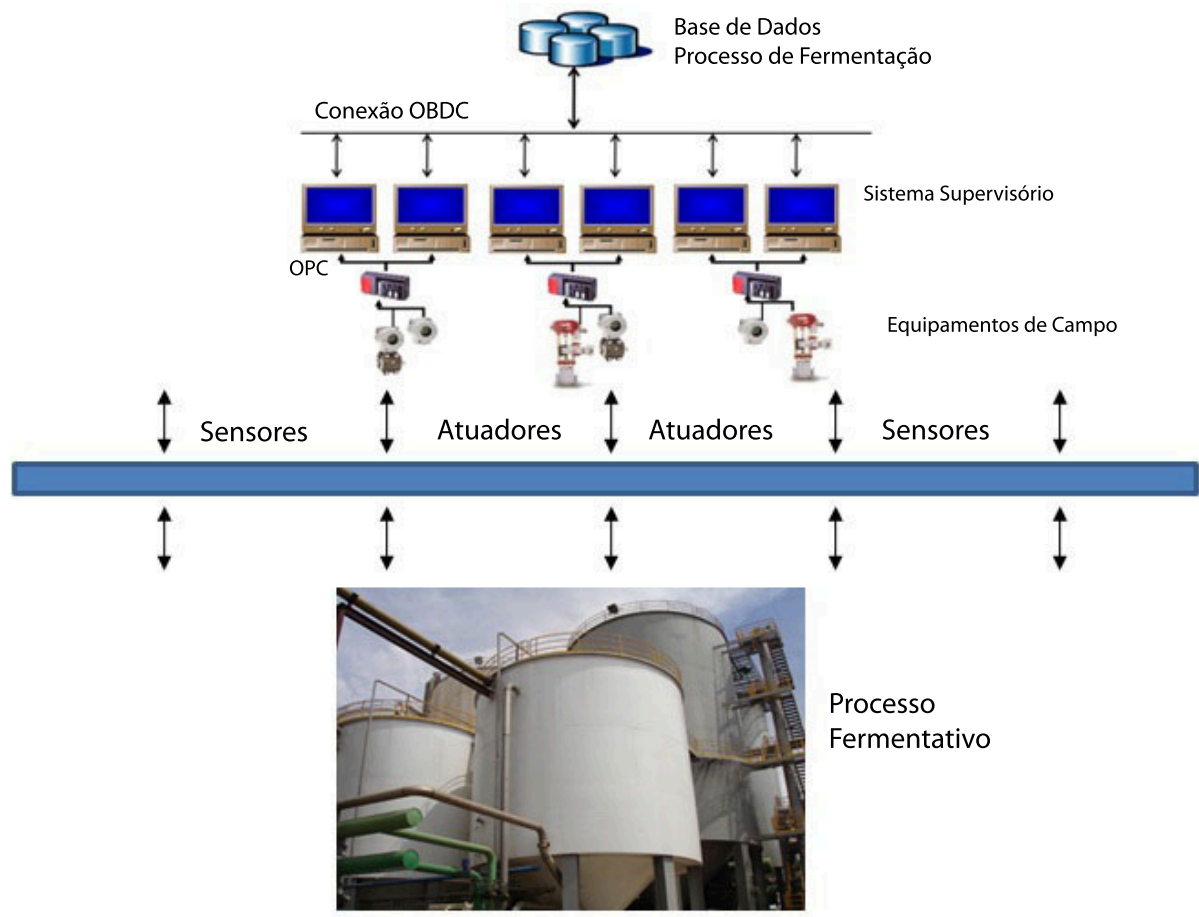

Figura 5.5 - Esquema de Aquisição de Dados do Processo de Fermentação.

Como pode ser observado, a aquisição das informações do processo de fermentação obedece uma hierarquia de acesso. As informações são processadas na camada de sensores e passam pelos equipamentos de campo. Através do OPC, essas informações ficam disponíveis para os sistemas supervisórios, que por sua vez as disponibilizam para outros sistemas por meio de conexões ODBC. Por fim, as informações geradas pelas conexões ODBC são armazenadas em sistemas de banco de dados (Data Warehouse).

O sistema gerenciador de banco de dados utilizado nesse trabalho foi o SQL Server 2008 da Microsoft. O nome das tabelas está relacionado ao tipo de informação do processo de fermentação gravado. 
Os campos das tabelas descrevem as informações referentes ao instante de aquisição, onde são armazenados os valores do momento de aquisição, hora e data, e o valor da variável em um determinado instante. A Figura 5.6 mostra a estrutura de uma tabela dos valores armazenados:

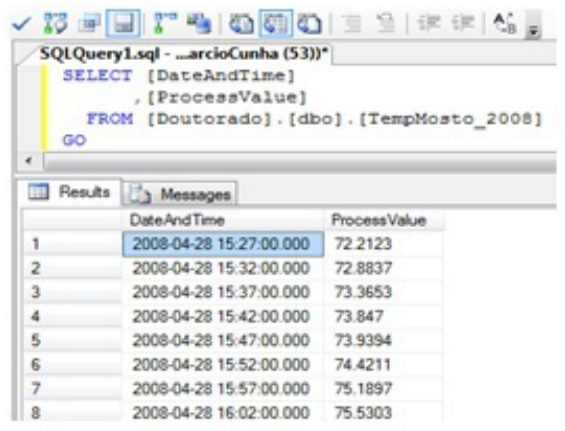

Figura 5.6 - Exemplo de Tabela com Dados do Processo de Fermentação.

Na Figura 5.6, foram armazenados dados referentes a temperatura do mosto, armazenados no período da safra do ano de 2008.

\subsubsection{Tratamento de Dados}

As tabelas passam por tratamentos de verificação e validação de seus registros. Essas verificações consistem em localizar anomalias em seus registros, como por exemplo, ruídos nos registros armazenados, registros armazenados com valores em branco e dentre outros. Nessa etapa, é importante ressaltar que cada tabela possui uma quantidade diferente de registros armazenados referente ao processo de fermentação. Por exemplo, enquanto a tabela TempMosto2008 possui 146663 registros, a tabela de ART_Mosto2008 possui 898 registros.

Inicialmente quando se trabalha com arquiteturas que envolvem inteligência artificial, deve-se realizar o pré-processamento e o redimensionamento dos dados. No Data Warehouse do processo de fermentação, os dados armazenados possuem dimensões diferentes, isto é, cada tabela possui uma quantidade de registros diferente das outras. Isto ocorre pela forma da configuração da taxa de amostragem com que cada variável é armazenada, pois cada variável do processo possui variação e comportamento diferentes das outras.

Deste modo, as técnicas de redimensionamento são aplicadas nos dados armazenados para que eles tenham a mesma dimensão. É importante ressaltar que essas técnicas devem ser aplicadas nos dados sem que o comportamento original do dado seja modificado. 
Na Figura 5.7, é mostrado o comportamento da variável do ART do Mosto no seu estado atual, contendo em média 930 pontos.

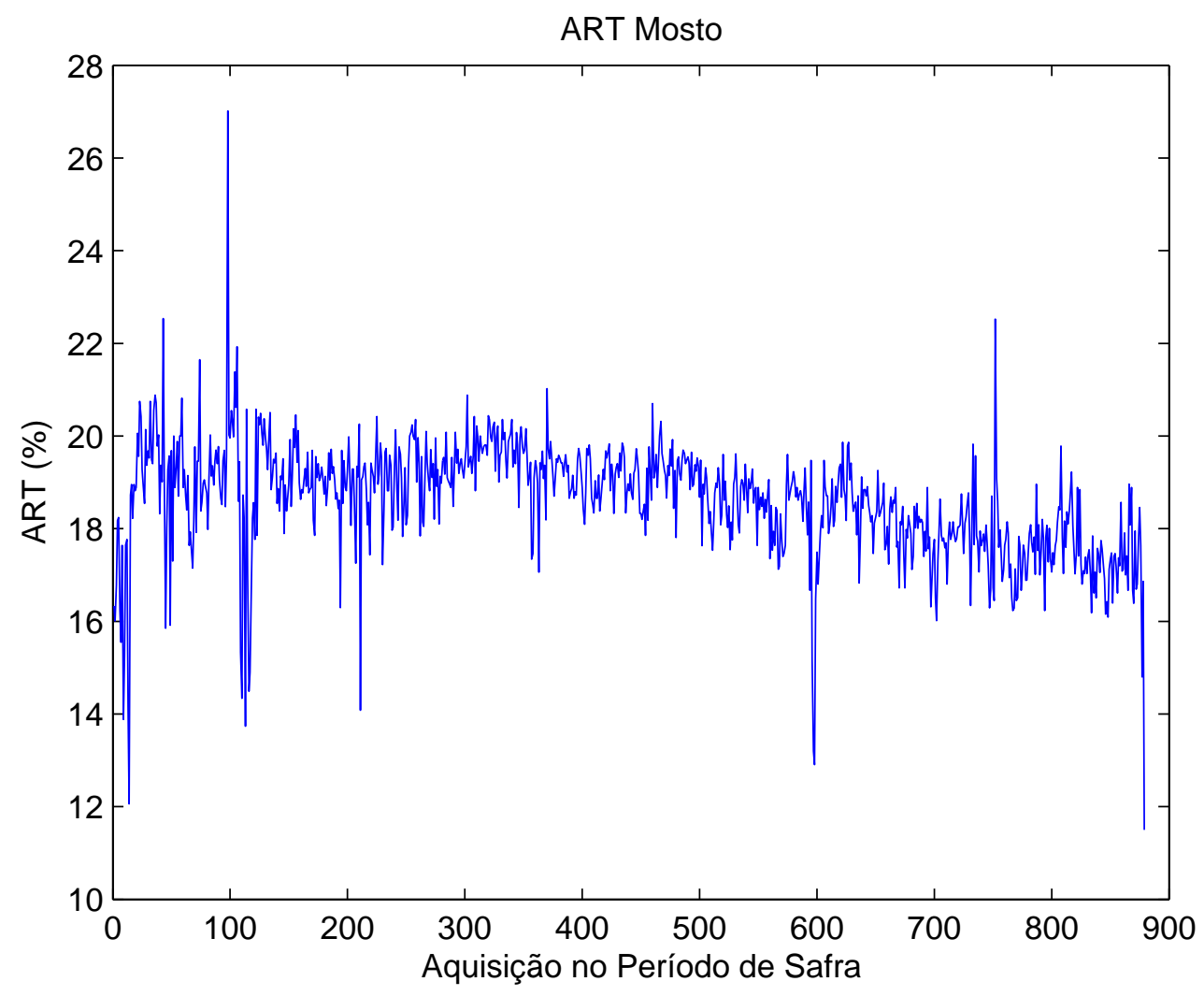

Figura 5.7 - ART Mosto Original.

A partir de técnicas de Interpolação de dados citadas no Capítulo 4, a mesma saída redimensionada é mostrada na Figura 5.8. 


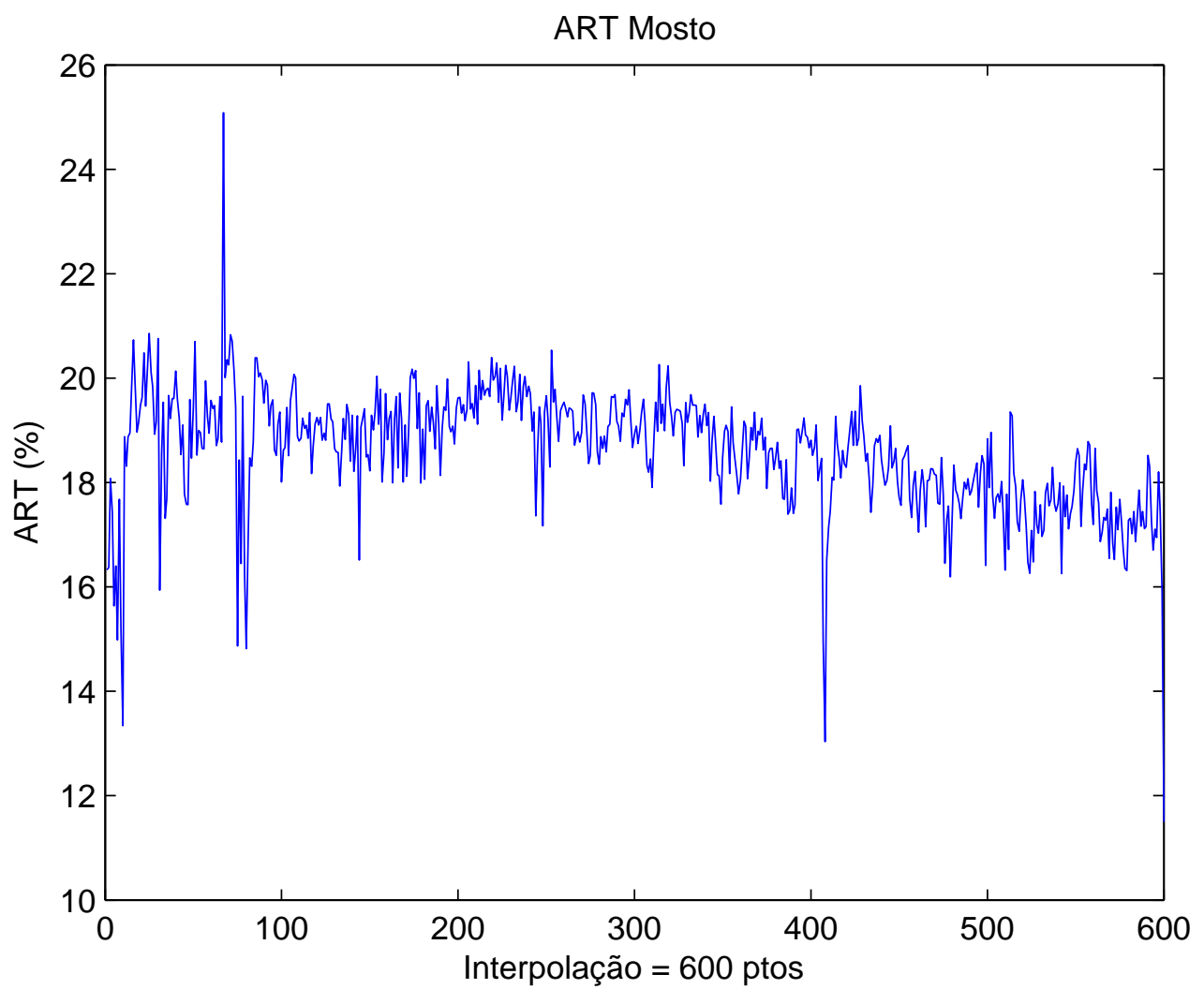

Figura 5.8 - ART Mosto Dimensão Modificada.

As ferramentas de tratamentos e redimensionamento dos dados foram desenvolvidas em Matlab.

\subsubsection{Mineração de Dados}

Na mineração de dados foram utilizados dois módulos de processamento de dados do Matlab, o módulo de Redes Neurais e o módulo de Identificação de Sistemas.

A Figura 5.9, mostra a interface de operação do módulo de redes neurais utilizado no algoritmo de mineração de dados. Nesse módulo são informadas as características de treinamento e a forma de processamento. Também é possível visualizar o desempenho e a performance de treinamento da rede. 


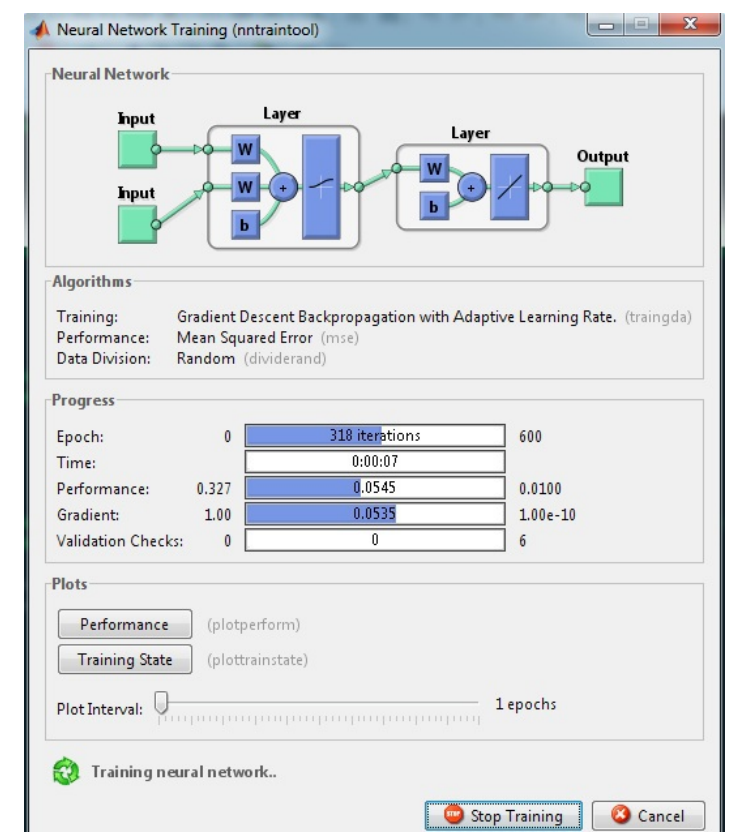

Figura 5.9 - Interface de Treinamento de Redes Neurais NARX do Matlab.

Após a execução da rede neural NARX, uma nova arquitetura de rede é identificada e uma nova saída é gerada através dos pontos experimentais de treinamento.

Semelhante ao que foi utilizado no tópico anterior com as redes NARX, o processo de Identificação de Sistemas necessita que os dados passem por um tratamento antes que eles sejam processados. Para isso, são utilizados os mesmos procedimentos de tratamento e redimensionamento de dados utilizados do tópico anterior.

O objetivo da Identificação de Sistemas é encontrar um modelo matemático que represente o comportamento de um determinado sistema, por meio meio de um processo interativo que utiliza como base de conhecimento, os dados históricos de entrada e saída. O resultado desse processo é a obtenção de um modelo matemático para cada conjunto de dados.

Para a Identificação de Sistemas foi utilizado o módulo do Matlab, conhecido como System Identification Tool. Nesse módulo, todo ambiente de identificação é configurado pelo usuário, como por exemplo, a definição dos dados de entrada e saída, as configurações da Identificação, como por exemplo, a quantidade de regressores, qual o modelo matemático utilizado, dentre outras informações. Como resultado, o módulo retorna o modelo matemático identificado e a sua simulação. A interface do módulo System Identification Tool é mostrado na Figura 5.10. 
System Identification Tool - Untitled

可 $\mathbf{X}$

File Options Window $\underline{\text { Help }}$

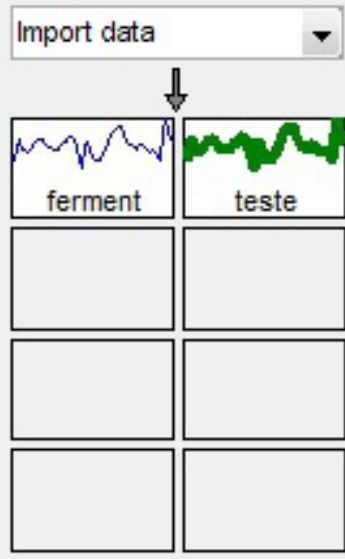

Data Views

$\square$ Time plot

Data spectra

Frequency function

Exit
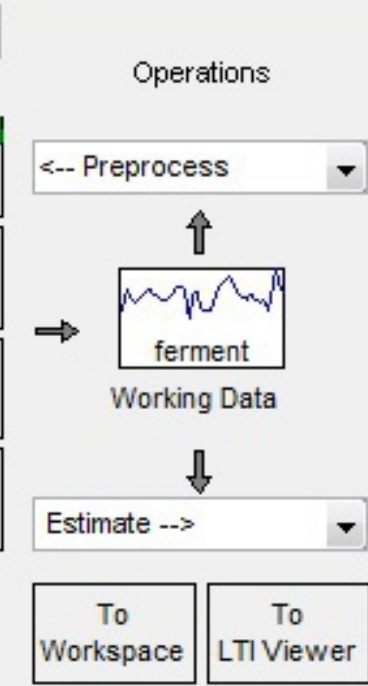

$\frac{|+| j|| \mid}{\text { Trash }}$
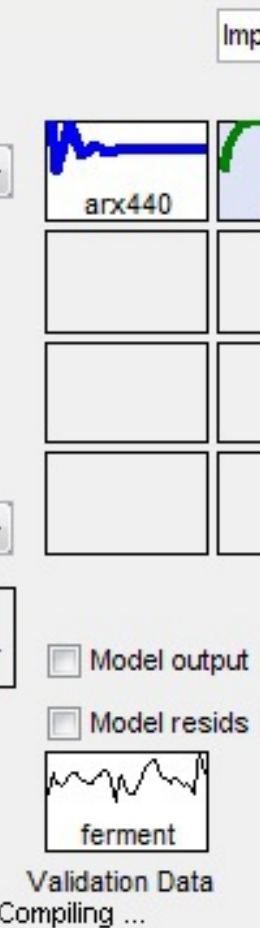
Compiling ...
Import models

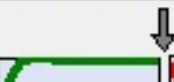

$\sqrt{3}$

nlarx1

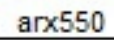

Model Views

$\square$ Transient resp $\square$ Nonlinear ARX

$\square$ Frequency resp $\square$ Hamm-Wiener

Zeros and poles

Noise spectrum

Figura 5.10 - Módulo de Identificação de Sistemas do Matlab.

\subsubsection{Validação}

O módulo de validação, desenvolvido em Matlab, é responsável pelos cálculos dos erros calculados a partir das saídas reais (do processo de fermentação) e as saídas calculadas pelo processo KDD.

O erro de resposta, tanto da Rede Neural NARX e do processo de identificação de sistemas, é calculado com base nos Erros Quadráticos Médios (MSE - Erros Médios Quadráticos (Mean Square Error - MSE), os Erros Percentuais Relativos Médios (Percentual Mean Relative Error - PMRE) e os Erros Percentuais Relativos (Percentual Relative Error - PRE). Tais erros são calculados pelas seguintes equações: 


$$
\begin{gathered}
M S E=\frac{1}{N} \sum_{k=1}^{N}\left\|y_{k}^{d}-y_{k}^{o}\right\|^{2} \\
P M R E=\frac{1}{N} \sum_{k=1}^{N}\left\|\frac{y_{k}^{d}-y_{k}^{o}}{y_{k}^{d}}\right\|^{2} \\
P R E=\left\|\frac{y_{k}^{d}-y_{k}^{o}}{y_{k}^{d}}\right\| * 100
\end{gathered}
$$

onde $y_{k}^{d}$ é definido como a amostra no período $k$, e $y_{k}^{o}$ é a previsão calculada pelos modelos encontrados pela rede NARX no período e pelo processo de identificação de sistemas no instante $k$.

Esse módulo também apresenta um comparativo entre as respostas por meio de gráficos, conforme a Figura 5.11:

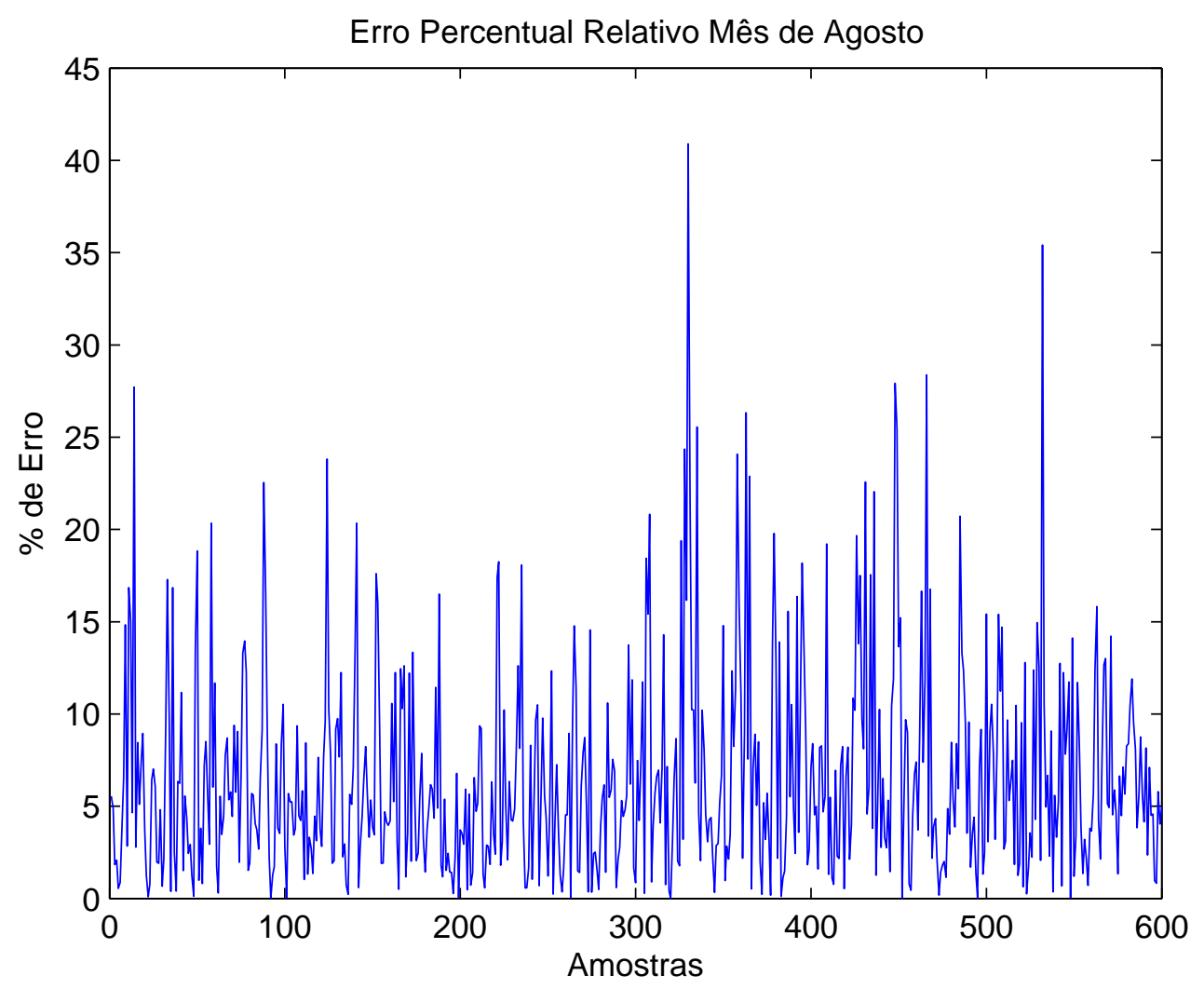

Figura 5.11 - Erro Percentual Relativo do Mês de Agosto. 
Na Figura 5.11 são mostrados os valores de erros calculados a cada interação, no comparativo entre a resposta do sistema real e a resposta identificada pelos modelos identificados pelo processo KDD. 


\section{Capítulo 6}

\section{Testes e Resultados}

Inicialmente, para comprovar a aplicabilidade do processo KDD em ambientes Sucroalcooleiros, foram utilizados dados experimentais de apenas uma dorna de fermentação alcoólica de uma usina de cana-de-açúcar, tendo em vista que esse processo é considerado como um dos mais complexos na indústria Sucroalcooleiras, devido a diversos fatores de não-linearidade, influência de variáveis externas, dentre outros. Outra observação a ser feita é com relação à dinâmica do processo, pois se algumas das variáveis do processo sofrerem mudança, o produto final pode ser totalmente comprometido, conforme visto no Capítulo 3.

Os dados experimentais utilizados nesse trabalho, foram obtidos através de sensores e atuadores distribuídos no processo de fermentação, conforme visto no Capítulo 5.

Seguindo os passos do processo KDD, inicialmente são aplicadas as técnicas de tratamento dos dados que foram descritas no módulo de tratamento de dados. Na Figura 6.1 é mostrado a aplicação da técnica de interpolação de dados em todas as variáveis de entrada do processo de fermentação utilizadas no processo do KDD: 


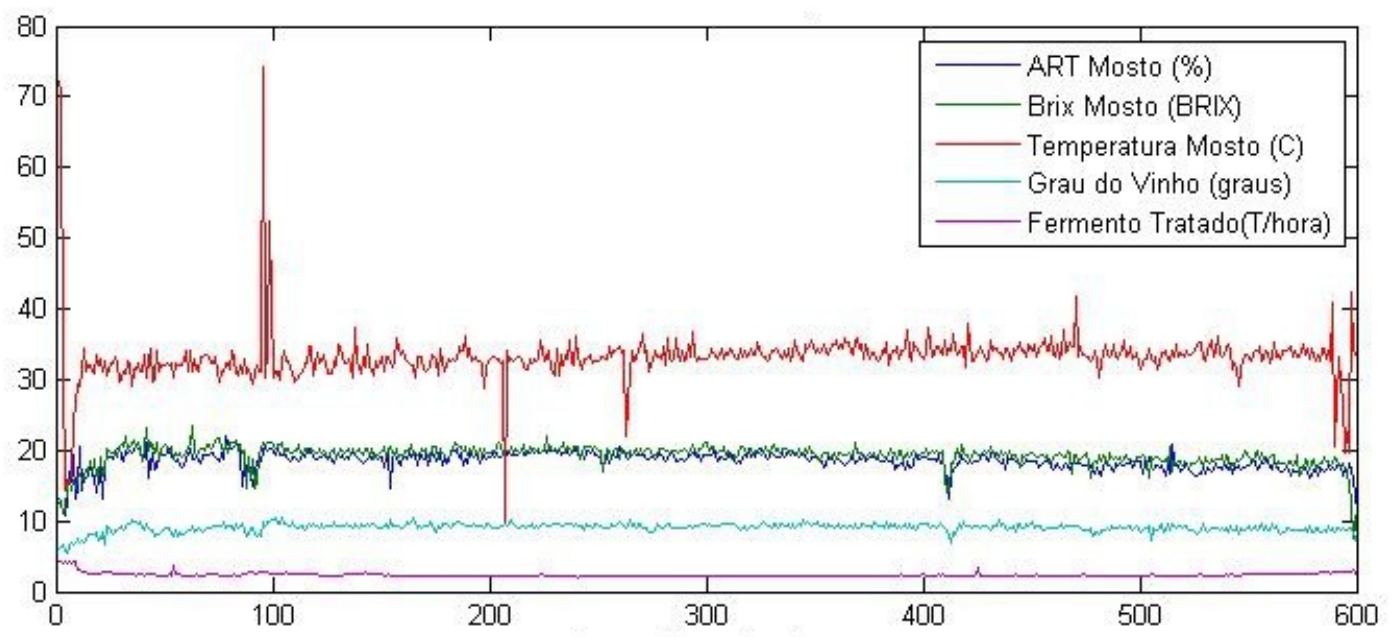

Figura 6.1 - Pontos do Processo Fermentativo Interpolados.

Com os dados pré-processados e prontos, os mesmos são utilizados nas próximas etapas do processo do KDD. A próxima etapa do processo do KDD é a etapa de mineração de dados.

\subsection{Aplicação de Redes Neurais NARX na Mineração de Dados do Processo KDD}

A arquitetura da rede Neural NARX utilizada nesse trabalho é constituída pela seguinte arquitetura:

- Cinco variáveis na camada de entrada;

- Dez neurônios na camada escondida;

- Uma variável na camada de saída;

- Função de treinamento do tipo gradiente ascendente;

- Função de ativação do tipo sigmóide.

O objetivo de se utilizar Redes Neurais NARX na etapa de mineração de dados, é obter uma arquitetura de rede capaz de representar o comportamento de um determinado processo por 
meio de seus dados experimentais. As aquisições dos dados do processo de fermentação foram feitas nos meses referentes ao período de safra do ano de 2008.

Os dados do processo de fermentação possuem comportamento e taxa de amostragem diferentes, como por exemplo, a Temperatura do Mosto com aproximadamente 15000 amostras, o Brix do Mosto com aproximadamente 3000 amostras. Assim, para que se trabalhe com as redes neurais NARX, é necessário que todas as amostras passem por um processo de redimensionamento de dados, para que possuam a mesma quantidade de amostras, sem que elas percam as características originais. A quantidade de pontos definidos para o redimensionamento é de 600, obtendo assim uma média 20 pontos por dia.

Antes do treinamento, os dados do processo de fermentação de entrada do processo de fermentação são redimensionados, conforme a Figura 6.2 abaixo: 


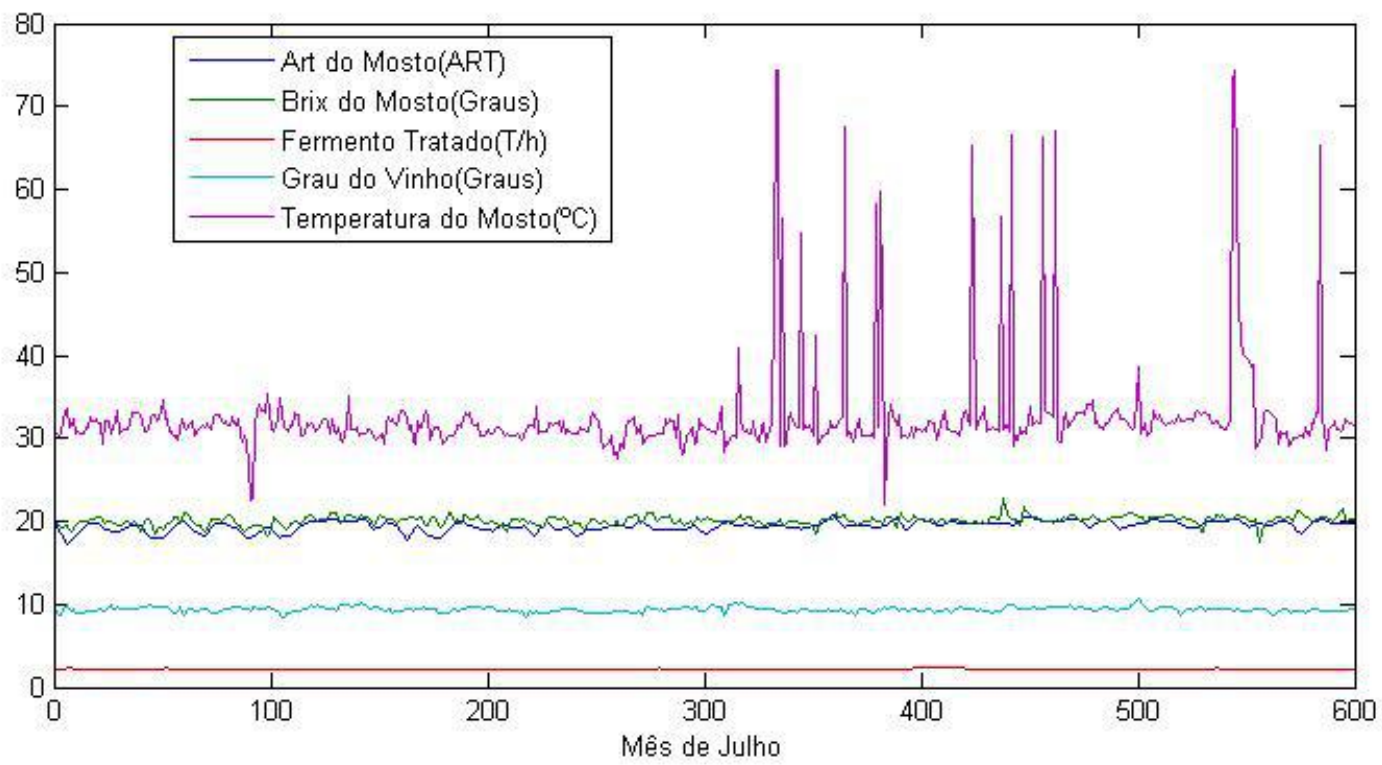

Figura 6.2 - Variáveis de Entrada do Processo Fermentativo Interpolados Julho de 2008.

A mesma técnica é aplicada para para os dados de saída, o Grau de Levedo contidos no Vinho, conforme a Figura 6.3 abaixo:

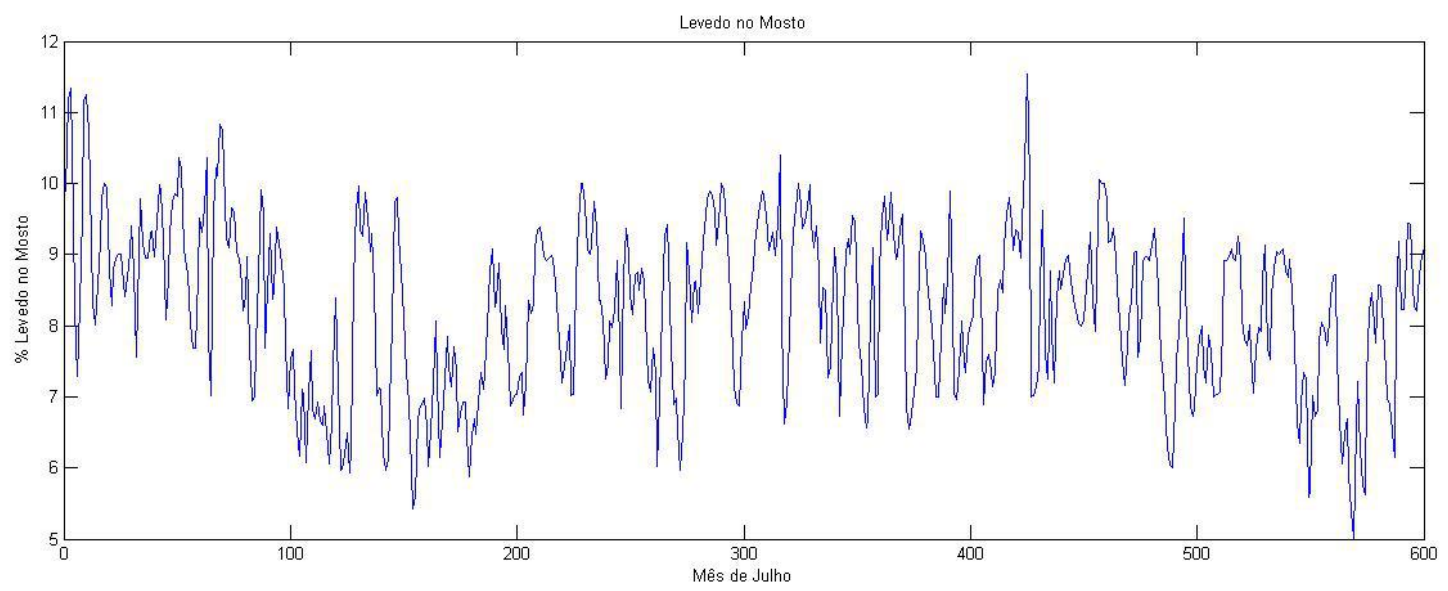

Figura 6.3 - Variáveis de Entrada do Processo Fermentativo Interpolados Julho de 2008.

Com os dados redimensionados, os mesmos são normalizados para que sejam minerados pela rede neural NARX. O resultado da normalização é observado na Figura 6.4: 

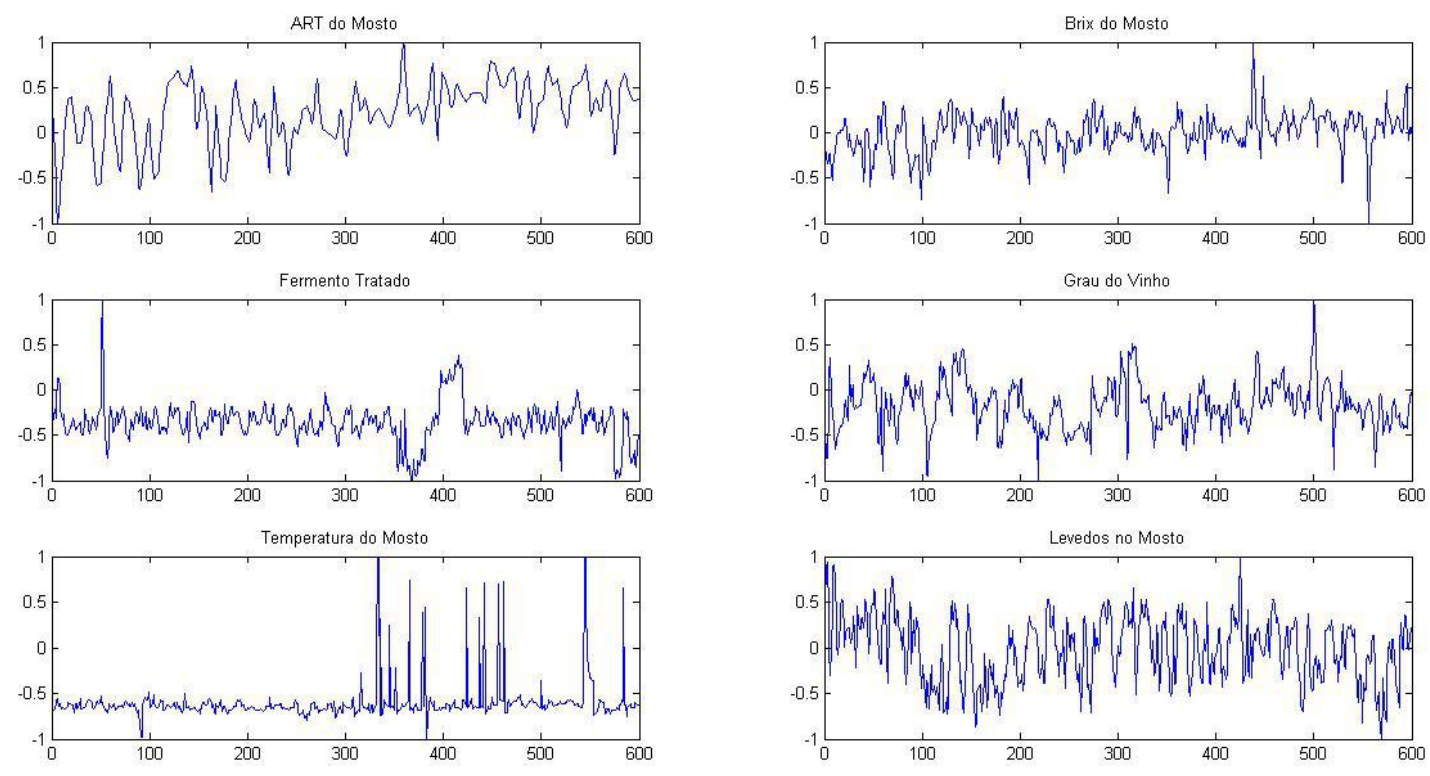

Figura 6.4 - Variáveis de Entrada e Saída Processo Fermentativo Normalizadas.

Após a execução da rede neural NARX, uma nova arquitetura de rede é identificada e uma nova saída é gerada através dos pontos experimentais de treinamento. A Figura 6.5 mostra a comparação entre a saída gerada pela rede NARX e a saída real do sistema.

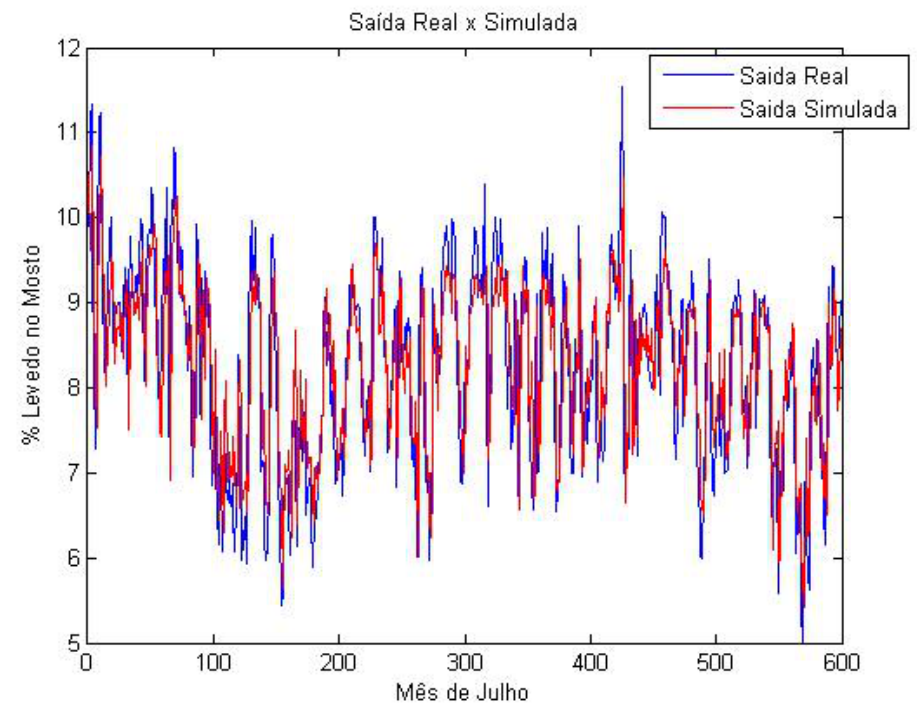

Figura 6.5 - Comparativo Saída Real x Saída Simulada. 
A validação da rede ocorre no intervalo dos meses de Agosto até Dezembro. A Figura 6.6 mostra as variáveis de entrada e de saída utilizadas no processo de validação, as mesmas descritas na Tabela 5.1, bem como a resposta da rede para o mês de Agosto de 2008.

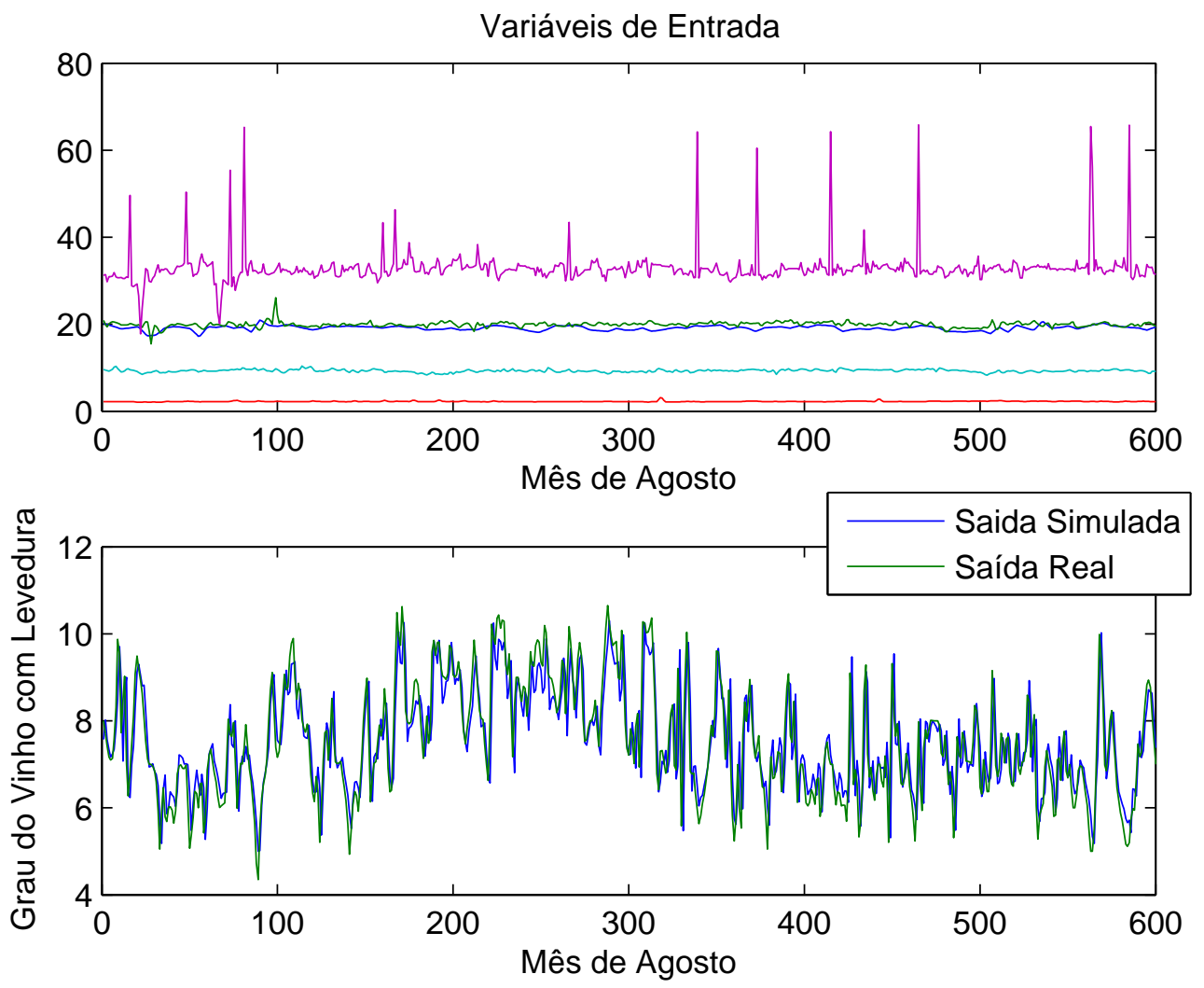

Figura 6.6 - Validação de rede NARX (Ago/2008). 
A curva do Erro Percentual Relativo para o mês de Agosto entre a saída real do processo de fermentação e a saída calculada pela rede NARX, é mostrada na Figura 6.7:

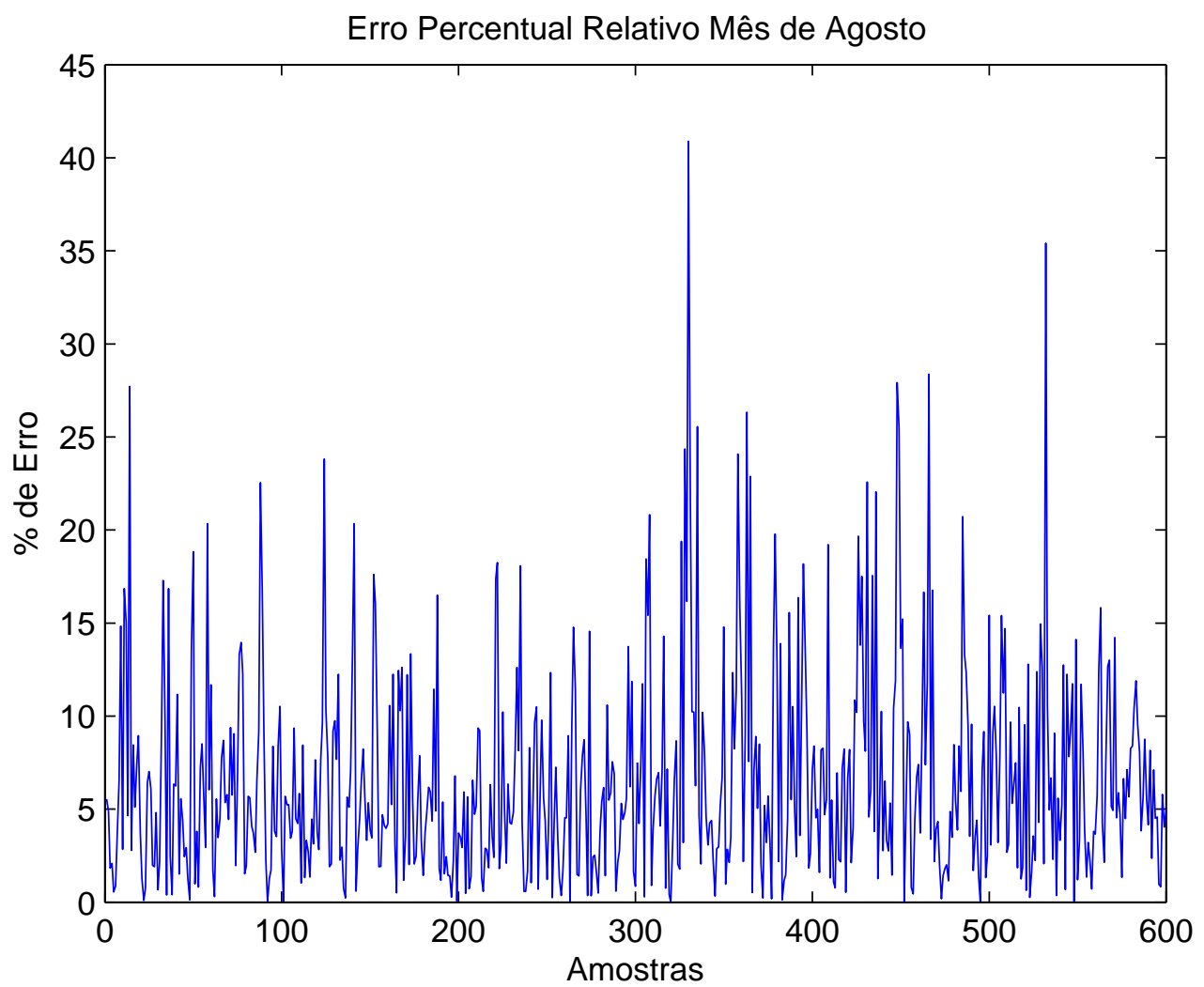

Figura 6.7 - Erro Percentual Relativo do Mês de Agosto.

O PRE calculado para o mês de Agosto possui alguns picos que chegam aos 40\%, mas em média esse erro permanece entre 0 a $6 \%$.

Semelhante ao mês de Agosto, a Figura 6.8 mostra as variáveis de entrada e de saída utilizadas no processo de validação para o mês de Setembro de 2008. 

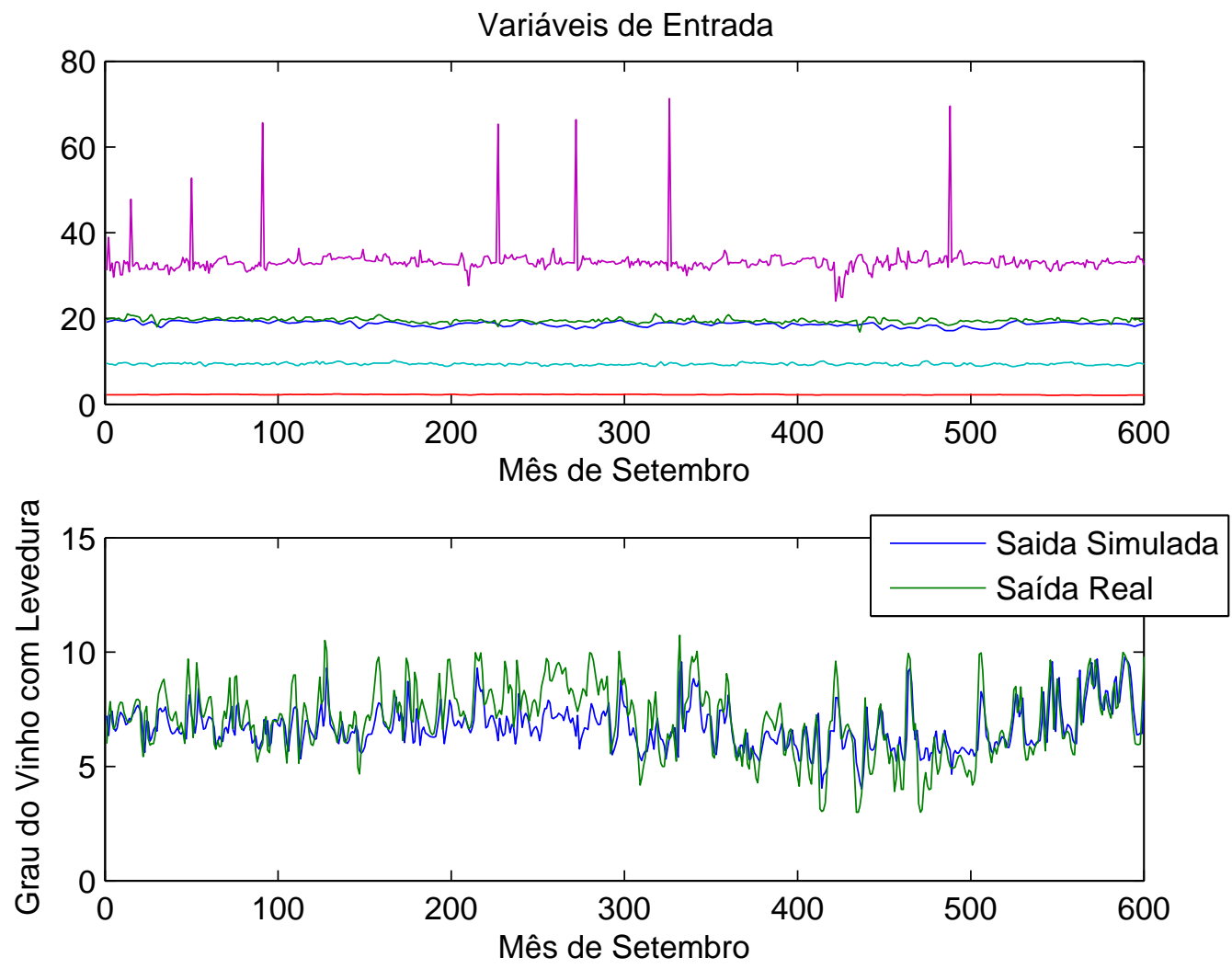

Figura 6.8 - Validação da rede NARX (Set/2008).

A curva do Erro Percentual Relativo para o mês de Setembro é mostrada na Figura 6.9:

Semelhante ao PRE calculado para o mês de Agosto, o mês de Setembro possui alguns picos que chegam aos $40 \%$, mas em média esse erro permanece entre 0 a $6 \%$. 


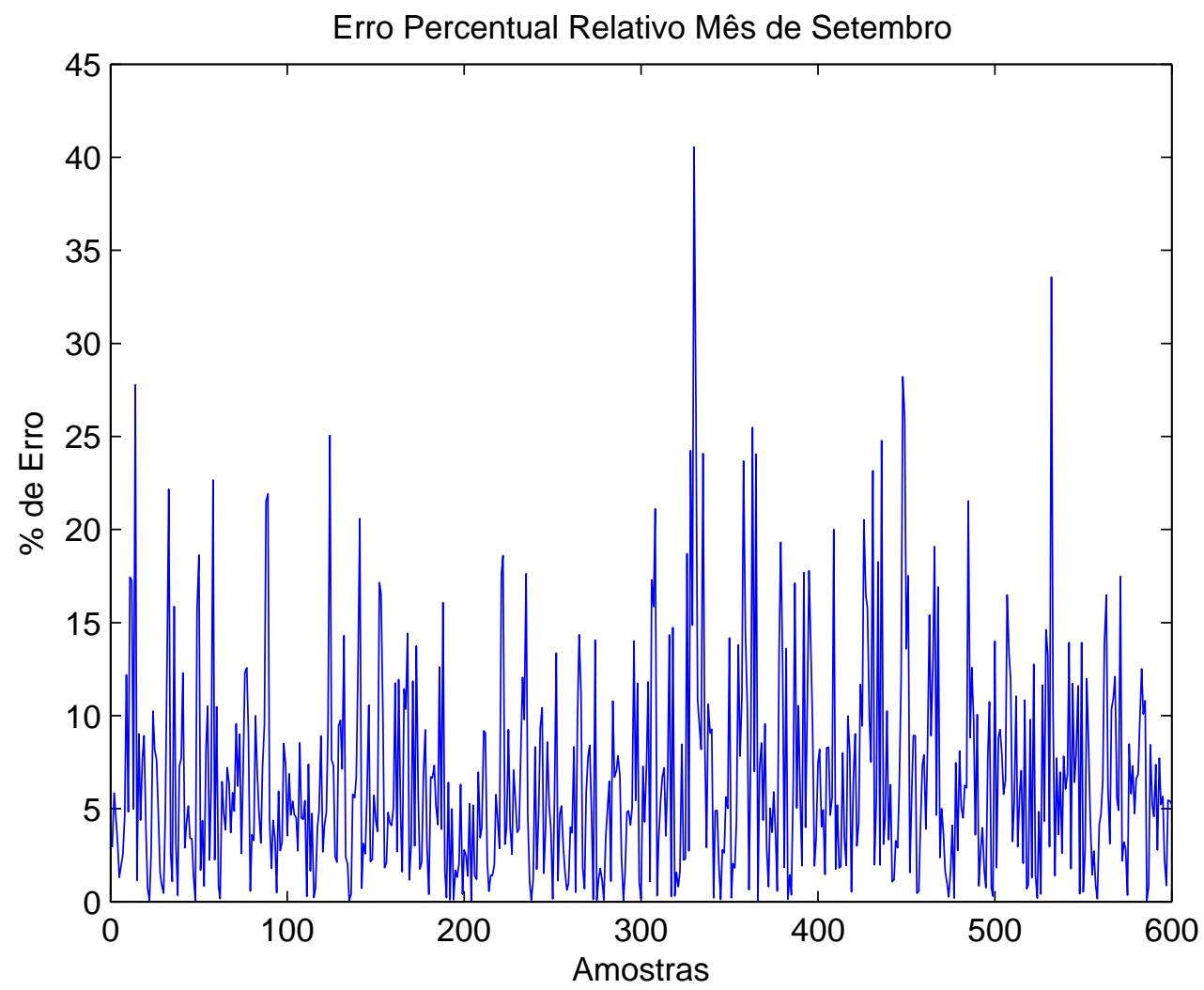

Figura 6.9 - Erro Percentual Relativo do Mês de Setembro.

Para o mês de Outubro, tem-se as seguintes variáveis de entrada e saída utilizadas para a validação, conforme a Figura 6.10 . 

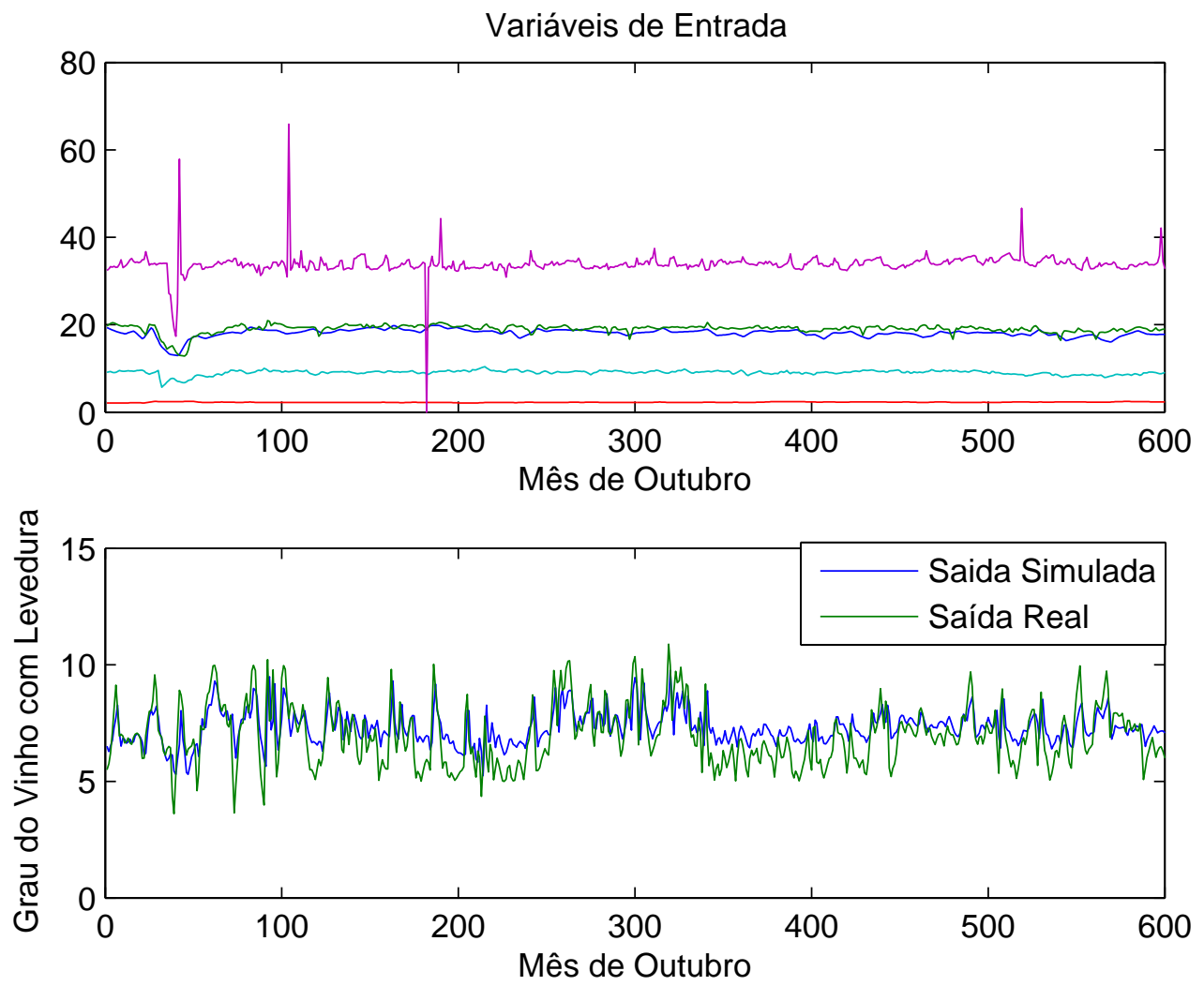

Figura 6.10 - Validação da rede NARX (Out/2008).

A curva do Erro Percentual Relativo para o mês de Outubro é mostrada na Figura 6.11:

Já para o mês de Outubro, o PRE calculado possui alguns picos que chegam aos 70\%. Em média esse erro permanece entre 0 a $11 \%$. 


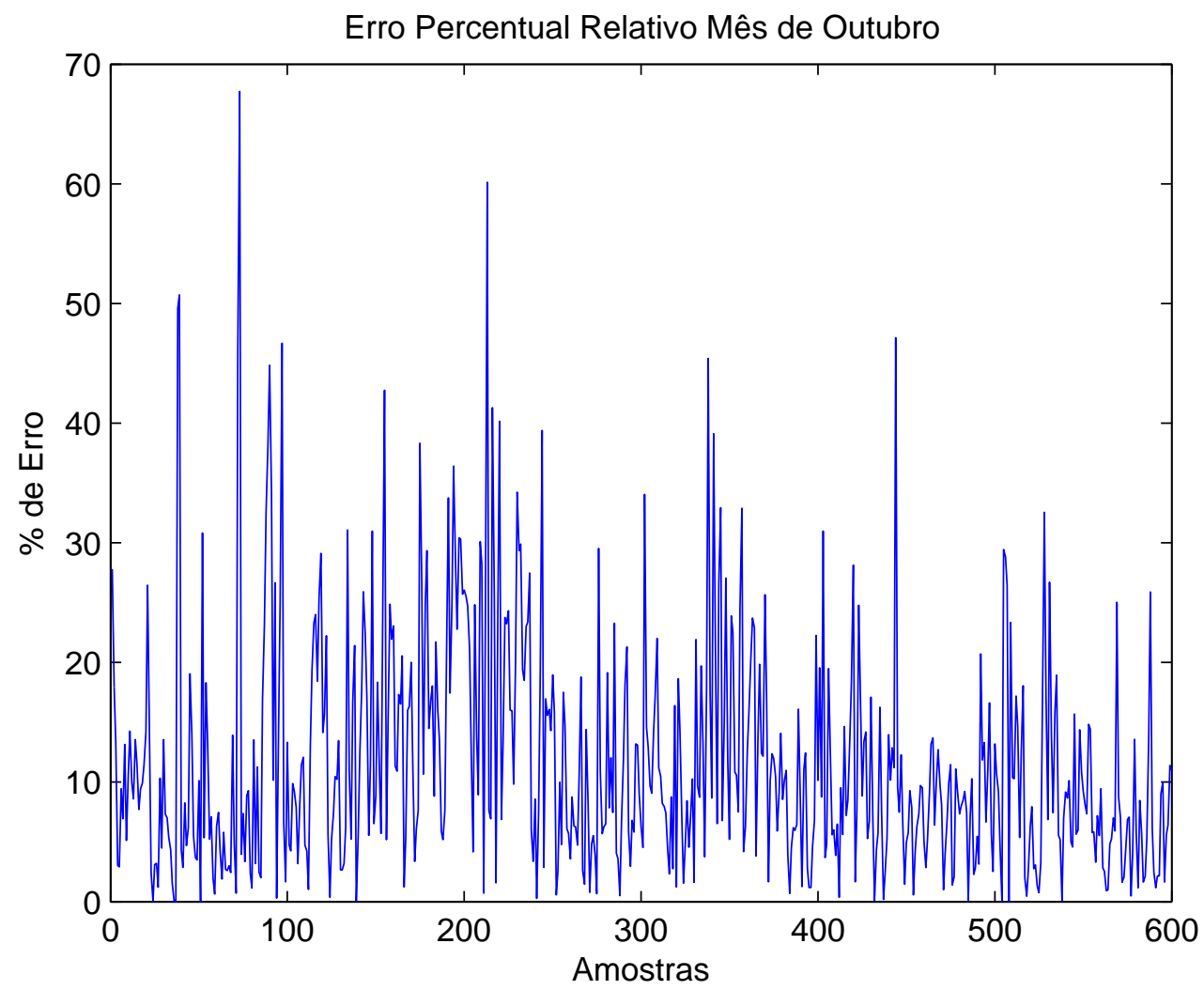

Figura 6.11 - Erro Percentual Relativo do Mês de Outubro.

No mês de Novembro, a validação é mostrada na Figura 6.12 . 


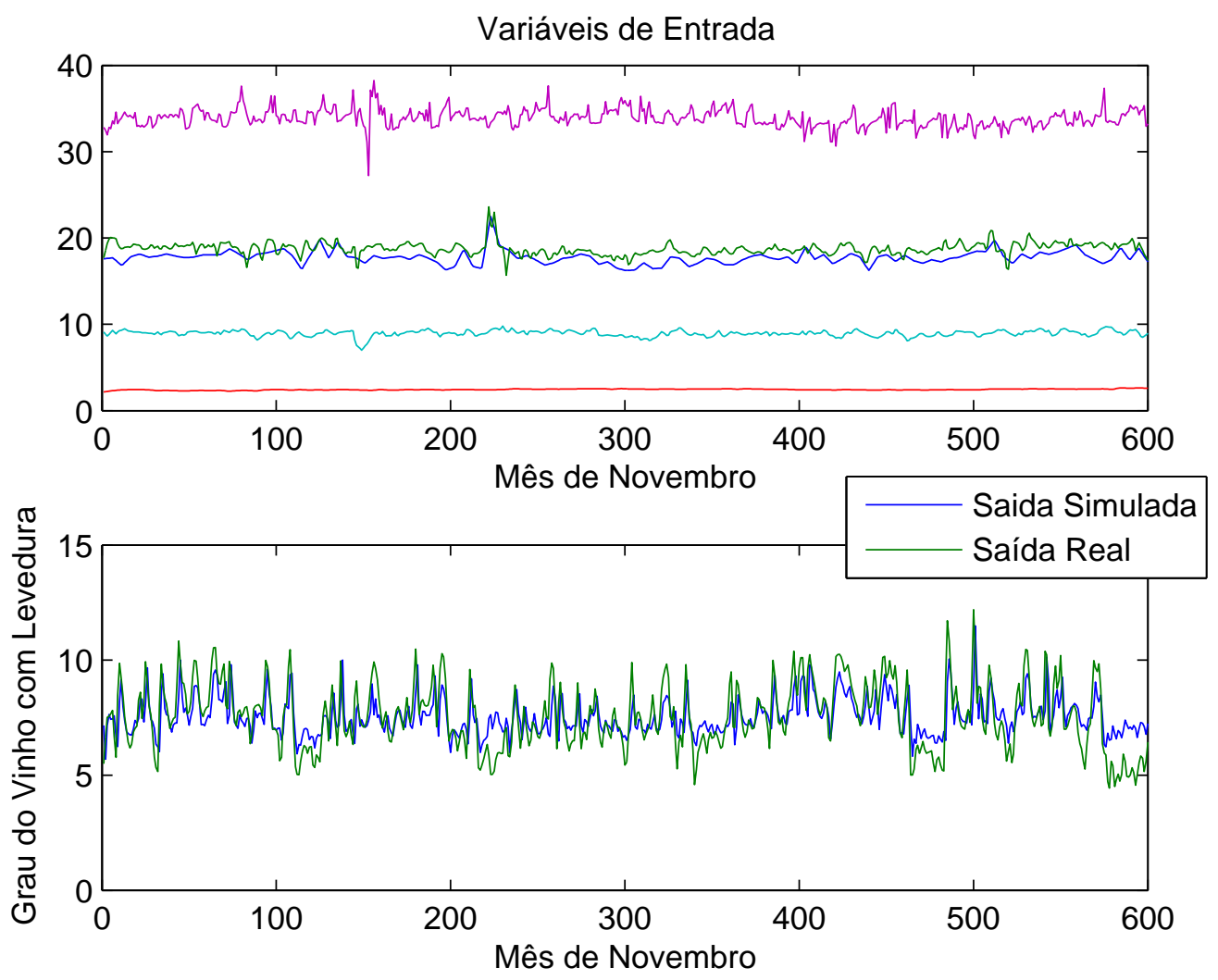

Figura 6.12 - Validação da rede NARX (Nov/2008).

A curva do Erro Percentual Relativo para o mês de Novembro é mostrada na Figura 6.13:

No mês de Novembro, o PRE calculado possui alguns picos que chegam aos 45\%. Na média o PRE permanece entre 0 a $8 \%$. 


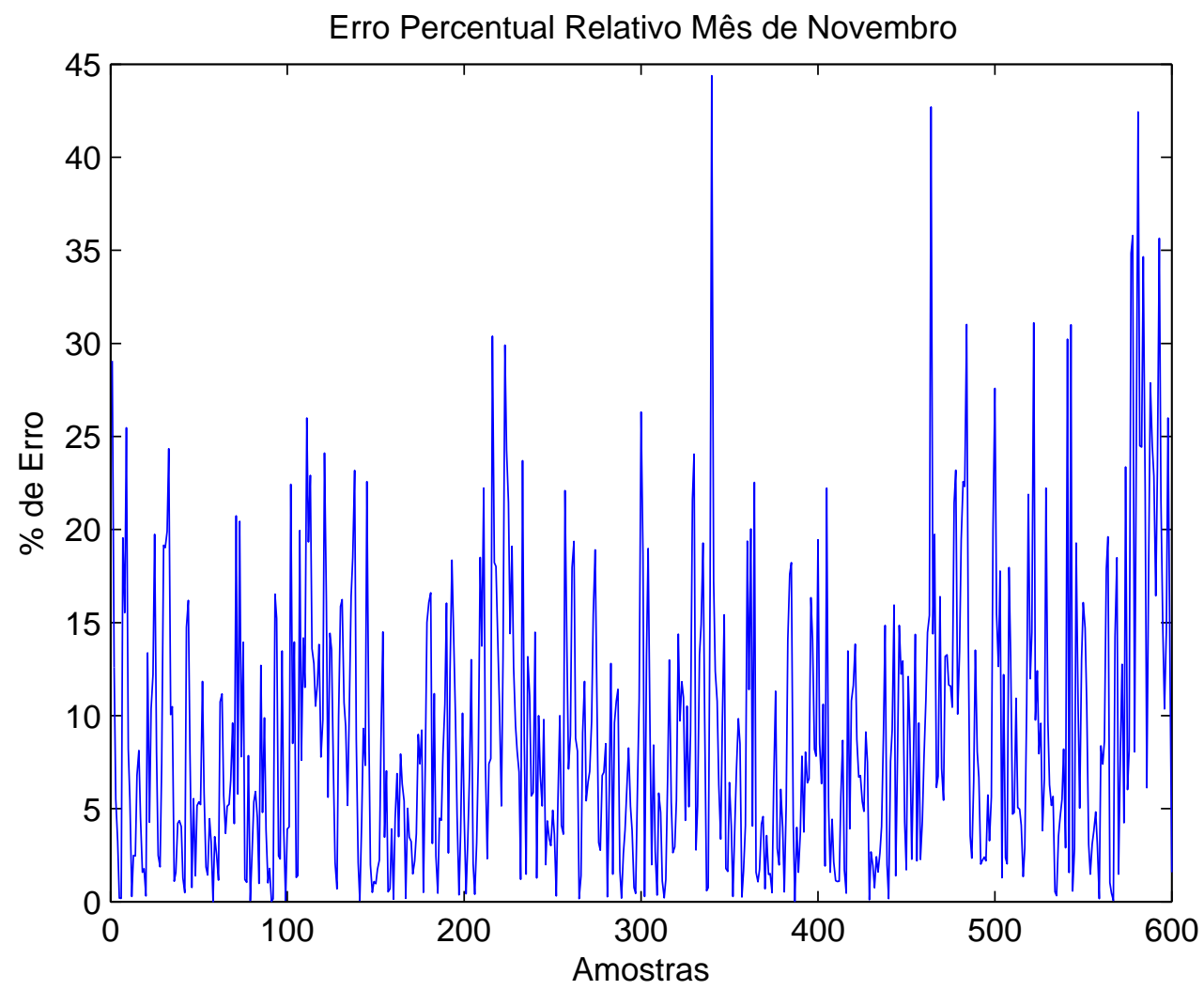

Figura 6.13 - Erro Percentual Relativo do Mês de Novembro.

Por fim, a validação da rede para o mês de Dezembro, conforme a Figura 6.14. 

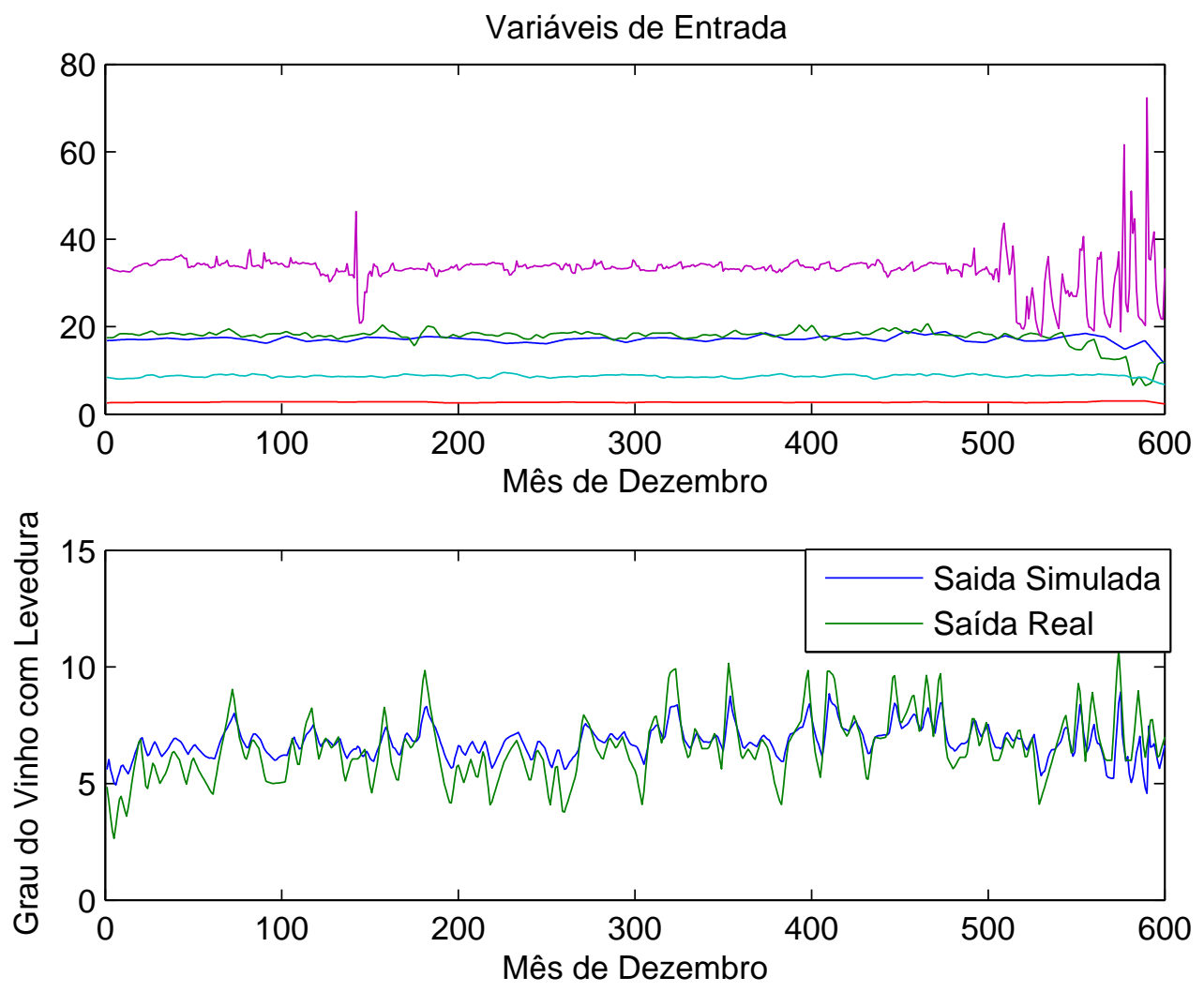

Figura 6.14 - Validação da rede NARX (Dez/2008).

A curva do Erro Percentual Relativo para o mês de Dezembro é mostrada na Figura 6.15: 


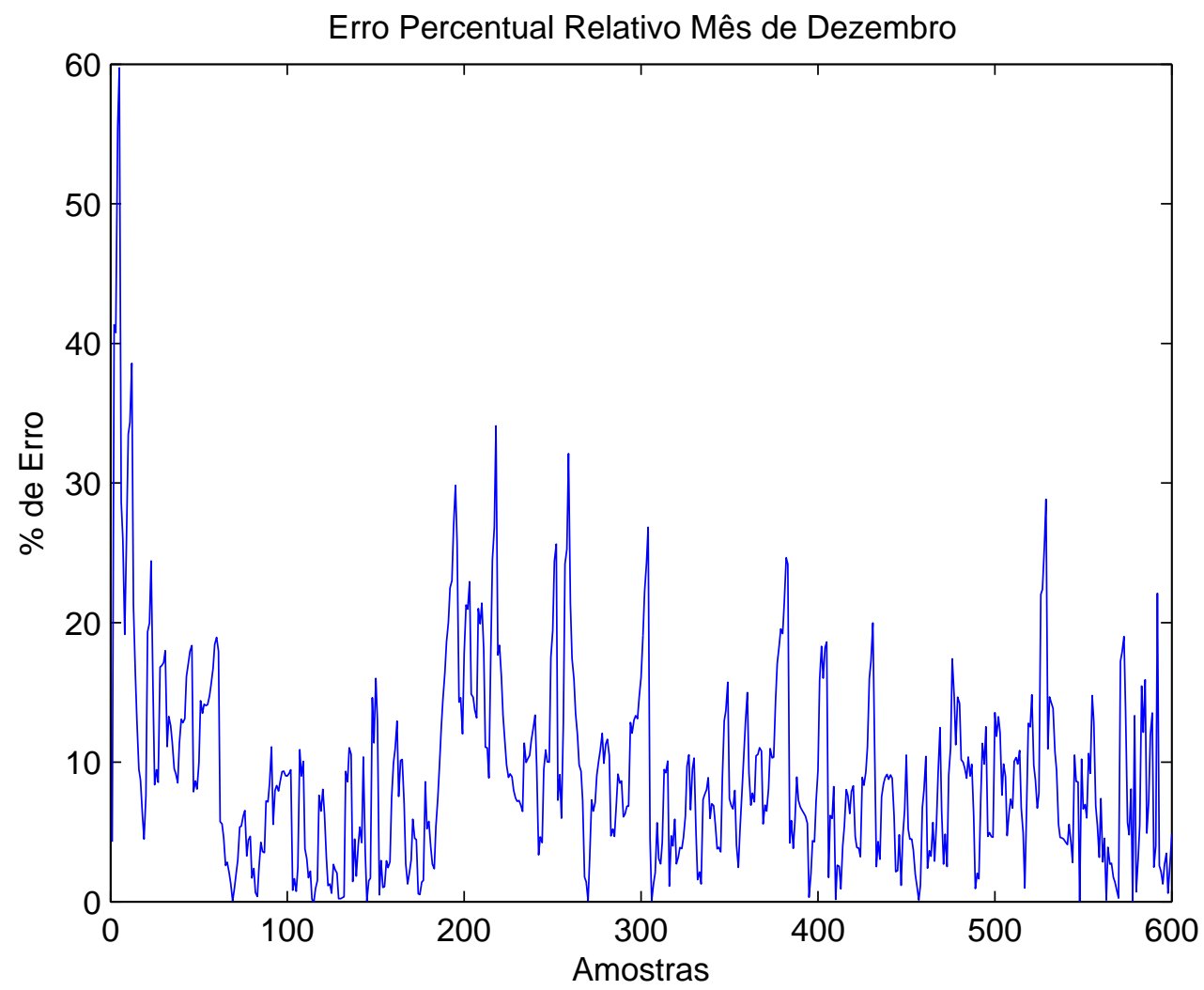

Figura 6.15 - Erro Percentual Relativo do Mês de Dezembro.

Para o mês de Dezembro, o PRE calculado possui alguns picos iniciais que chegam aos $60 \%$, mas depois esses picos ficam na faixa de 0 a $9 \%$. 
A Tabela 6.2 apresenta os Erros Médios Quadráticos e os Erros Relativos Médios, calculados pelas Equações 5.1 e 5.2:

Tabela 6.1 - Erros de Previsão do Grau do Vinho com Levedura.

\begin{tabular}{||c|c|c||}
\hline \hline Mês & MSE(NARX) & PMRE(\%)(NARX) \\
\hline \hline Agosto & 0.4035 & 6.6071 \\
\hline Setembro & 1.1177 & 6.6327 \\
\hline Outubro & 0.9032 & 11.7913 \\
\hline Novembro & 0.9187 & 8.9377 \\
\hline Dezembro & 0.7307 & 9.2915 \\
& & \\
\hline
\end{tabular}

Os valores apresentados na Tabela 6.2, correspondem à resposta da rede NARX utilizando como entrada os dados não utilizados na fase de treinamento. Os valores apresentados nos gráficos referentes ao Erro Percentual Relativo, são calculados a cada interação da rede. Isto significa que alguns valores mostrados são maiores dos que foram calculados e mostrados na Tabela 6.2, na coluna MRE. Porém, o cálculo do MRE é feito através do somatório dos erros e depois dividido pela quantidade de pontos, onde possivelmente essa média será menor do que os valores mostrados no gráfico.

A análise dos valores de desempenho, calculados através do Erro Quadrático Médio, mostram uma diferença do Grau do Vinho calculado pela rede NARX que varia de 0.40 a 1.11 entre os meses de Agosto e Dezembro, e para o Erro Relativo Médio a diferença do Grau do Vinho calculado pela rede NARX varia de $6.60 \%$ para $11.79 \%$. Os resultados são interessantes e diferem do comportamento esperado para a rede. Esperava-se obter resultados que se degradassem com o tempo, no entanto, o erro permanece constante. Considerações sobre a significância do erro devem levar em consideração dois aspectos. 
Em primeiro lugar os sensores adotados fornecem valores com uma precisão, o que implica que o modelo com um desvio considerável para esse tipo de processo pode ter alcançado um limite suficiente de precisão. Por outro lado um erro de N\% no cálculo do teor alcoólico pode representar X litros de álcool por batelada e uma possível perda de Y reais por safra.

\subsection{Aplicação de Identificação de Sistemas na Mineração de Da- dos do Processo KDD}

A Figura 6.16 mostra os dados experimentais de entrada e saída do processo de fermentação para o mês de Agosto, conforme descrito na Tabela ??:
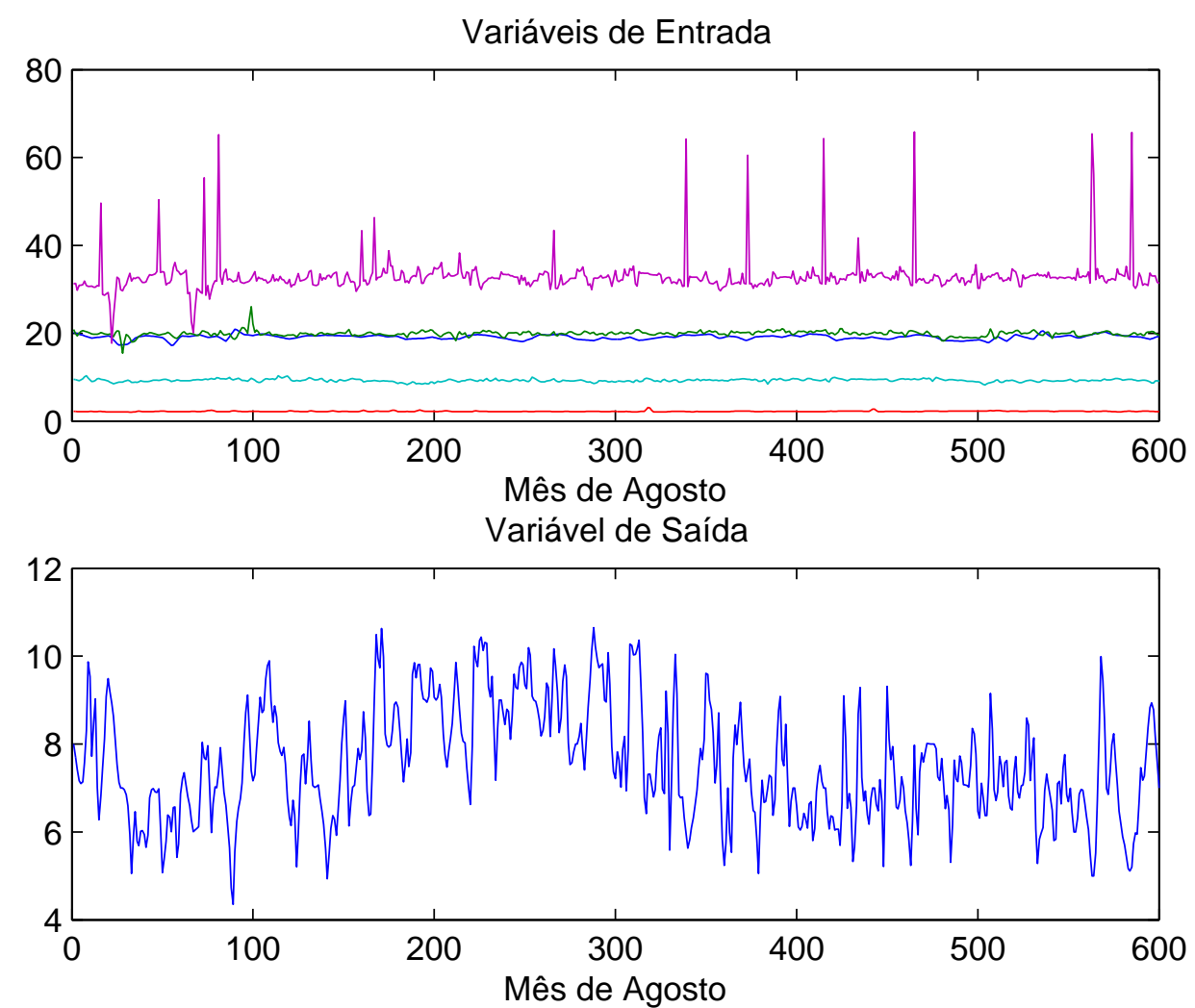

Figura 6.16 - Variáveis do Processo de Fermentação no Mês de Agosto.

Com os dados selecionados e tratados, o próximo passo é a configuração dos parâmetros utilizados no processo de Identificação de Sistemas. Para todos os experimentos utilizados nesse 
trabalho, o processo de Identificação é configurado da seguinte maneira:

- Regressores: são utilizados 5 regressores de entrada e 5 regressores de saída;

- Modelo Matemático: o modelo matemático utilizado é o ARX;

- Validação: são comparadas as saídas do sistema real e com a saída gerada pelo novo sistema identificado;

- Erro: os erros são calculados de acordo com as Equações 5.2, a Equação 5.1 e a Equação 5.3

Para o mês de agosto, o seguinte modelo matemático é identificado:

$$
\begin{gathered}
\left(\begin{array}{c}
y_{k} \\
y_{k+1} \\
y_{k+2} \\
\vdots \\
y_{k+i}
\end{array}\right)=\left(\begin{array}{ccccc}
2.2845 & 1 & 0 & 0 & 0 \\
-2.5255 & 0 & 1 & 0 & 0 \\
2.1422 & 0 & 0 & 1 & 0 \\
-1.3579 & 0 & 0 & 0 & 1 \\
0.4426 & 0 & 0 & 0 & 0
\end{array}\right)\left(\begin{array}{c}
y_{k-1} \\
y_{k-2} \\
y_{k-3} \\
\vdots \\
y_{k-i}
\end{array}\right)+ \\
\left(\begin{array}{cccccc}
0.0052 & 0.1286 & -0.5456 & -0.0228 & -0.0054 \\
-0.0634 & -0.2050 & 0.6854 & 0.0923 & -0.0020 \\
0.1970 & 0.1545 & 0.0764 & -0.1832 & 0.0104 \\
-0.1800 & -0.0626 & -0.9352 & 0.0292 & -0.0030 \\
0.0519 & -0.0056 & 0.7007 & 0.0466 & 0.0003
\end{array}\right)\left(\begin{array}{c}
u_{k} \\
u_{k-1} \\
u_{k-2} \\
\vdots \\
u_{k-i}
\end{array}\right)
\end{gathered}
$$


A simulação do sistema identificado é feita com base no modelo matemático encontrado. Na Figura 6.17, é mostrada a comparação entre a resposta da simulação do sistema identificado e a resposta real do processo de fermentação.

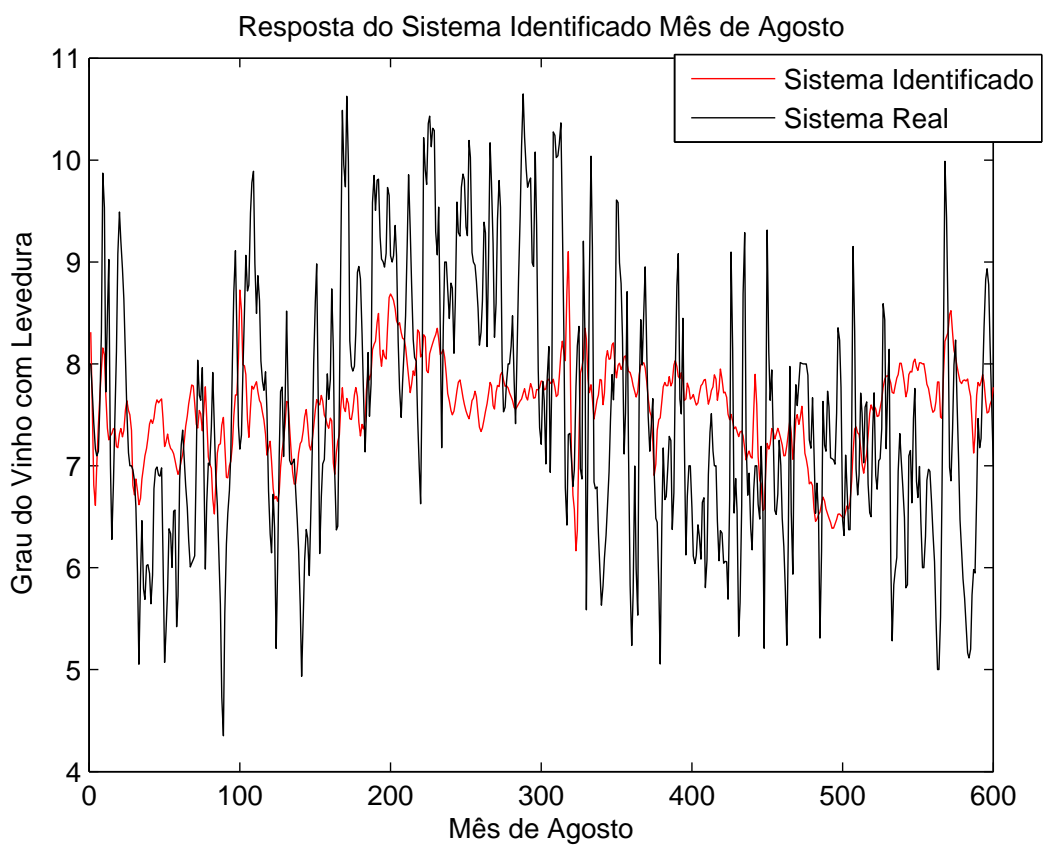

Figura 6.17 - Comparativo Sistema Identificado e o Sistema Real para o Mês de Agosto.

O Erro Percentual Relativo é calculado, comparando a resposta da simulação do sistema identificado e a resposta do processo fermentativo, em um mesmo instante do mês de agosto. A Figura 6.18 mostra o resultado do Erro Percentual Relativo: 


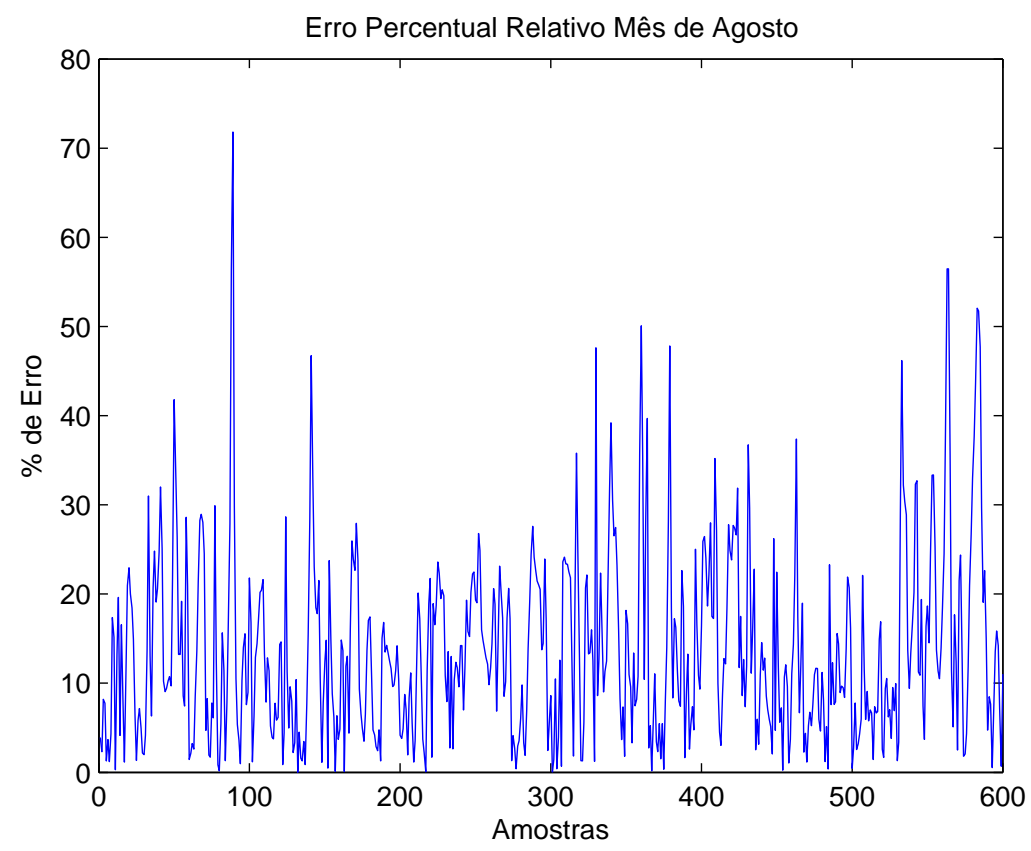

Figura 6.18 - Erro Percentual Relativo do Mês de Agosto.

Na Figura 6.18 é possível verificar que o comportamento do sistema identificado possui, em alguns casos, um erro muito elevado. 
Para o mês de setembro, o seguinte modelo matemático é identificado:

$$
\begin{gathered}
\left(\begin{array}{c}
y_{k} \\
y_{k+1} \\
y_{k+2} \\
\vdots \\
y_{k+i}
\end{array}\right)=\left(\begin{array}{ccccc}
2.3315 & 1 & 0 & 0 & 0 \\
-2.7287 & 0 & 1 & 0 & 0 \\
2.2797 & 0 & 0 & 1 & 0 \\
-1.3394 & 0 & 0 & 0 & 1 \\
0.4400 & 0 & 0 & 0 & 0
\end{array}\right)\left(\begin{array}{c}
y_{k-1} \\
y_{k-2} \\
y_{k-3} \\
\vdots \\
y_{k-i}
\end{array}\right)+ \\
\left(\begin{array}{ccccc}
-0.7821 & 0.1676 & 7.8895 & -0.3422 & -0.0074 \\
2.2919 & -0.4130 & -20.5502 & 0.4032 & 0.0131 \\
-2.1203 & 0.2714 & 21.1160 & -0.4513 & -0.0192 \\
0.5077 & -0.0204 & -10.2790 & 0.7141 & 0.0249 \\
0.1123 & 0.0068 & 1.6808 & -0.3550 & -0.0048
\end{array}\right)\left(\begin{array}{c}
u_{k} \\
u_{k-1} \\
u_{k-2} \\
\vdots \\
u_{k-i}
\end{array}\right)
\end{gathered}
$$

Na Figura 6.19, tem-se a comparação entre a resposta do sistema real e o sistema identificado.

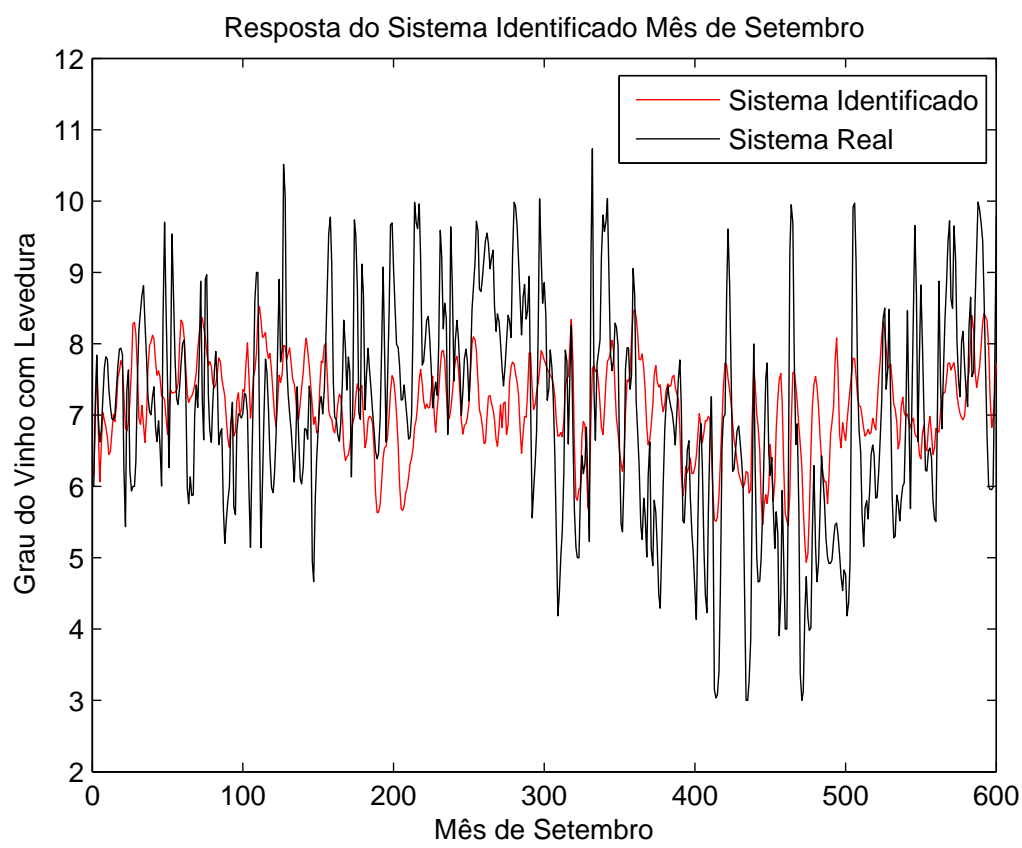

Figura 6.19 - Comparativo Sistema Identificado e o Sistema Real para o Mês de Setembro. 
O Erro Percentual Relativo calculado para o mês de setembro é mostrado na Figura 6.20:

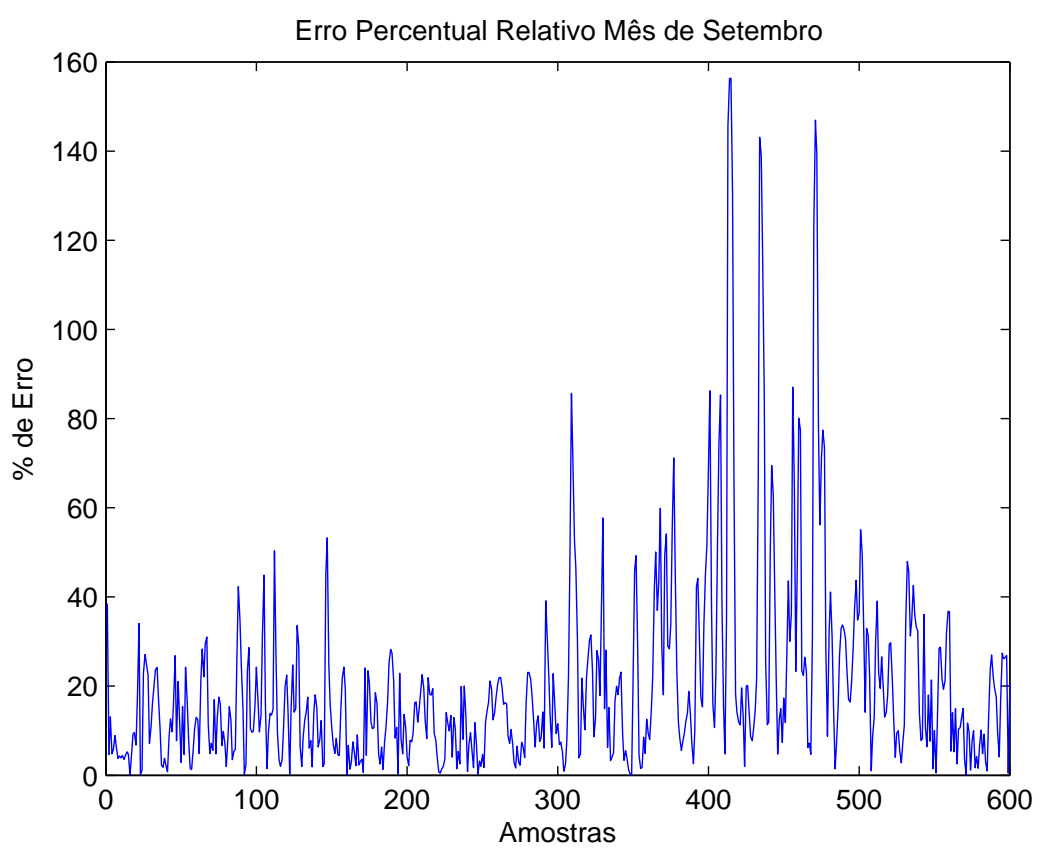

Figura 6.20 - Erro Percentual Relativo do Mês de Setembro.

Para o mês de setembro, o desempenho do sistema identificado é considerado como ruim, pois a o Erro Percentual Relativo, em alguns casos, chega os $150 \%$. 
Para o mês de outubro, o seguinte modelo matemático é identificado:

$$
\begin{gathered}
\left(\begin{array}{c}
y_{k} \\
y_{k+1} \\
y_{k+2} \\
\vdots \\
y_{k+i}
\end{array}\right)=\left(\begin{array}{ccccc}
2.1857 & 1 & 0 & 0 & 0 \\
-2.4317 & 0 & 1 & 0 & 0 \\
2.1304 & 0 & 0 & 1 & 0 \\
-1.3854 & 0 & 0 & 0 & 1 \\
0.4755 & 0 & 0 & 0 & 0
\end{array}\right)\left(\begin{array}{c}
y_{k-1} \\
y_{k-2} \\
y_{k-3} \\
\vdots \\
y_{k-i}
\end{array}\right)+ \\
\left(\begin{array}{cccccc}
-0.3679 & 0.0626 & 2.5705 & 0.0909 & 0.0373 \\
1.0416 & -0.1466 & -8.0666 & -0.2258 & -0.0466 \\
-0.8934 & 0.1755 & 8.4814 & 0.0934 & 0.0115 \\
0.1251 & -0.0931 & -3.8228 & 0.2326 & -0.0080 \\
0.0875 & 0.0040 & 0.8216 & -0.1859 & 0.0098
\end{array}\right)\left(\begin{array}{c}
u_{k} \\
u_{k-1} \\
u_{k-2} \\
\vdots \\
u_{k-i}
\end{array}\right)
\end{gathered}
$$

Na Figura 6.21, tem-se a comparação entre a resposta do sistema real e o sistema identificado.

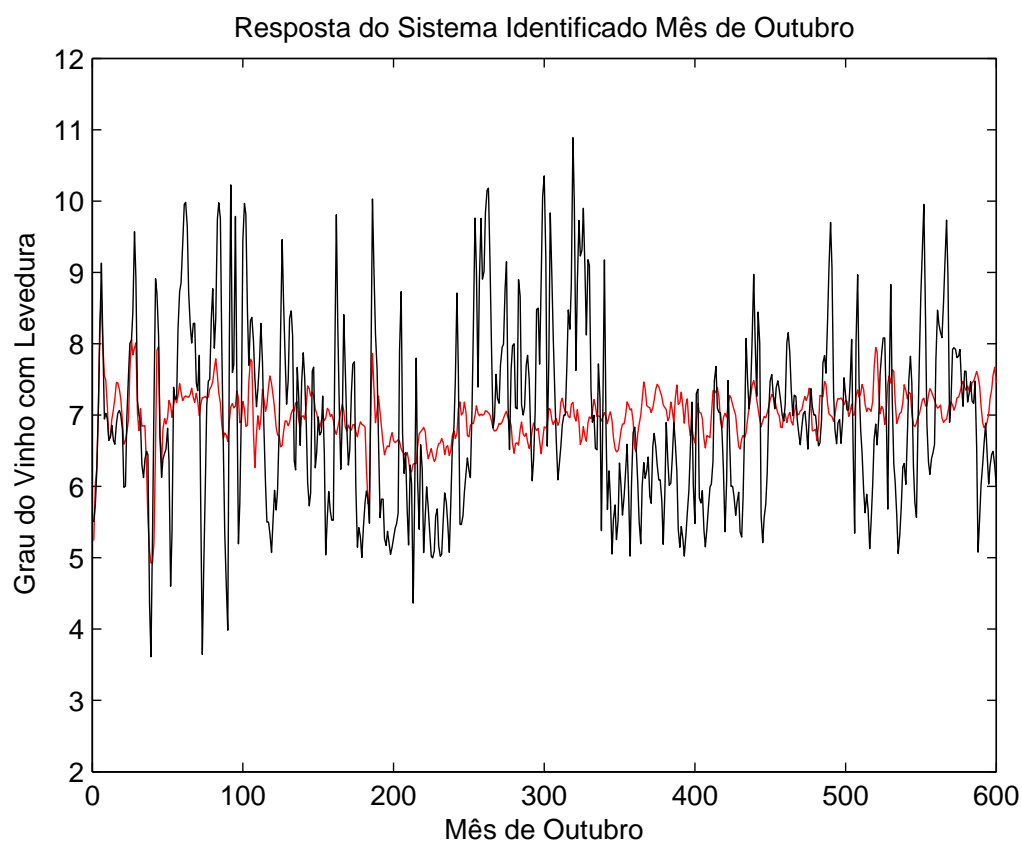

Figura 6.21 - Comparativo Sistema Identificado e o Sistema Real para o Mês de Outubro. 
No mês de outubro, o Erro Percentual Relativo calculado é mostrado na Figura 6.22:

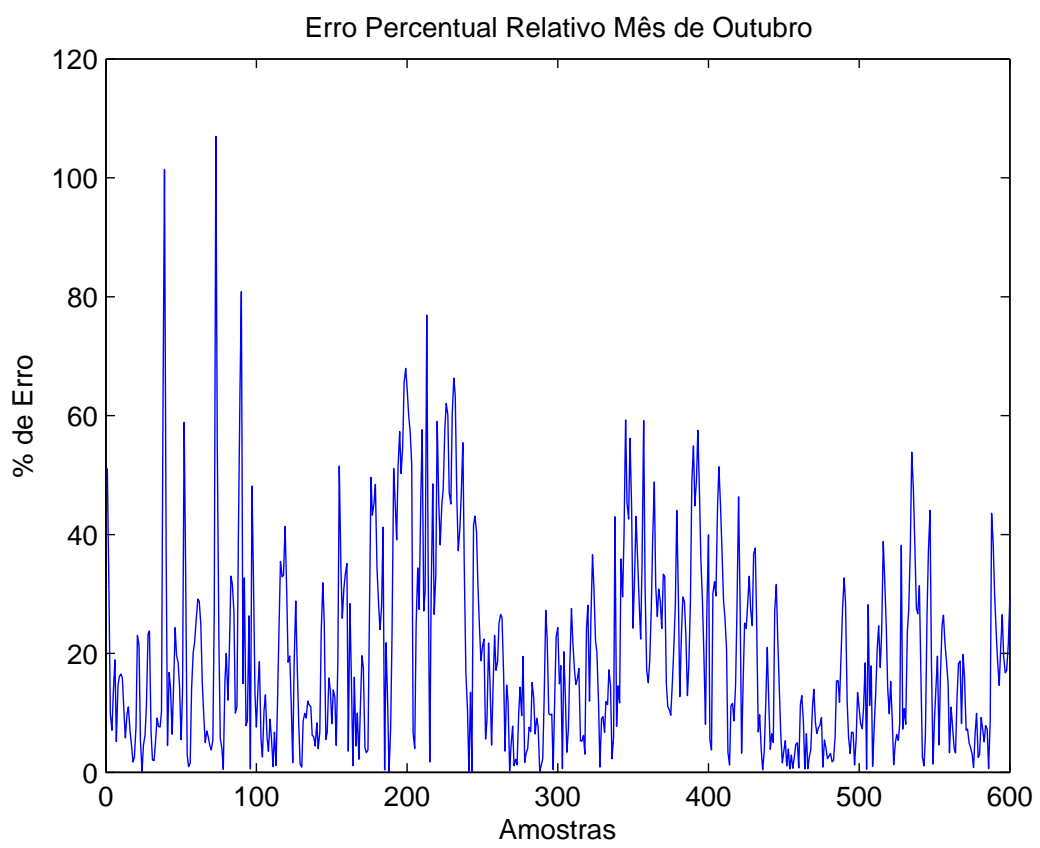

Figura 6.22 - Erro Percentual Relativo do Mês de Outubro.

O Erro Percentual Relativo para o mês de Outubro, inicialmente possui um erro muito grande, chegando aos 100\%. Porém para as últimas interações esse erro permanece entre 0\% e $60 \%$. 
Para o mês de novembro, o seguinte modelo matemático é identificado:

$$
\begin{gathered}
\left(\begin{array}{c}
y_{k} \\
y_{k+1} \\
y_{k+2} \\
\vdots \\
y_{k+i}
\end{array}\right)=\left(\begin{array}{cccccc}
2.4000 & 1 & 0 & 0 & 0 \\
-2.8723 & 0 & 1 & 0 & 0 \\
2.4078 & 0 & 0 & 1 & 0 \\
-1.3783 & 0 & 0 & 0 & 1 \\
0.4233 & 0 & 0 & 0 & 0
\end{array}\right)\left(\begin{array}{c}
y_{k-1} \\
y_{k-2} \\
y_{k-3} \\
\vdots \\
y_{k-i}
\end{array}\right)+ \\
\left(\begin{array}{cccccc}
-0.0993 & 0.1026 & -0.6772 & 0.0740 & 0.0814 \\
0.2935 & -0.1877 & -0.2347 & -0.0625 & -0.1555 \\
-0.3517 & 0.1560 & 2.7587 & -0.1008 & 0.1160 \\
0.2317 & -0.1005 & -3.0960 & 0.0871 & -0.0446 \\
-0.0700 & 0.0383 & 1.1503 & -0.0088 & 0.0067
\end{array}\right)\left(\begin{array}{c}
u_{k} \\
u_{k-1} \\
u_{k-2} \\
\vdots \\
u_{k-i}
\end{array}\right)
\end{gathered}
$$

Na Figura 6.23, tem-se a comparação entre a resposta do sistema real e o sistema identificado.

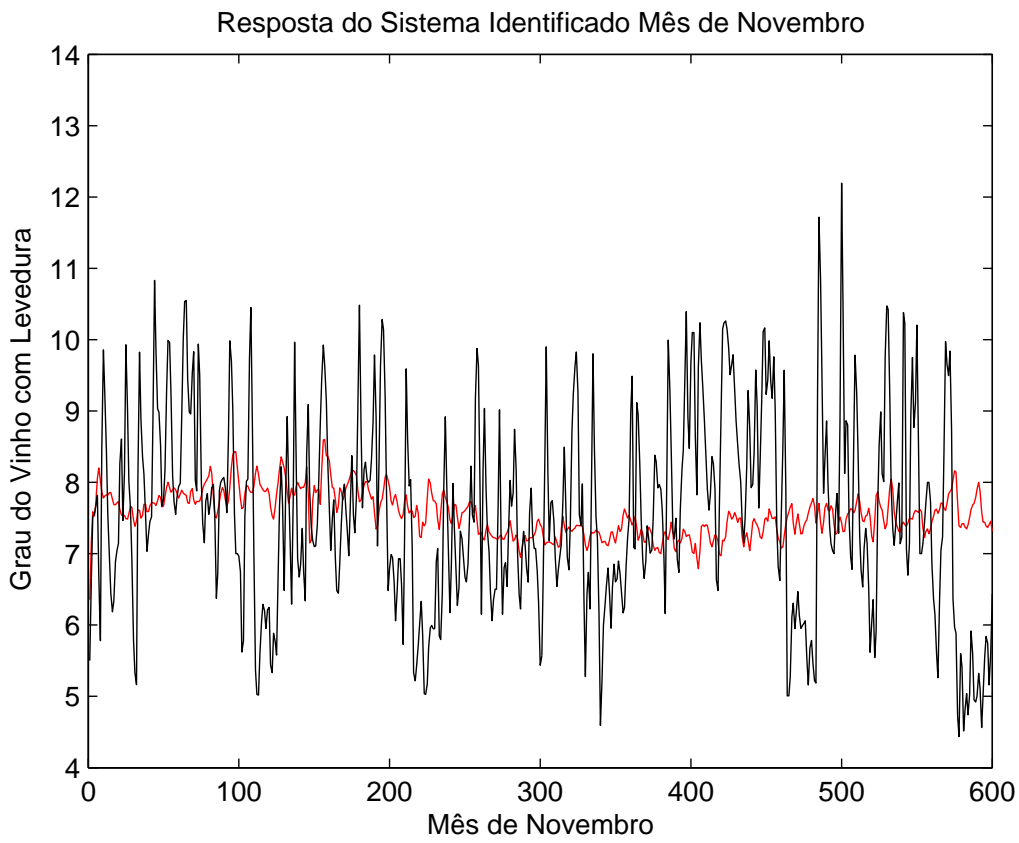

Figura 6.23 - Comparativo Sistema Identificado e o Sistema Real para o Mês de Novembro. 
O Erro Percentual Relativo calculado para o mês de novembro, é mostrado na Figura 6.24:

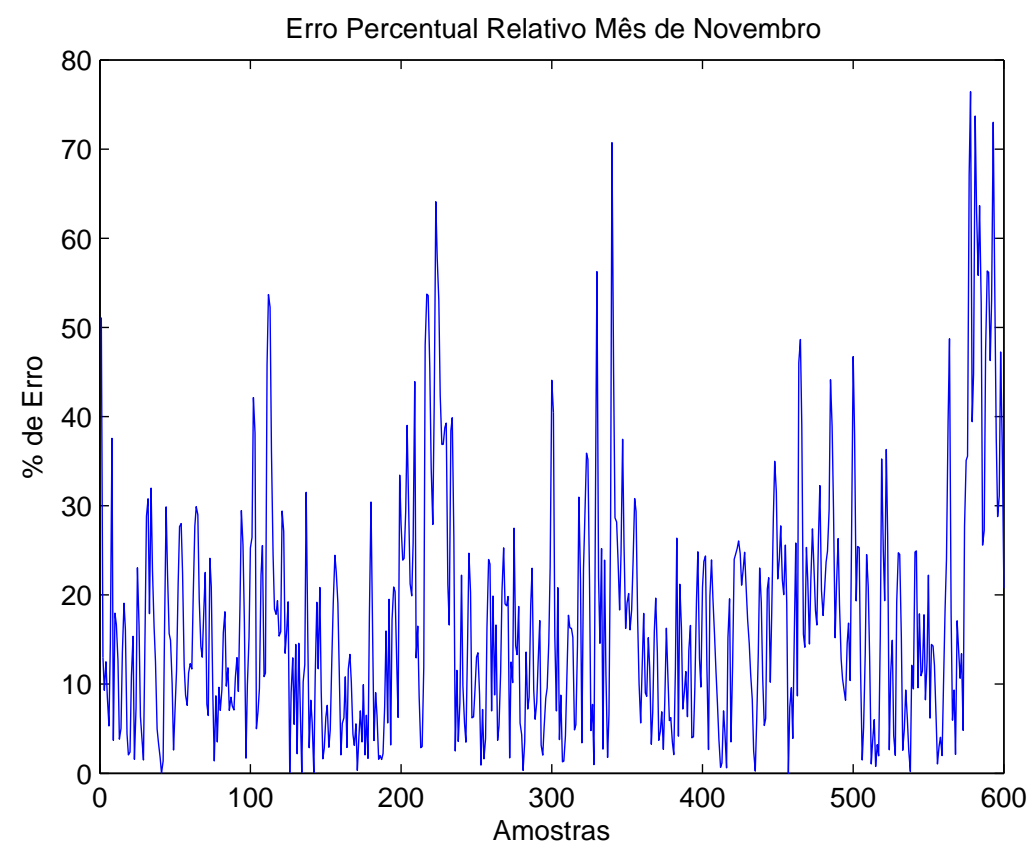

Figura 6.24 - Erro Percentual Relativo do Mês de Novembro.

A princípio o Erro Percentual Relativo do sistema identificado no mês de Novembro é considerado pequeno. Porém, no final, esse erro aumenta e chega aos $80 \%$. 
Para o mês de dezembro, o seguinte modelo matemático é identificado:

$$
\begin{gathered}
\left(\begin{array}{c}
y_{k} \\
y_{k+1} \\
y_{k+2} \\
\vdots \\
y_{k+i}
\end{array}\right)=\left(\begin{array}{cccccc}
3.5954 & 1 & 0 & 0 & 0 \\
-5.3792 & 0 & 1 & 0 & 0 \\
4.1282 & 0 & 0 & 1 & 0 \\
-1.5701 & 0 & 0 & 0 & 1 \\
0.2202 & 0 & 0 & 0 & 0
\end{array}\right)\left(\begin{array}{c}
y_{k-1} \\
y_{k-2} \\
y_{k-3} \\
\vdots \\
y_{k-i}
\end{array}\right)+ \\
\left(\begin{array}{cccccc}
0.1257 & 0.0104 & -0.5457 & -0.1368 & -0.0008 \\
-0.0477 & -0.0596 & -1.1787 & 0.5619 & 0.0011 \\
-0.2923 & 0.1056 & 4.8422 & -0.8746 & -0.0025 \\
0.2452 & -0.0930 & -3.9130 & 0.5795 & 0.0018 \\
-0.0229 & 0.0349 & 0.7719 & -0.1345 & 0.0006
\end{array}\right)\left(\begin{array}{c}
u_{k} \\
u_{k-1} \\
u_{k-2} \\
\vdots \\
u_{k-i}
\end{array}\right)
\end{gathered}
$$

Na Figura 6.25, tem-se a comparação entre a resposta do sistema real e o sistema identificado.

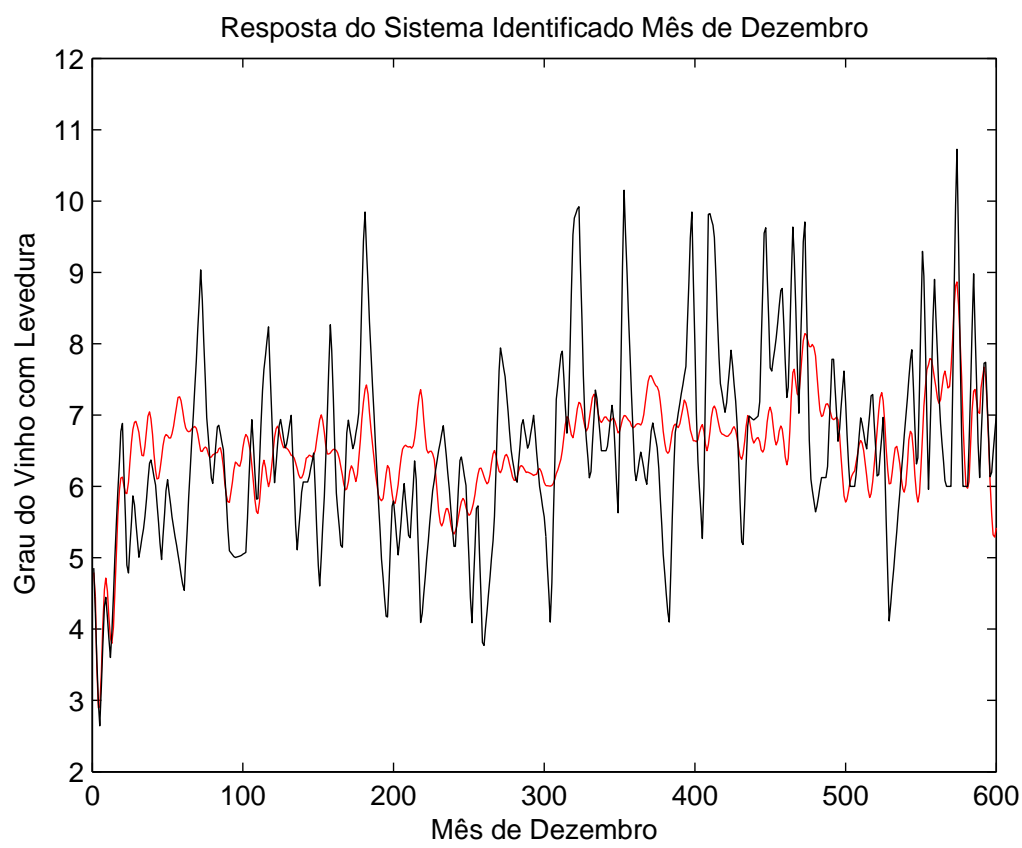

Figura 6.25 - Comparativo Sistema Identificado e o Sistema Real para o Mês de Dezembro. 
Semelhante aos outros meses, O Erro Percentual Relativo é calculado para o mês de dezembro. A Figura 6.26 mostra o resultado do Erro Percentual Relativo:

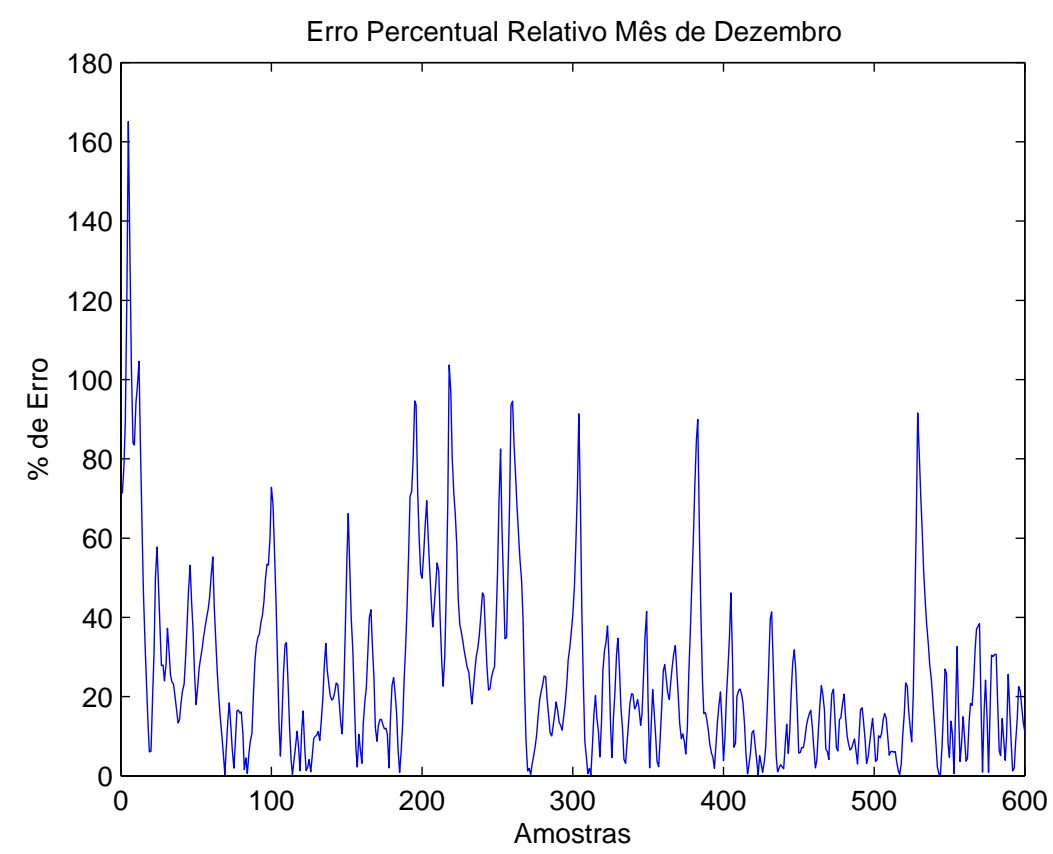

Figura 6.26 - Erro Percentual Relativo do Mês de Dezembro.

Inicialmente, o Erro Percentual Médio para o mês de dezembro é considerado alto e ultrapassa os 160\%. A variação no decorrer do processo está entre $0 \%$ e 100\%, em que se pode afirmar que, em alguns casos, o sistema identificado consegue acompanhar a resposta do sistema real. 
A Tabela 6.2 apresenta os Erros Médios Quadráticos e os Erros Relativos Médios, calculados pelas Equações 5.1 e 5.2, com base nos dados experimentais do processo de fermentação e a resposta dos modelos matemáticos encontrados.

Tabela 6.2 - Erros de Previsão do Grau do Vinho com Levedura.

\begin{tabular}{||c|c|c||}
\hline \hline Mês & MSE(I.S.) & PMRE(\%)(I.S.) \\
\hline \hline Agosto & 1.4678 & 17.30 \\
\hline Setembro & 1.8288 & 20.20 \\
\hline Outubro & 1.4979 & 19.76 \\
\hline Novembro & 2.3921 & 17.33 \\
\hline Dezembro & 1.3249 & 25.50 \\
\hline
\end{tabular}

Conforme visto nas Figuras 6.18, 6.20, 6.22, 6.24 e 6.26, o desempenho dos modelos identificados pelo processo de Identificação de Sistema não foi satisfatório, como o esperado. Isto pode ter acontecido por vários motivos, dentre eles a ordem do sistema identificado não está correta ou até mesmo pelo fato que o processo de fermentação possui algumas anomalias não identificadas pela ferramenta de identificação. A imprecisão de sensores no momento da aquisição da informação, pode ser considerado como outro ponto importante.

A Tabela 6.3 apresenta a comparação entre os erros calculados para as redes Neurais NARX e os modelos encontrados no processo de Identificação de Sistemas: 
Tabela 6.3 - Comparação dos Erros de Previsão do Grau do Vinho com Levedura.

\begin{tabular}{||c|c|c|c|c||}
\hline \hline Mês & MSE(I.S) & PMRE(\%)(I.S.) & MSE(NARX) & MSE(NARX) \\
\hline \hline Agosto & 1.4678 & 17.30 & 0.4035 & 6.6071 \\
\hline Setembro & 1.8288 & 20.20 & 1.1177 & 6.6327 \\
\hline Outubro & 1.4979 & 19.76 & 0.9032 & 11.7913 \\
\hline Novembro & 2.3921 & 17.33 & 0.9187 & 8.9377 \\
\hline Dezembro & 1.3249 & 25.50 & 0.7307 & 9.2915 \\
& & & & \\
\hline
\end{tabular}

A partir da comparação feita na Tabela 6.3 a rede neural NARX apresentou um desempenho superior ao Método de Identificação de Sistemas. Os valores calculados para o PMRE são bem maiores do que os calculados para a rede NARX. Supondo que o diferencial da rede NARX reside no fato dela ser desenvolvida para sistemas não lineares, enquanto que as estruturas matemáticas utilizadas no processo de Identificação de Sistemas são restritas a estruturas lineares. 


\section{Capítulo 7}

\section{Conclusões}

Esse trabalho se insere no contexto contemporâneo de relevância global: a área de biocombustíveis, oferecendo um vetor alternativo ao aumento de produtividade, não pelo aumento de área plantada, mas sim, por meio da implementação e disponibilização de novos conceitos na área da automação industrial, tais como o processo KDD.

Atualmente, a instrumentação dos equipamentos e subprocessos que compõe uma planta sucroalcooleira é utilizada de forma local para o monitoramento e controle dos mesmos. Se observados de forma holística, este dados constituem um enorme repositório de informação que poderia ser aproveitado de forma global para melhorar a eficiência do conjunto. Neste trabalho, a construção de uma ferramenta baseada no processo KDD, possui a capacidade de fornecer uma previsão da produção de uma usina de cana-de-açúcar, levando em conta dados históricos de operação, e padrões de variáveis contidas no processo de fabricação, tais como modelos matemáticos determinísticos, distribuições estatísticas, sistemas de aprendizado e inferência, que caracterizem o processo de forma aproximada.

Assim, tais modelos identificados pelo processo KDD podem ser utilizados para o monitoramento e controle de processos de forma global, auxiliando no desenvolvimento e implementação de novas malhas de controle, desenvolvimento de novos equipamentos e na aplicação de novas técnicas de controle de processos. 
Os módulos desenvolvidos nesse trabalho são:

- Módulo de Aquisição de dados: esse módulo é responsável pela aquisição e armazenamento dos dados disponíveis no ambiente industrial;

- Módulo de Tratamento de dados: o objetivo desse módulo é de realizar o tratamento dos dados armazenados na base de dados. Esse tratamento consiste na eliminação de dados inválidos, redimensionamento de valores, normalização e gravação de dados;

- Módulo de Mineração de Dados: esse módulo é composto pelas duas ferramentas de mineração de dados citadas no Capítulo 5, as redes neurais NARX e o processo de Identificação de Sistemas;

- Módulo de Validação: esse módulo é responsável por calcular e gerar os erros de resposta dos modelos encontrados pelo processo KDD.

Nesta tese, o processo de fermentação é considerado como um processo discreto. Para tanto dois modelos foram criados para que se tivesse uma resposta aproximada do comportamento do processo de fermentação; um modelo utilizando redes neurais NARX e outro utilizando o processo de Identificação de Sistemas.

Dentre os modelos, os melhores resultados foram obtidos pelo modelo gerado pelas redes neurais NARX, onde o erro calculado a partir da diferença da resposta gerada pela rede neural NARX e a resposta atual do processo fermentativo, não ultrapassou os $11 \%$. Com relação ao processo de Identificação de Sistemas, os resultados foram insatisfatórios, conforme visto nas Figuras $6.18,6.20,6.22,6.24$ e 6.26. Foi possível observar que em alguns casos, a diferença entre os valores, obtidos pela simulação do modelo encontrado pelo processo de Identificação de Sistemas, ultrapassou 100\%, tornando sua aplicação inviável.

Para melhor entender a aplicabilidade da proposta desse trabalho, foram analisados os tempos envolvidos no processo de fermentação. Em média, o período gasto na fermentação do vinho armazenado nas dornas é de 4 a 12 horas (AMORIN, 2005). Após esse período, tem-se a estimativa de como será a produção de vinho.

Com o modelo identificado pela rede neural NARX, essa estimativa é bem menor. Após o aprendizado, a rede neural oferece respostas (estimativas) de produção de vinho em 30 segundos. Assim, é possível obter antecipadamente como será a produção de álcool. 
Tomando como base os dados experimentais da dorna de fermentação utilizados nesse trabalho, um erro de $N \%$ corresponde a $M$ litros de álcool, que por sua vez correspondem aos preços de mercado de hoje em torno de $Y$ reais por litro. Outro ponto de vista é entendimento de qual é o montante de valor em relação ao valor produzido por batelada, onde um possível erro de $N \%$ no cálculo do teor alcoólico pode representar $X$ litros de álcool por batelada e uma possível perda de $Y$ reais por safra.

Um fato importante de se verificar também é a ocorrência da deterioração temporal das respostas geradas pela rede, conforme a Tabela 6.3. A deterioração temporal é um aspecto diferente a ser considerado, pois ela indica qual é o nível de confiança que se pode ter da resposta calculada pela rede. A alternativa para que esse erro seja minimizado é o retreinamento da rede. Esse retreinamento pode ser realizado por meio de arquiteturas computacionais de processamento paralelo, aumentando a performance e a confiabilidade nas estimativas calculadas pela rede neural NARX. Por meio desse retreinamento, são atualizados os parâmetros da rede e e seus ganhos após uma quantidade de bateladas. Desta forma, essa arquitetura faz com que o tempo gasto no treinamento da rede diminua. Neste trabalho, a rede neural NARX demorou em média 12 minutos para ser treinada com os dados experimentais de uma dorna de fermentação. Dependendo da arquitetura utilizada no processamento paralelo, a estimativa é que esse tempo diminua em torno de $60 \%$. Um aspecto importante a ser considerado é que a partir dessas deteriorações, novas linhas de pesquisa são abertas, para que sejam voltadas na otimização do processo de fermentação.

Nas usinas existem em média 4 dornas de fermentação, todas ligadas em série. Deste modo, o modelo identificado pode ser colocado em diversos núcleos de processamento, formados por vários computadores ou pelos vários núcleos de um processador, onde cada núcleo executa e realiza estimativas do comportamento do processo de fermentação em série. Assim, tal arquitetura fornece um meio de auxiliar os engenheiros em possíveis correções no processo nos instantes em que ocorre a parada no processo de fermentação. 
Assim, tomando como base os algoritmos desenvolvidos e a pesquisa realizada, ficam como sugestão para estudo os seguintes trabalhos futuros:

- Desenvolvimento de ferramentas para a verificação de não linearidades do processo de fermentação;

- Aplicação do processo de Identificação de Sistemas para sistemas não lineares, tendo em vista que o uso das estruturas lineares não tiveram uma desempenho satisfatório;

- Caracterização e mapeamento do processo de fermentação para um melhor compreendimento de seu funcionamento, em que se é possível verificar o comportamento e a influência de cada variável no processo de fermentação;

- Aplicação do processo KDD para todo o processo de fermentação;

- Aplicação do processo KDD para outros processos da usina, tais como extração do caldo, destilação, geração de energia, etc;

A aplicabilidade do processo KDD em ambientes sucroalcooleiros foi uma das principais contribuições, pois não foram encontradas referências sobre esse tipo de aplicação na literatura científica voltadas para indústrias sucroalcooleiras. Partindo desse ponto de vista, esse trabalho mostrou a aplicação do processo KDD em ambientes sucroalcooleiros. O processo KDD pode ser aplicado como uma ferramenta de apoio à decisões, com a finalidade de auxiliar o gerente ou chefe de operação em suas decisões cotidianas bem como em projetos futuros visando a melhoria dos processos. 


\section{Apêndice A}

\section{Identificação de Sistemas}

Um dos objetivos do estudo do processo KDD é verificar sua aplicabilidade em processos de controle de sistemas, como por exemplo, o processo de identificação de sistemas de sistemas lineares. De uma maneira simplificada, o processo do KDD pode interagir diretamente com o processo de Identificação de Sistemas, uma vez que o KDD possui etapas similares ao processo de identificação de sistemas e o resultado de ambos, pode ser definido como um modelo matemático capaz de representar o comportamento do sistema dinâmico identificado.

Conceitualmente, a identificação de sistemas é um procedimento simples; com base nos sinais de entrada $u(k)$ e nos sinais de saída real de um sistema a ser identificado $y(k)$, um modelo matemático será obtido, e este será responsável por representar o comportamento do sistema a ser identificado, seja ele total ou de forma aproximada, conforme na Figura A.1 (AGUIRRE, 2000):

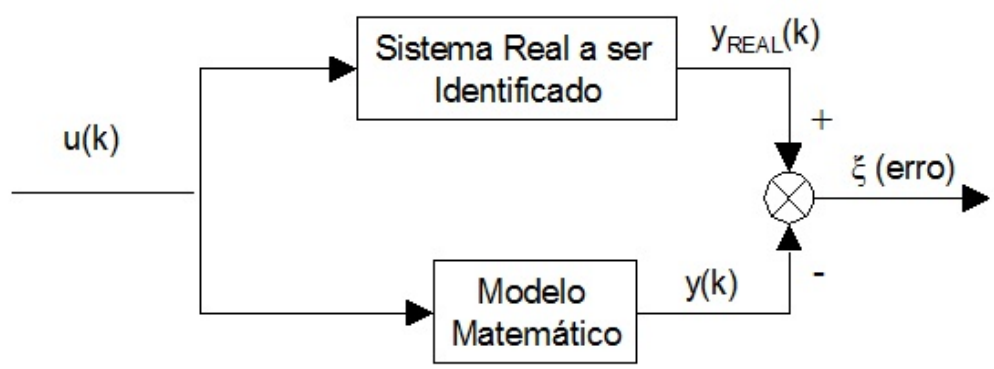

Figura A.1 - Representação do Processo de Identificação de Sistemas.

De uma forma geral, a identificação de sistemas inicia-se com a aquisição de dados experimentais, dados de entrada e saída, e informações sobre as excitações utilizadas, como por exemplo, 
um degrau na variável de entrada.

Após a aquisição de dados, propõe-se uma estrutura matemática apropriada para o modelo, por exemplo, uma equação polinomial de certa ordem. A seguir, são feitas as estimações dos parâmetros utilizados em tal modelo, onde tais parâmetros são ajustados por meio de algoritmos de ajuste polinomial, como por exemplo, o método dos mínimos quadrados.

A estimação, paramétrica e a do modelo, são feitas de forma iterativa, onde a estrutura é escolhida e os parâmetros são estimados. Após a escolha do modelo, este é validado, e caso não se chegue a um resultado esperado, são feitas novas estimações até que o modelo seja validado. Um exemplo de modelo é descrito na Equação A.1, onde $u$ e $y$ são os respectivos sinais de entrada e saída do sistema, $a$ e $b$ são os parâmetros, $n a$ e $n b$ são as ordens dos polinômios e $k$ o número de amostras.

$$
y(k)+a_{1} y(k-1)+\cdots+a_{n} a(k-n a)=b_{1}(k-1)+\cdots+b_{n} b(k-n b)
$$

\section{A.1 Etapas do Processo de Identificação de Sistemas}

Existem duas formas de se obter um modelo que represente um sistema, on-line e off-line. No processo em off-line, os dados experimentais são processados e armazenados em uma base de dados. A partir dos dados armazenados, é feita a identificação, sem a necessidade do sistema estar em funcionamento. Já no processo de Identificação on-line, os dados são processados, e a identificação é feita juntamente com o sistema em funcionamento. Dentre as técnicas de Identificação de Sistemas off-line, pode-se destacar Resposta em Frequência (ex. Diagrama de Bode, Diagrama Polar), Resposta Temporal e Identificação Paramétrica, Variáveis Instrumentais, Redes Neurais Artificiais.

A sequência de etapas da Identificação de Sistemas pode ser apresentada da seguinte maneira ((AGUIRRE, 2000);(RODRIGUES, 2000)):

- Testes dinâmicos e aquisição de dados;

- Aplicação de técnicas para a verificação de não-linearidades;

- Escolha da representação da estrutura matemática;

- Determinação da estrutura de modelo; 
- Estimação paramétrica e não paramétrica;

- Validação do modelo identificado.

Tal sequência é representada pela Figura A.2 (LJUNG, 2002):

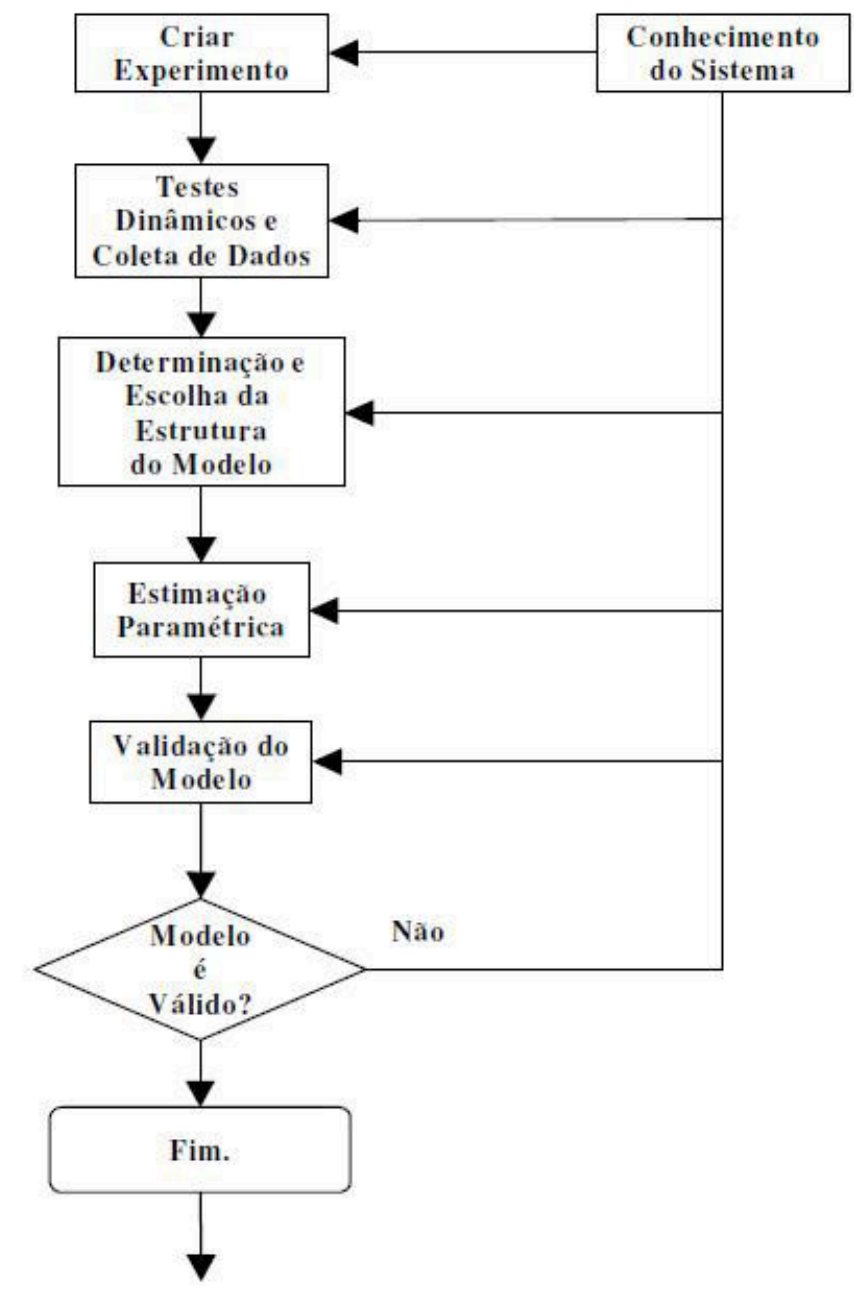

Figura A.2 - Fluxograma do Algoritmo de Identificação de Sistemas.

Na etapa de testes dinâmicos e aquisição de dados são obtidos as informações utilizadas no processo de identificação. Assim é de grande importância que se defina bem as informações que são utilizadas nesse processo, tais como a aplicação e manipulação das variáveis utilizadas, o tempo de amostragem, a decisão quanto ao número de amostras adquiridas e o pré-processamento dos dados amostrados. Os sinais de entradas a serem utilizados para excitar o sistema devem ser projetados para satisfazer determinadas propriedades, ou seja, os sinais de entrada devem possuir um espectro de frequência adequado para excitar os diversos constituintes da planta, garantindo assim a adequabilidade dos dados obtidos. 
Na etapa de aplicação de testes aos dados obtidos para detecção de não-linearidades, todos os sistemas reais em última instância são não-lineares, pois a não-linearidade existe mesmo sendo de uma forma bem suave, o que torna possível sua representação por de modelos lineares. Este autor utiliza técnicas para testar as não-linearidades de um sistema baseado no método da correlação cruzada não-linear (RODRIGUES, 2000).

$\mathrm{Na}$ escolha da representação da estrutura matemática é feita a escolha de qual modelo matemático utilizar para descrever o sistema. Tal escolha deve ser fundamentada no conhecimento do processo de identificação, assim como o conhecimento à priori sobre o sistema a ser identificado. De fato, os modelos matemáticos como foi visto anteriormente, são utilizados para descrever as propriedades de um sistema, sejam essas em partes ou de forma aproximada, o que explicaria à relação de causa e efeito sobre os dados experimentais (AGUIRRE, 2000). Essa etapa é considerada como a mais importante.

Um modelo matemático, pode ser representado pela seguinte estrutura polinomial:

$$
\begin{gathered}
y(k)=\sum_{i=1}^{n} \varphi_{i}^{T}(k) \Theta_{i}+e(k) \\
\varphi=[y(k-1) \cdots y(k-n a) \quad u(k-1) \cdots u(k-n b)]
\end{gathered}
$$

em que:

- $\varphi$ é definido como o vetor de regressores contendo os valores experimentais de entrada e saída do sistema a ser identificado, conforme Equação A.3, em que $y(k)$ e $u(k)$ são os sinais de saída e entrada, na representa os regressores de saída, $n b$ representa os regressores de entrada;

- $\Theta$ é definido como o vetor com os parâmetros que devem ser estimados de acordo com a estrutura escolhida;

- e(k) é definido como o erro de predição, definido pela diferença entre as respostas do sistema identificado e o sistema real.

No final da escolha da representação a ser utilizada são determinados, para sistemas lineares, a quantidade de pólos e zeros e o atraso puro do sistema. Já para sistemas não-lineares, deve-se 
verificar e determinar a quantidade de termos dos modelos polinomiais, uma vez que o número de termos em modelos polinomiais cresce de acordo com a não-linearidade.

Depois de determinada a estrutura, a próxima etapa é a escolha de qual método de identificação paramétrica utilizar. Nesta etapa são estimados os parâmetros da estrutura matemática escolhida, responsável por representar o comportamento do sistema dinâmico a ser identificado, conforme A.2.

Seja o sistema linear de uma entrada e uma saída (SISO - Single Input Single Output), representado pela Figura A.1. O algoritmo dos Mínimos Quadrados é utilizado para que seja feito o cálculo dos parâmetros de $\Theta$ para cada interação de $y(k)$, tendo como base amostras obtidas dados de funcionamento do sistema. A Equação A.2 pode ser representada pela seguinte equação diferença:

$$
y(k)=a_{1} y(k-1)+a_{2} y(k-2)+\cdots+a_{n} a(k-n a)+b_{1}(k-1)+b_{2}(k-2)+\cdots+b_{n} b(k-n b)
$$

em que $a$ e $b$ são os parâmetros do sistema a ser identificado, $u(k)$ e $y(k)$ são os dados experimentais obtidos no sistema. Os termos na e $n b$ definem a ordem da equação.

Semelhante aos modelos SISO, modelos MIMO (Multiple Input Multiple Output), obtém-se a seguinte estrutura matemática de ordem $\mathrm{N}$, observando que a forma de representação parâmetros de entrada e saída é feita por meio de matrizes.

$$
\begin{gathered}
\left(\begin{array}{c}
y 1 \\
y 2 \\
\vdots \\
y_{i}
\end{array}\right)(k)=\left(\begin{array}{ccccc}
a 1_{11} & a 1_{12} & \cdots & a 1_{1 j} \\
a 1_{21} & a 1_{22} & \cdots & a 1_{2 j} \\
\vdots & \vdots & \ddots & \vdots \\
a 1_{i 1} & a 1_{i 2} & \cdots & a 1_{i j}
\end{array}\right)\left(\begin{array}{c}
y_{1} \\
y_{2} \\
\vdots \\
y_{i}
\end{array}\right)(k-1)+\cdots+\left(\begin{array}{cccc}
a N_{11} & a N_{12} & \cdots & a N_{1 j} \\
a N_{21} & a N_{22} & \cdots & a N_{2 j} \\
\vdots & \vdots & \ddots & \vdots \\
a N_{i 1} & a N_{i 2} & \cdots & a N_{i j}
\end{array}\right)\left(\begin{array}{c}
y_{1} \\
y_{2} \\
\vdots \\
y_{i}
\end{array}\right)(k-N)+ \\
\left(\begin{array}{ccccc}
b 1_{11} & b 1_{12} & \cdots & b 1_{1 j} \\
b 1_{21} & b 1_{22} & \cdots & b 1_{2 j} \\
\vdots & \vdots & \ddots & \vdots \\
b 1_{i 1} & b 1_{i 2} & \cdots & b 1_{i j}
\end{array}\right)\left(\begin{array}{c}
u_{1} \\
u_{2} \\
\vdots \\
u_{i}
\end{array}\right)(k-1)+\cdots+\left(\begin{array}{cccc}
b N_{11} & b N_{12} & \cdots & b N_{1 j} \\
b N_{21} & b N_{22} & \cdots & b N_{2 j} \\
\vdots & \vdots & \ddots & \vdots \\
b N_{i 1} & b N_{i 2} & \cdots & b N_{i j}
\end{array}\right)\left(\begin{array}{c}
u_{1} \\
u_{2} \\
\vdots \\
u_{i}
\end{array}\right)(k-N)+\left(\begin{array}{c}
e_{1} \\
e_{2} \\
\vdots \\
e_{i}
\end{array}\right)(k) \text { (A.5) }
\end{gathered}
$$

Escrevendo a Equação A.5 na forma matricial, obtém-se a Equação A.6, em que $n$ representa o número mínimo de amostras necessárias para iniciar o processamento através de equações 
diferenças e $N$ representa a grandeza total de amostras consideradas.

$$
\left(\begin{array}{l}
y_{p}(n) \\
y_{p}(n+1) \\
\vdots \\
y_{p}(N)
\end{array}\right)=\left(\begin{array}{llllll}
y(n-1) & \cdots & y(0) & u(n-1) & \cdots & u(0) \\
y(n) & \cdots & y(1) & u(n) & \cdots & u(1) \\
\vdots & \vdots & \vdots & \vdots & \vdots & \vdots \\
y(N-1) & \cdots & y(N-n) & u(N-1) & \cdots & u(N-n)
\end{array}\right)\left(\begin{array}{c}
a_{1} \\
\vdots \\
a_{n a} \\
b_{1} \\
\vdots \\
b_{n b}
\end{array}\right)+\left(\begin{array}{c}
e(n) \\
e(n+1) \\
\vdots \\
e(N)
\end{array}\right)
$$

A partir da equação A.6, defini-se:

$$
\begin{aligned}
& Y=\left(\begin{array}{c}
y_{p}(n) \\
y_{p}(n+1) \\
\vdots \\
y_{p}(N)
\end{array}\right)_{N-n+1 X(1)} \\
& \Psi=\left(\begin{array}{llllll}
y(n-1) & \cdots & y(0) & u(n-1) & \cdots & u(0) \\
y(n) & \cdots & y(1) & u(n) & \cdots & u(1) \\
\vdots & \vdots & \vdots & \vdots & \vdots & \vdots \\
y(N-1) & \cdots & y(N-n) & u(N-1) & \cdots & u(N-n)
\end{array}\right)_{N-n+1 X(1)} \\
& \Theta=\left(\begin{array}{c}
a_{1} \\
\vdots \\
a_{n} \\
b_{1} \\
\vdots \\
b_{n}
\end{array}\right)_{(2 n) X(1)}
\end{aligned}
$$




$$
E=\left(\begin{array}{c}
e(n) \\
e(n+1) \\
\vdots \\
e_{N}
\end{array}\right)_{(N-n+1) X(1)}
$$

Assim, a Equação A.2, pode ser escrita da seguinte maneira, de forma compacta:

$$
Y(k)=\Psi(k) \Theta+E(k)
$$

em que as variáveis são definidas como:

- $Y$ - Vetor linha com as medidas do sistema calculadas;

- $\Psi$ - Matriz contendo os regressores, obtidos através de amostras do sistema a ser identificado;

- $\Theta$ - Vetor contendo os parâmetros estimados no processo de Identificação de Sistemas;

- E - Vetor contendo o erro calculado entre a resposta calculada pelo sistema de Identificação de Sistemas e a saída real gerada pelo sistema a ser identificado.

Definindo o funcional $J$ como sendo o erro quadrático médio calculado, como a Equação A.12:

$$
J=\frac{1}{2} \sum_{k=n}^{N} e^{2}(k)
$$

ou pela forma matricial:

$$
J=\frac{1}{2} E^{T} E
$$

Para se evitar a necessidade de se calcular os mínimos quadrados novamente a cada amostra adquirida, é necessário atualizar meramente a prévia da estimação calculada no tempo $\Theta(t)$, para obter uma nova estimação $\Theta(t+1)$. Portanto, o vetor $\Theta$ é processado recursivamente para cada conjunto de $n$ amostras, a partir de uma suposição inicial de um vetor de parâmetros, com 
uma quantidade mínima de parâmetros para processar a primeira interação, obtendo assim um novo vetor $\Theta$ a cada nova interação. Deste modo, a resposta atual do algoritmo é uma previsão baseada em parâmetros processados pela planta, com o sistema em funcionamento. Este método é conhecido como Mínimos Quadrados Recursivo (RLS) (LJUNG, 2002), conforme a Equação A.14:

$$
Y(k)=\Psi(k-1) \Theta(k-1)
$$

Inicialmente, é possível que se obtenha um valor alto para o erro, dependendo do conjunto de parâmetros iniciais escolhidos. Assim, para solucionar tal problema, é necessário que se tenha o conhecimento, a priori, da ordem do sistema a ser identificado. Dessa forma, o erro tenderá a zero, convergindo para a saída aproximada do sistema, conforme a Equação A.15 (LJUNG, 2002):

$$
Y(k)=\Psi(k-1) \Theta(k-1)+E(k-1)
$$

Aplicando os procedimentos de minimização do erro quadrático mostrados nas Equações A.14 e A.15 para os Mínimos Quadrados Recursivos, obtém-se a Equação A.16:

$$
\Theta^{N+1}=\Theta^{N}+K_{N+1}\left(Y^{N+1}-\Psi^{N+1} \Theta^{N}\right)
$$

em que as variáveis são definidas como:

- $\Theta^{N+1}$ - Vetor com os parâmetros estimados;

- $\Theta^{N}$ - Matriz com parâmetros estimados em uma etapa passada;

- $K_{N+1}$ - Vetor com ganho de Kalman, contendo as ponderações a serem aplicadas em $\Theta$.

Dentre os métodos de identificação paramétrica, podemos citar o método dos mínimos quadrados recursivo, variáveis instrumentais, redes neurais artificiais (PAIVA, 1999).

Para se validar o modelo identificado é necessário verificar se este incorpora ou não as características de interesse do sistema original. (AGUIRRE, 2000) ressalta a importância de se comparar os modelos entre si e decidir se há algum candidato melhor, tornando-se assim uma etapa subjetiva e o resultado dependerá da aplicação pretendida para o modelo e da quantidade 
de informação disponível sobre o sistema original. A verificação e a validação do modelo são feitas comparando as saídas do modelo com as respostas do sistema real para um conjunto de sinais de entrada (RODRIGUES, 2000).

As etapas citadas acima, podem ser aplicadas para os sistemas lineares e os sistemas não lineares. A principal diferença está na forma como cada procedimento é desenvolvido. Este trabalho, no entanto tem aplicação somente em sistemas lineares. Aplicações com sistemas não-lineares podem ser encontrados em ((RODRIGUES, 2000); (LJUNG, 2002);(AGUIRRE, 2000)). 


\section{Apêndice B}

\section{Séries Temporais}

As séries temporais são definidas como coleções de dados de um determinado fato executado ao longo de um determinado tempo, em que a ordem dos dados que a compõe buscam analisar e modelar a dependência da observação que a observação vizinha tem com a outra.

As séries temporais podem ser classificadas como discretas, quando as observações são feitas em tempos específicos e distribuídos de maneira uniforme; contínuas quando as observações são realizadas continuamente ao longo do tempo, sem a necessidade de discretizar um determinado tempo. As séries temporais também são utilizadas para analisar o passado e predizer o futuro (ALENCAR, 2007).

A análise de séries temporais consiste na aplicação de estruturas matemáticas e estatísticas nas suas observações para que seja compreendido ou quantificado um fenômeno inerente nos dados da série temporal. Assim, essa análise resulta em dois objetivos, extrair o conhecimento através de suas observações, compreendendo o comportamento da série em questão e a partir desse conhecimento, é possível predizer qual será o comportamento da mesma série no futuro (ABELÉM, 1994). 
Na Figura B.1, tem-se um exemplo de uma série temporal da venda das ações da Microsoft de 1996 até 2004. De 2005 até 2008 tem-se a previsão de como será o comportamento dessa série nos próximos anos (TANG e MACLENNAN, 2008).

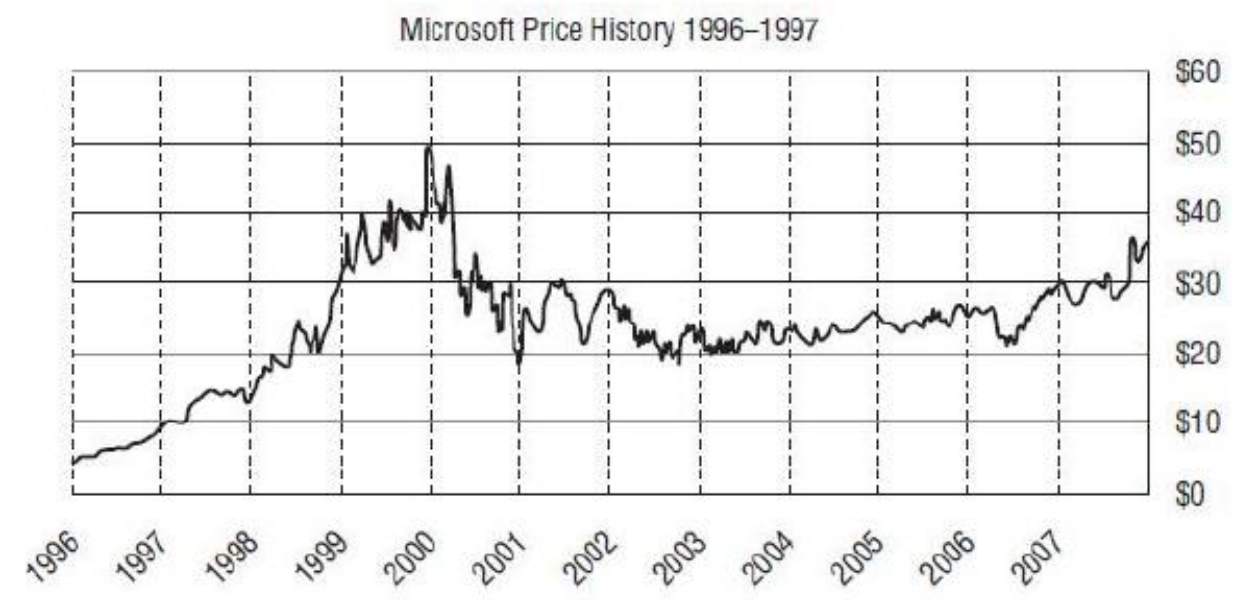

Figura B.1 - Série Temporal Ações Microsoft.

Quando se trabalha com uma série temporal é necessário que se identifique qual o tipo de informação que é relevante, e por meio dessas informações, definir regras para determinar um objetivo. Para que isso aconteça, é necessário que se identifique os seguintes componentes (OLIVEIRA, 2007):

- Tendências: são identificados os componentes que descrevem o comportamento, caracterizados pela taxa de modificações que ocorreram na série temporal, como por exemplo, se os valores da série temporal aumentaram ou se os valores da série temporal diminuíram;

- Ciclos: aqui são identificados os componentes responsáveis por descrever quais são os padrões que descrevem o comportamento de uma série temporal. Por exemplo, a cada onze anos, as manchas solares atingem o seu cume, conforme a Figura B.2;

- Estações: As estações são responsáveis por descrever os ciclos de um determinado fator observado em uma série temporal. Exemplo, o número de vendas de um determinado mês teve um aumento e no mês seguinte teve uma queda;

- Irregularidades: nesse ponto verifica-se se a série temporal analisada são normais ou possuem algum tipo de anomalia. Um conjunto de dados gravados com problema de comunicação pode ser considerado como um tipo de irregularidade (TANG e MACLENNAN, 2008). 


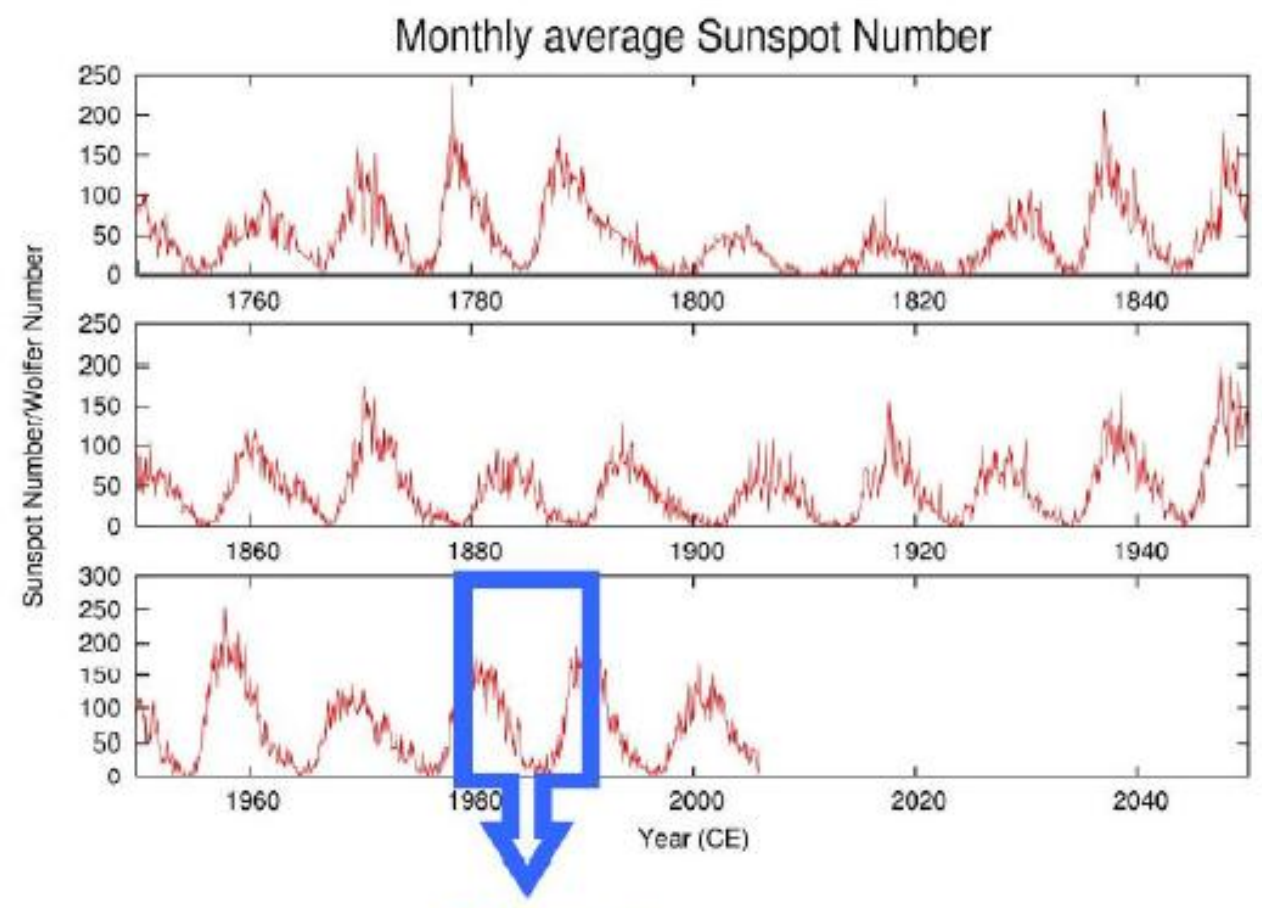

11 Anos

Figura B.2 - Previsão do Comportamento Solar Utilizando Séries Temporais.

Então considerando uma série temporal qualquer $\left[z\left(t_{1}\right), \ldots, z\left(t_{n}\right)\right]$ em um determinado tempo de amostragem $\left[t_{1}, \ldots, t_{n}\right]$, em que o interesse é definido como:

- Investigar o mecanismo gerador temporal;

- Descrever o comportamento da série temporal;

- Localizar periodicidades relevantes;

- Calcular valores futuros da série temporal.

Assim todos os modelos probabilísticos ou estocásticos desenvolvidos para uma determinada série temporal, devem possuir características de simplicidade e facilidade de utilização para usuários que desejam manipular em séries (ABELÉM, 1994). 


\section{B.1 Métodos de Previsão de Séries Temporais}

Os Métodos de Previsão de séries temporais tem por objetivo a definição de um determinado padrão, definido como um conjunto de procedimentos, que são usados para que sirvam na utilização de previsão de séries temporais. Tais métodos são baseados na suposição de observações ditas como passadas, que descrevem qual foi o comportamento da série em um determinado tempo ou amostragem (TANG e MACLENNAN, 2008).

\section{B.1.1 Modelos Auto-Regressivos}

Seja a seguinte série temporal, definida para o Modelo Auto-Regressivo:

$$
X_{t}=\sum_{i=1}^{p} \alpha_{i} X_{t-i}+\xi_{t}
$$

em que o valor da série temporal em um determinado tempo $t$, é calculado a partir de uma combinação linear de valores passados. Os termos dessa série são definidos como:

- $\alpha_{i}$ : parâmetro do Modelo Regressivo;

- $X_{t-i}$ : amostra da série temporal no tempo $t$;

- $\xi$ : erro aleatório, que não pode ser explicado pelo modelo.

Assim, se as amostras da série temporal podem ser representadas pela Equação B.1, bem como a determinação do modelo e a estimação paramétrica da série, é possível prever qual será o comportamento futuro da série. 


\section{B.2 Modelo de Médias Móveis}

Um Modelo de Médias Móveis é representado pela seguinte Equação:

$$
X_{t}=e_{t}-\theta_{1} e_{t-1}-\theta_{2} e_{t-2}-\theta_{3} e_{t-3}-\cdots-\theta_{q} e_{t-q}
$$

em que o valor da série temporal em um determinado tempo $t$, é calculado a partir de uma combinação linear de valores passados. Os termos dessa série são definidos como:

- $\theta_{i}$ : parâmetro do Modelo Regressivo;

- $X_{t-i}$ : amostra da série temporal no tempo $t$;

- e: erro aleatório, que não pode ser explicado pelo modelo.

Outros modelos de Média Móvel podem ser derivados do modelo obtido pela Equação B.2:

- Média Móvel Simples [Simple Moving Average - SMA]: Corresponde a uma série simples, calculada a partir da soma dos valores da série temporal dividido pela quantidade de elementos da série;

$$
S M A=\frac{p_{1}+p_{2}+\cdots+p_{n}}{n}
$$

- Média Móvel Ponderada [Weighted Moving Average - WMA]: Nesse modelo representado pela Equação B.4, cada valor de $p$ da série temporal, é multiplicado por uma função decrescente, onde cada elemento no instante $p$ possui um peso diferente no cálculo da série no instante $t$. Assim, os valores que estão mais próximos do tempo em que foi feita a amostragem possuem maior importância;

$$
W M A=\frac{n p_{1}+(n-1) p_{2}+\cdots+2 p_{n-1}+p_{n}}{n+(n-1)+\cdots+2+1}
$$


- Média Móvel Exponencial [Exponential Moving Average - EMA]: Semelhante ao modelo da Equação B.4, os valores da série são multiplicados por uma função decrescente, porém de características exponenciais, conforme a Equação B.5:

$$
E M A=\frac{p_{1}+(1+\alpha) p_{2}+(1+\alpha)^{2} p_{3}+\ldots}{1+(-\alpha)+(1-\alpha)^{2}+\ldots}
$$

\section{B.3 Árvores Auto-Regressivas}

As árvores auto-regressivas (Autoregressive Trees - ART), são caracterizadas pela generalização entre um modelo auto-regressivo e as árvores de decisão (referência). Esses modelos são considerados como modelos preditivos e permitem o mapeamento dos itens da série em conclusões sobre um possível valor, baseado em informações passadas da série temporal. Esse mapeamento é feito por meio de uma árvore, onde as folhas da árvore são os possíveis e os nós são caracterizados como os esquemas da decisão.

O Modelo ART é ilustrado na Figura B.3, onde é mostrado um exemplo de como o modelo pode ser utilizado para determinar a venda de pães (TANG e MACLENNAN, 2008).

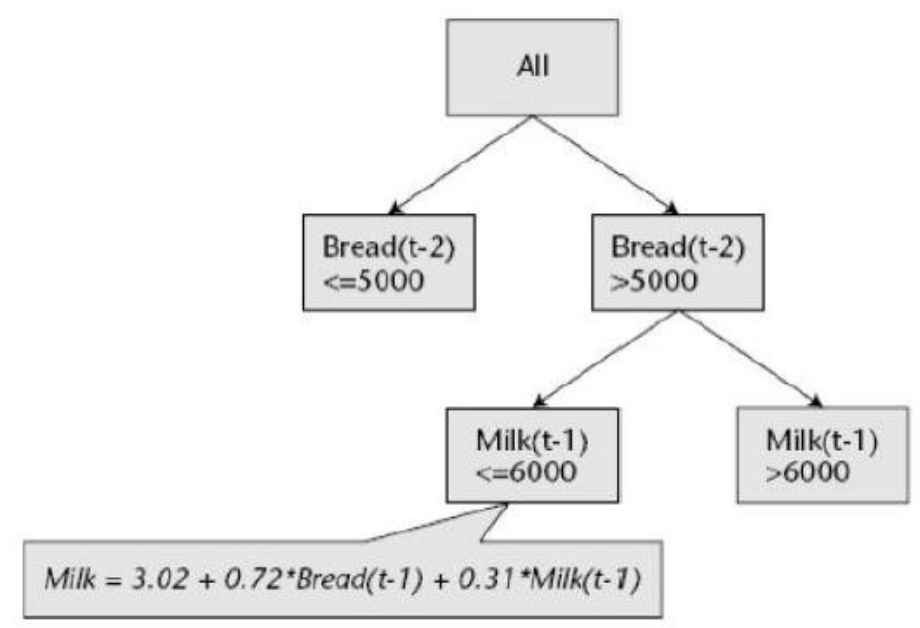

Figura B.3 - Árvores Auto-Regressivas. 


\section{Apêndice $\mathrm{C}$}

\section{Redes Neurais Artificiais NARX}

Uma das principais ferramentas utilizadas na etapa de Mineração de Dados no processo KDD são as redes neurais. As redes neurais são consideradas como modelos matemáticos que tem como objetivo fazer a representação do cérebro humano (AMARAL, 2005). Uma outra definição: as redes neurais são consideradas como sistemas de processamento paralelo e distribuído, constituídas por unidades de processamento chamadas de neurônios e que tem a capacidade de armazenar e processar um conhecimento experimental e utilizá-lo em outros tipos de processamentos (HAYKIN, 1999). Outras definições sobre o funcionamento e a estrutura das redes neurais, podem ser encontradas em (BATTISTELLA e CECHIN, 2004). Esse trabalho descreve apenas a estrutura de funcionamento das redes neurais do tipo NARX (Non Linear Auto Regressive eXogenous Model - modelo não-linear, auto-regressivo e entrada externa). Porém, antes de se detalhar as Redes Neurais NARX, é necessário descrever o sistema dinâmico e os modelos dinâmicos que a compõe.

Conforme descrito no Capítulo 5, um sistema dinâmico é descrito pela Equação A.1. Porém, quando o sistema é tido como um sistema não linear, a mesma equação pode ser descrita como:

$$
y(k+1)=F\left[y(k), \cdots, y\left(k-n_{y}\right), u(k), \cdots, u\left(k-n_{u}\right)\right]
$$

onde $F$ representa uma função não linear das medidas das entradas, $u(k)$, e das saídas, $y(k)$ do sistema a ser modelado ou identificado.

Dentre as estruturas matemáticas utilizadas para representar os modelos dinâmicos não 
lineares, destacam-se as estruturas NARX e NARMAX (Non Linear Auto-Regressive Moving eXogenous Model, (Modelo não-linear, auto-regressivo, de média móvel e entrada externa) ). A estrutura NARX é representada pela seguinte Equação:

$$
\begin{aligned}
& y(k)=F\left[y(k-1), y(k-2), \cdots, y\left(k-n_{y}\right),\right. \\
& \left.u(k-d-1), \cdots, u\left(k-d-n_{u}+1\right)\right]+e(k)
\end{aligned}
$$

em que $k=1, \cdots, N, \mathrm{~F}$ é definida como uma função não-linear qualquer, $y(k)$ e $u(k)$ são definidos como as amostras de entrada e saída do sistema a ser identificado. As variáveis $n_{y}$ e $n_{u}$ são definidos como os atrasos de entrada e saída, $d$ é definido como o tempo de atraso do sistema e $e(k)$ representa os erros ou as incertezas inerentes no sistema.

A estrutura NARMAX é definida como sendo:

$$
\begin{array}{r}
y(k)=F\left[y(k-1), y(k-2), \cdots, y\left(k-n_{y}\right), u(k-d-1), \cdots,\right. \\
\left.u\left(k-d-n_{u}+1\right), \cdots, v(k-1), v(k-2), \cdots, v\left(k-d-n_{v}\right)\right]+v(k)
\end{array}
$$

A principal diferença entre os modelos NARX e NARMAX é que no modelo NARMAX é possível que se incorpore regressores de ruído, evitando a polarização do modelo (AMARAL, 2005). Desta forma, a incerteza $e(k)$ inerente no modelo NARX se torna ruído branco $v(k)$ no modelo NARMAX, conforme a Equação C.3.

As redes neurais do tipo NARX, se baseiam no modelo descrito pela Equação C.2, e redefinido pela Equação C.4:

$$
\begin{array}{r}
y(k)=F\left[y(k-1), y(k-2), \cdots, y\left(k-n_{y}\right),\right. \\
\left.u(k-d-1), \cdots, u\left(k-d-n_{u}+1\right), W\right]
\end{array}
$$

em que as entradas e saídas da rede são definidas por $u$ e $y$ respectivamente no intervalo $k, n_{u}$ e $n_{y}$ representam as memórias de entrada e saída da rede e $W$ é a matriz de pesos. 
A função $F$ geralmente é desconhecida na maioria dos sistemas. Quando essa função é aproximada por uma rede do tipo MLP - (Multi Layer Perceptron), a topologia resultante se caracteriza em uma rede do tipo NARX, conforme mostrado na Figura C.1 (AMARAL, 2005).

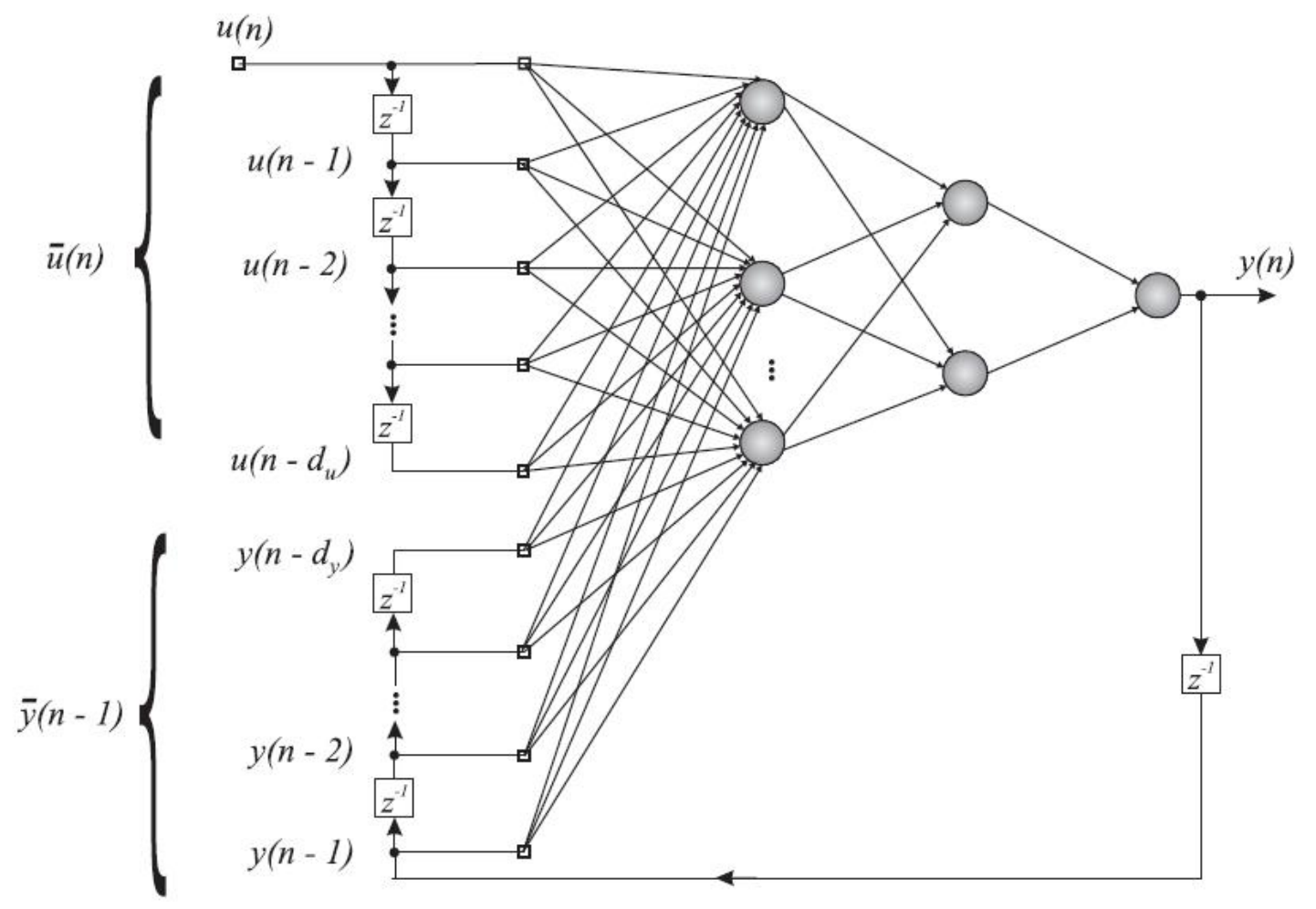

Figura C.1 - Rede Neural NARX.

Os regressores do modelo NARX são caracterizados por $n_{u}$ e $n_{y}$, obtidos pelas amostras do sistema.

As redes neurais do tipo NARX pertencem ao tipo de redes neurais Dinâmicas Recorrentes, pois ela possui realimentação nas suas conexões sinápticas, permitindo assim o fluxo dos sinais de ativação e saída neurais entre neurônios de camadas diferentes. Outra característica desse tipo de rede é que a recorrência permite que a rede tenha uma lembrança de informações passadas ou já processadas.

Uma ligação sináptica é caracterizada pela ligação entre dois neurônios, onde é importante verificar qual é o tipo de ligação que se deseja fazer. Dentre os tipos de conexão pode-se destacar a conexão com alimentação direta e a conexão com realimentação. Na conexão com alimentação direta (feed-forward) é definida no momento em que um sinal tem sua orientação dentro do processamento da rede, no sentido da entrada para a saída. Já a na conexão de realimentação (feedback) o sentido do sinal tem a sua orientação oposta, isto é, o sinal tem o seu sentido da 
saída para entrada, gerando assim os sinais de ativação para as outras camadas.

O modo de treinamento das Redes NARX é feito nos seguintes modos:

- Modo de Identificação Paralelo: Nesse modo de treinamento, a saída estimada é alimentada e incluída na saída do regressor, conforme a Equação C.5:

$$
\begin{array}{r}
\widehat{y}(k)=\widehat{F}\left[\widehat{y}(k-1), \widehat{y}(k-2), \cdots, \widehat{y}\left(k-n_{y}\right),\right. \\
\\
\left.u(k-d-1), \cdots, u\left(k-d-n_{u}+1\right)\right]
\end{array}
$$

- Modo de Identificação Semi-Paralelo: Nesse modo de treinamento. a saída do regressor é alimentada somente pela saída atual do sistema, conforme Equação C.6:

$$
\begin{array}{r}
\widehat{y}(k)=\widehat{F}\left[y(k-1), y(k-2), \cdots, y\left(k-n_{y}\right),\right. \\
\\
\left.u(k-d-1), \cdots, u\left(k-d-n_{u}+1\right)\right]
\end{array}
$$

Assim, o caminho de realimentação é utilizado apenas no Modelo de Identificação Paralelo. Vale ressaltar que, semelhante a uma ferramenta de identificação de sistemas, a Rede Neural NARX é aplicada em diversos tipos de sistemas encontrados nos setores industriais, tais como trocadores de calor, plantas de tratamento de água, refinarias de petróleo, dentre outros (JUNIOR, 2006). 


\section{Referências Bibliográficas}

ABELÉM, A. J. G. (1994). Redes neurais na previsão de séries temporais. Dissertação de Mestrado, Pontifícia Universidade Católica do Rio de Janeiro.

AGUIRRE, L. A. (2000). Introdução a Identificação de Sistemas, Técnicas Lineares e Não Lineares Aplicadas a Sistemas Reais. Belo Horizonte: Editora UFMG.

ALENCAR, A. (2007). Mineração e visualização de coleções em séries temporais. Dissertação de Mestrado, Instituto de Ciências Matemáticas e Computação.

AMARAL, G. F. V. (2005). Uso de redes neurais e conhecimento a priori na identificação de sistemas dinâmicos não lineares. Dissertação de Mestrado, Universidade Federal de Minas Gerais.

AMORIN, H. V.; LEÃO, R. M. (2005). Fermentação Alcoólica Ciência e Tecnologia. Piracicaba: Editora Piracicaba.

BARIONI, M. C. N. (2002). Visualização de operações de junção em sistemas de base de dados para mineração de dados. Dissertação de Mestrado, Instituto de Ciências Matemáticas e Computação.

BASSETO, N. Z. (2006). Sistema especialista para planta de producção de álcool. Dissertação de Mestrado, Faculdade de Engenharia Química, Universidade Estadual de Campinas.

BATTISTELLA, E. e A. CECHIN (2004). The protein folding problem solved by a fuzzy inference system extracted from an artificial neural network. In Proceedings of Ibero-American Conference on Artificial Intelligence (IBERAMIA), Volume 3315, pp. 474-483.

BAYMA, C. (1974). Tecnologia do açúcar: da matéria prima à evaporação. Rio de Janeiro: Colecção Canavieiro. 
BERRY, M. J. A.; LINOFF, G. S. (2004). Data Mining Techiques: For Marketing, Sales and Customer Relationship Management. Indianápolis, IN: Wiley Publishing, Inc.

BRANDÃO, D. (2005). Ferramento de Simulação para Projeto, Estudo e Treinamento de Redes Fieldbus. Tese de Doutorado, Escola de Engenharia de São Carlos, Universidade de São Paulo.

BROWNE, W., L. YAO, I. POSTLETHWAITE, S. LOWES, e M. MAR (2005). Knowledgeelicitation and data-mining: Fusing human and industrial plant information. In Engineering Applications of Artificial Intelligence, Volume 19, pp. 345-359.

BRUMAZI, S. (2009). Difusores. Disponível em http://www.brumazi.com.br, 1-3.

CABEnA, P. e. a. (1997). Discovering Data Mining: from concept to implementation. New Jersey: Prentice Hall.

CHEN, R. S., Y. S. TSAI, e C. C. CHANG (2006). Design and implementation of an intelligent manufacturing execution system for semiconductor manufacturing industry. In International Symposium on Industrial Electronics IEEE Symposium, Volume 4, pp. 2948-2953.

DAL BEM, A. J. (2003). Desenvolvimento de um simulador para o processo industrial de fabricação de açúcar E Álcool. Monografia de Trabalho de Conclusão de Curso, Fundação Getúlio Vargas.

DATE, C. (2000). Introdução a sistemas de banco de dados. Rio de Janeiro: Editora Campus.

FAYYAD, U.; SHAPIRO, G. P. (1996). Data Mining and Knowledge Discovery in Databases: an Overview, Volume 11. Communications ACM, Special Issue on Data Mining.

FOURTULAN, M. R. (2006). O uso de Businnes Inteligence para gerar indicadores de desempenho no chão-de-fábrica: uma proposta de aplicação em uma empresa de manufatura. Tese de Doutorado, Escola de Engenharia de São Carlos, Universidade de São Paulo.

FRAWLEY W., G. PIATETSKY-SHAPIRO, C. M. (1992). Knowledge discovery in databases: An overview. AI Magazine.

GOLDSCHMIDT, R.; PASSOS, E. (2005). Data Mining - Um Guia Prático. Rio de Janeiro: Editora Campus.

HAN, J.; KAMBER, M. (2006). Data Mining: Concepts and Techniques. California, EUA: Morgan Kaufmann Publishers. 
HARDING, J. A.; SHAHBAZ M.; KUSAIAK, A. (2006). Data mining in manufacturing: A review. In Jornal of Manufacturing Science and Engineering, Volume 128, pp. 969-976.

HAYKIN, S. (1999). Neural Networks - A Comprehensive Foundation. Prentice Hall.

HIGA, M. (2003). Cogeração e integração térmica em usinas de açúcar e álcool. . Tese de Doutorado, Faculdade de Engenharia Mecânica, Universidade Estadual de Campinas.

ICONICS, I. (2010). Manual of bizviz - business visualization. Disponível em http://www.iconics.com, 1-3.

JANKE, M. (2000). Opc plug and play integration to legacy systems. In IEEE Conference Record of 2000 Annual Pulp and Paper Industry Techincal Conference, pp. 68-72.

JOAQUIM, R. C. (2006). Novas tecnologias para comunicação entre chão de fábrica e sistema fabril. Dissertação de Mestrado, Escola de Engenharia de São Carlos, Universidade de São Paulo.

JUNIOR, J. M. P. M. (2006). Redes neurais dinâmicas para predição e modelagem não linear de séries temporais. Dissertação de Mestrado, Universidade Federal do Ceará.

KITAYAMA, M., R. MATSUBARA, e Y. IZUI (2002). Application of data mining to customer profile analysis in the power electric industry. In Power Engineering Society Winter Meeting, Volume 1, pp. 27-31.

LAUDON, K. C.; LAUDON, J. P. (1988). Management information systems. Prentice Hall.

LEE, H. D. (2005). Seleção de atributos importantes para a extraçõ de conhecimento em base de dados. Tese de Doutorado, Escola de Engenharia de São Carlos, Universidade de São Paulo.

LJUNG, L. (2002). System Identification. Englewood: Prentice Hall.

LUO, Q. (2008). Advancing knowledge discovery and data mining. In IEEE Computer and society, pp. 3-5.

McDONALD, J. R..; STEELE, J. A. (2006). Knowledge discovery in database: Applications in electrical power engineering domain. In IEEE Power Engineering Society Winter Meeting.

MEIRA, C. A. A. (2008). Processo de descoberta de conhecimento em bases de dados para análise e o alerta de doenças de culturas agrícolas e sua aplicação na ferrugem do cafeeiro. Tese de Doutorado, Faculdade de Engenharia Agrícola, Universidade Estadual de Campinas. 
MESA, F. (2010). Manufacturing enterprise solutions. Disponível em http://www.mesa.org, $1-15$.

PAIVA, R. P. P. C. (1999). Identificação neurodifusa aspectos de interpretabilidade. Dissertação de Mestrado, Universidade de Coimbra.

REZENDE, S. O., J. B. PUGLIESE, E. A. MELANDA, e M. F. PAUlA (2002). Sistemas Inteligentes: fundamentos e aplicações. Barueri: Editora Manole.

RODRIGUES, G. G. (2000). Identificação de sistemas dinmîicos nõlineares utilizando modelos narmax polinomiais: Aplicação em sistemas reais. Dissertação de Mestrado, Universidade Federal de Minas Gerais.

SADOYAN, H., A. ZAKARIAN, e P. MOHANTY (2006). Data mining algorithm for manufacturing process control. In International Advanced Manufactory Technology, Volume 28, pp. $342-350$.

SASSI, R. J. (2006). Uma Arquitetura Hibrida para Descoberta de conhecimento em Base de Dados: Teoria dos Rough Sets e Redes Neurais Artificiais Mapas Auto-Organizáveis. Tese de Doutorado, Escola de Engenharia de São Carlos, Universidade de São Paulo.

SHIBA, S. K. (2008). Desenvolvimento de modelo de processamento de extração de conhecimento em banco de dados para sistemas de suporte à decisão. Dissertação de Mestrado, Escola Politécnica, Universidade de São Paulo.

SILVA, D. R.; VIEIRA, M. T. P. (2002). Using data warehouse and data mining resources for ongoing assessment in distance learning. In The Second IEEE International Conference on Advanced Learning Technologies.

SMAR, E. I. (2005). Manual da Produção de Açúcar e Álcool.

SU, C. T., Y. H. CHEN, e D. SHA (2006). Linking innovative product development with customer knowledge: a data mining approach. In Technovation Conference, Volume 26, pp. $784-795$.

TANG, Z. e J. MACLENNAN (2008). Data Mining with SQL Server 2008. Indianapolis: Wiley Publishing. 